\title{
Stickstoffkreislauf und Primärproduktion im mesotrophen Vierwaldstättersee (Horwer Bucht) und im eutrophen Rotsee, mit besonderer Berücksichtigung des Nitrats als limitierenden Faktors
}

\author{
Von Pius Stadelmann \\ Eidg. Anstalt für Wasserversorgung, Abwasserreinigung und Gewässerschutz \\ (EAWAG) an der ETH Zürich in Dübendorf \\ Direktor: Prof. Dr. W.Stumm (ehemals Prof. Dr. O. Jaag)
}

\section{INHALTSVERZEICHNIS}

1. Einleitung und Problemstellung . . . . . . . . . . . . . . . . . . . . . 2

2. Methoden

2.1 Physikalische Methoden. . . . . . . . . . . . . . . . . . . . . . . 5

2.11 Temperaturmessung . . . . . . . . . . . . . . . . . . . . . . . 5

2.12 Messung der Lichtverhältnisse . . . . . . . . . . . . . . . . . . . . 5

2.2 Chemische Analysenmethoden . . . . . . . . . . . . . . . . . . . . . . . . 5

2.21 Bestimmung der anorganischen Stickstoffkomponenten . . . . . . . . . . . . . 5

2.22 Bestimmung der organischen Stickstoffkomponenten . . . . . . . . . . . . . . 5

2.221 Bestimmung des partikulären organischen Stickstoffs mit der Kjelđahl-Methode : . 6

2.222 Bestimmung des gelösten organischen Kjeldahl-Stickstoffs . . . . . . . . . . . 8

2.23 Bestimmung des Kjeldahl-Stickstoffs im aufgefangenen Sediment . . . . . . . . 10

2.24 Bestimmung der Phosphorkomponenten . . . . . . . . . . . . . . . . . . 10

2.25 Bestimmung des gelösten Sauerstoffs und des Sulfids . . . . . . . . . . . . . . . 10

2.26 Bestimmung des anorganischen Gesamtkohlenstoffs . . . . . . . . . . . . . . 10

2.3 Biologische Untersuchungsmethoden . . . . . . . . . . . . . . . . . . . . . . 10

2.31 Produktionsmessung mit der $\mathrm{C}^{14}$-Methode . . . . . . . . . . . . . . . . . . 10

2.32 Planktonuntersuchungen . . . . . . . . . . . . . . . . . . . . . . . 11

\section{Resultate der Seeuntersuchungen}

3.1 Orographie und Probenahmestelle . . . . . . . . . . . . . . . . . . . . . . . 12

Vierwaldstättersee (Horwer Bucht) . . . . . . . . . . . . . . . . . . . . 12

Rotsee . . . . . . . . . . . . . . . . . . . . . . . . 12

3.2 Thermik . . . . . . . . . . . . . . . . . . . . . 12

3.3 Lichtverhältnisse . . . . . . . . . . . . . . . . . . . . . . . 15

3.4 Samerstoff. . . . . . . . . . . . . . . . . . . . . . . 16

3.5 Phosphorkomponenten . . . . . . . . . . . . . . . . . . . . . . . . . . . 19

3.6 Stickstoffkomponenten ......................... . 19

3.61 Anorganische N-Komponenten . . . . . . . . . . . . . . . . . . . . . . . 19

3.62 Organische N-Komponenten. . . . . . . . . . . . . . . . . . . . . . . . . 27

3.621 Partikulärer Stickstoff . . . . . . . . . . . . . . . . . . . . . . . . . . 27

3.622 Gelöster organischer Stickstoff . . . . . . . . . . . . . . . . . . . . . . . 29

3.7 Stickstoffsedimentation . . . . . . . . . . . . . . . . . . . . . . . . . . . 29

3.8 Primärproduktion . . . . . . . . . . . . . . . . . . . . . . . 34

3.9 Plankton dev Horwer Bucht . . . . . . . . . . . . . . . . . . . . . . . . . . 34 
4. Experimentelle Düngversuche im Vierwaldstättersee . . . . . . . . . . . 38

5. Diskussion

5.1 Stickstoff als wachstumbegrenzender Faktor . . . . . . . . . . . . . . . . . . . 45

$5.2 \quad$ N-Fixierung. . . . . . . . . . . . . . . . . . . . . . . . . . . . . . . . 47

5.3 Das N:P-Gewichtsverhälnis im partikulären Material . . . . . . . . . . . . . . . . . 49

5.4 Der tägliche Biomassenzuwachs und Sedimentationsverlust . . . . . . . . . . . . . . . . . 53

5.5 Stichstoffbilanz . . . . . . . . . . . . . . . . . . . . . . . . . . . . . 55

5.6 Ammonifikation, Nitrifikation und Denitrifikation . . . . . . . . . . . . . . . . . . . . . . . . 57

6. Schlussfolgerungen . . . . . . . . . . . . . . . . . . . . . . . . . . . 58

7. Zusammenfassung . . . . . . . . . . . . . . . . . . . . . . . . . . . 59

Summary. . . . . . . . . . . . . . . . . . . . . . . . . . . . . . . . . 61

Literaturverzeichnis . . . . . . . . . . . . . . . . . . . . . . . 62

Verdankung . . . . . . . . . . . . . . . . . . . . . . . . . 65

\section{Einleitung und Problemstellung}

In den Alpenrandseen beobachtet man eine Zunahme der Pflanzennährstoffe durch die kulturbedingte Verschmutzung. Diese Nährstoffe stammen aus häuslichen Abwässern, aus Abwässern industrieller und landwirtschaftlicher Betriebe und gelangen auch durch Erosionsprozesse der landwirtschaftlich genutzten Flächen und durch natürliche Bodenauswaschung und Verwitterung in die Gewässer. Der See reagiert auf diese Nährstoffanreichungen mit übermässigem Algenwachstum. Als Folge davon treten Nebenerscheinungen auf, wie Sauerstoffschwund im Tiefenwasser, übermässige Zunahme des Gesamtfischbestandes, aber Verminderung des Edelfischbestandes. Die Trinkwasser- und Industriewasseraufbereitung wird erschwert, und die landschaftlichen und touristischen Werte werden beeinträchtigt. Hat ein See diesen Zustand erreicht, ist es fast unmöglich, die Verschmutzung wieder rückgängig zu machen. Günstige Aussichten für eine Sanierung der Alpenrandseen bestehen indessen vor allem dort, wo die Zuflüsse aus nicht oder extensiv bewirtschafteten Berggebieten stammen und somit arm an Nährstoffen sind. Die wesentliche Bedingung für den Seenschutz bleibt in solchen Fällen die Eliminierung der Nährstoffzufuhr aus den eigentlichen Abwässern. Dabei verdienen Seen, die auch in Zukunft als Trinkwasserreservoire vorgesehen sind, besondere Aufmerksamkeit.

Die besonders wirksamen Pflanzennährelemente sind Phosphor und Stickstoff. Wenn auch normalerweise der Hauptteil der Nährstoffzufuhr, dies gilt besonders für Stickstoff [4], aus landwirtschaftlich genutzten Flächen stammt, wird mit zunehmender Besiedlungsdichte die Phosphor- und Stickstoffzufuhr beträchtlich anwachsen. Phosphor ist in der Regel der Initialfaktor für die Erhöhung der Algenproduktion in unseren Gewässern, bei höherer Gesamtproduktion wirkt aber auch Stickstoff wachstumsbegrenzend $[12,24,43,66,76]$.

Da biologisch gereinigte Abwässer noch beträchtliche Mengen an Pflanzennährstoffen enthalten, werden gegenwärtig verschiedene Methoden vorgeschlagen, um zuerst einmal Phosphor- und Stickstoffverbindungen in einer «dritten Reinigungsstufe» zu entfernen (Zusammenfassung bei VOLLENWEIDER [76]).

Phosphor wird mit Hilfe der Kationen Fe (III), Al (III) und ( $\left.\mathrm{Ca}^{2+}\right)$, die mit Phosphat schwerlösliche Salze bilden, ausgefällt. Bei der Stickstoffelimination werden die 
in der biologischen Reinigungsstufe zu Nitrat und Nitrit mineralisierten N-Verbindungen in einer nachgeschalteten anaeroben Phase mit Hilfe der mikrobiellen Denitrifikation zu elementarem Stickstoff reduziert und somit aus dem Abwasser entfernt. Da die verfahrenstechnischen Grundlagen für die Elimination von Stickstoff- und besonders für Phosphorverbindungen aus Abwässern bekannt und experimentell erprobt sind, bleibt nur die Frage, ob für die Sanierung eines Sees N und P gemeinsam entfernt werden müssen oder ob es genügt, wenn man nur eines der beiden Nährelemente eliminiert [78].

Die Kenntnis des Stickstoffkreislaufs in Seen ist daher für die Lösung des Eutrophierungsproblems wichtig.

Im Gegensatz zum Phosphor, der hauptsächlich in den Energiehaushalt der Algenzelle eingeschaltet ist, wird Stickstoff als eigentliches Bauelement bei der Synthese von Proteinen benötigt. Das Protein jeder höheren Stufe (Zooplankton, Fische) ist dabei von der ersten Aminosäuresynthese durch das Phytoplankton abhängig.

Für die Bildung des Protoplasmas braucht es nach der Gleichung von STumm [63] $1 \mathrm{HPO}_{4}^{2-}+16 \mathrm{NO}_{3}{ }^{-}+106 \mathrm{CO}_{2}+122 \mathrm{H}_{2} \mathrm{O}+18 \mathrm{H}^{+} \stackrel{\text { Licht }}{\longrightarrow}\left(\mathrm{CH}_{2} \mathrm{O}\right)_{106}\left(\mathrm{NH}_{3}\right)_{16} \mathrm{H}_{3} \mathrm{PO}_{4}+138 \mathrm{O}_{2}$

Das P:N-Atomverhältnis in Algen liegt also bei $1: 16$, das Gewichtsverhältnis demnach bei etwa 1:7. Erwähnenswert ist dabei, dass auch im Meer das $\mathrm{PO}_{4}-\mathrm{P}$ : $\mathrm{NO}_{3}-\mathrm{N}$-Atomverhältnis bei etwa 1:16 liegt [48]. In biologisch gereinigtem städtischem Abwasser liegt ein $\mathrm{P}: \mathrm{N}$-Gewichtsverhältnis von etwa 1:5 vor [78]; verglichen mit dem Verhältnis in Biomasse ist also hier zuviel Phosphor vorhanden.

Stickstoff kommt im Wasser in den Oxydationsstufen -3 bis +5 vor. Biochemische Reaktionen, die die Wertigkeit der N-Verbindungen im Wasser beeinflussen, sind in Abb. 1 zusammengestellt.

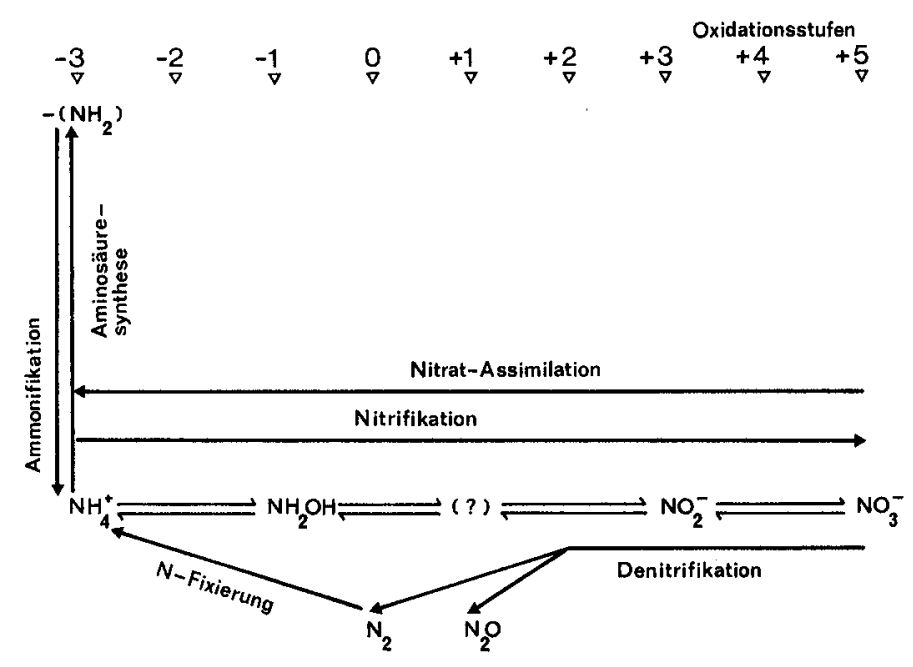

Abb. 1. Biochemische Reaktionen, die die Verteilung der N-Verbindungen im Wasser beeinflussen. 
Die Nitratassimilation (assimilatorische N-Reduktion):

Nitrat wird in vier Reaktionsschritten zu Ammonium reduziert, wobei jeweils zwei Elektronen übertragen werden. Ein wichtigstes Enzym, das den Ablauf der Reaktion ermöglicht, ist die Nitratreduktase, ein Molybdoflavoprotein.

Die N-Fixierung:

Manche Blaualgen und auch einige Bakterien sind befähigt, elementaren Stickstoff zu verwerten; dadurch kann das anorganische N-Angebot ergänzt werden [20].

Die Denitrifikation (dissimilatorische N-Reduktion) :

Bei der bakteriellen Denitrifikation dienen Nitrate und Nitrite als Wasserstoffakzeptoren. Als Endprodukte entstehen die flüchtigen Verbindungen $\mathrm{NO}, \mathrm{N}_{2} \mathrm{O}$ und $\mathrm{N}_{2}$. Durch diese Reaktion kann daher dem Wasser Stickstoff entzogen werden.

Einige Bakterien können Nitrat sogar $\mathrm{zu} \mathrm{NH}_{4}$ reduzieren (Nitratammonifikation). Die Ammonifikation:

Der in den Algen gebundene Stickstoff wird nach dem Absterben rasch mineralisiert, dies geschieht meist durch proteolytisch tätige Bakterien, aber auch das Zooplankton scheidet Ammonium aus.

\section{Nitrifikation:}

Gleichzeitig mit der Mineralisation von organischen N-Verbindungen findet die biologische Oxydation von Ammonium zu Nitrit und Nitrat statt. Dieser Prozess wird von den chemo-autotrophen Bakterien Nitrosomonas und Nitrobacter ausgeführt.

Organische N-Verbindungen finden wir im Wasser in suspendierter Form, also gebunden im Phyto- und Zooplankton, in Bakterien und Detritus, während Aminosäuren, gelöste Eiweisse, Vitamine, Purine, Huminsäuren, Harnstoffe usw. die gelöste Fraktion ausmachen.

Das Ziel der vorliegenden Arbeit ist die Untersuchung des Stickstoffkreislaufs in Seen verschiedenen Trophiegrades.

Nachdem GÄCHTER [24] den Phosphorhaushalt im Vierwaldstättersee (Horwer Bucht) ausführlich untersucht hat, wird für den gleichen Seeteil der Stickstoffkreislauf beschrieben. Auf Grund der Nährstoffkonzentration während der Zirkulationszeit gilt nach dem Schema von Volienweider [77] die Horwer Bucht als mesotroph, das heisst, sie muss als gefährdet betrachtet werden. Die in den See geleiteten Abwässer werden in nächster Zeit biologisch gereinigt, so in Hergiswil (4500 Einwohner) ab 1970. Für das Gebiet der Gemeinde Horw (10000 Einwohner) ist geplant, das Abwasser vom See fernzuhalten und in einer regionalen Anlage mit dem Abwasser der Stadt Luzern zu reinigen. Unsere Untersuchungen stellen also eine Bestandesaufnahme vor Inbetriebnahme der Kläranlagen dar.

Als See mit eutrophem Charakter wurde der Rotsee (bei Luzern) ausgewählt.

In den Seen wird vielfach im Herbst ein Nitratminimum festgestellt. Der Nitratgehalt fällt dabei unter die Grenze der analytischen Nachweisbarkeit, so zum Beispiel im Zürichsee [69], Baldeggersee [3], Vierwaldstättersee 1964 (AмвüHL, mündliche Mitteilung), Luganersee [79] und Sempachersee [45].

Mit Nährstofftestzellen von etwa 1400 I Inhalt (Gächter [24]) sollte in situ geprüft werden, ob im Vierwaldstättersee zu gewissen Jahreszeiten mit einer Nitratdüngung die Photosyntheseaktivität des Planktons erhöht werden kann. 
Die Untersuchungen des N-Kreislaufs in Seen verlangen eine genaue Bestimmung aller $\mathrm{N}$-Komponenten. Während die anorganischen $\mathrm{N}$-Verbindungen $\left(\mathrm{NO}_{3}, \mathrm{NO}_{2}\right.$, $\mathrm{NH}_{3} / \mathrm{NH}_{4}$ ) im Seewasser bis auf Mikrogramme pro Liter genau erfasst werden können [61], bieten sich bei der Bestimmung des partikulären und gelösten organischen Stickstoffs analytische Schwierigkeiten. Der im Plankton gebundene, sogenannte "geformte» oder "partikuläre» Stickstoff gewinnt besondere Bedeutung, weil er eine gute Vergleichsbasis für die vorhandene Biomasse liefert [44]. Es war deshalb nötig, eine genaue und störungsfreie Bestimmungsmethode des partikulären Stickstoffs zu erarbeiten.

\section{Methoden}

\subsection{Physikalische Methoden}

\subsection{Temperaturmessung}

Die Temperatur wurde mit der Elektrosonde «Oxytester» [2] gemessen.

\subsection{Messung der Lichtverhältnisse}

Die Sichttiefe wurde mit der Secchi-Scheibe bestimmt. Mit Hilfe eines Sperrschichtphotometers kombiniert mit spektralselektiven Filtern (BG12, VG9 und RG2 der Firma Schott und Gen., Mainz) wurden nach den Empfehlungen von SAUBERER [52] die vertikalen Extinktionen gemessen.

\subsection{Chemische Analysenmethoden}

\subsection{Bestimmung der anorganischen Stickstoffkomponenten}

Ammoniumbestimmung:

Das Ammonium wurde nach vorhergehender Wasserdampfdestillation der alkalisch gemachten Seewasserprobe mit Nessler-Reagenz nach ScHmid [57] bestimmt.

Nach unseren Untersuchungen beträgt bei einer Destillation von $250 \mathrm{ml}$ Seewasser und einem Gehalt von $60 \mu \mathrm{g} \mathrm{NH}_{4}-\mathrm{N} / \mathrm{l}$ die Standardabweichung $s= \pm 10 \mu \mathrm{g} \mathrm{NH}-\mathrm{N} / \mathrm{l}$.

Alle Reagenzien wurden mit $\mathrm{NH}_{4}$-freiem Wasser hergestellt. Man lässt dabei frisch destilliertes Wasser durch eine Kationenaustauschsäule passieren (Dowex X 8 20/80).

Nitratbestimmung:

Das Nitrat wurde mit der Natriumsalicylatmethode nach MüLLER und WIDEMANN [39] bestimmt.

Bei einem Gehalt von $70 \mu \mathrm{g} \mathrm{NO}_{3}-\mathrm{N} / 1$ (Vierwaldstätterseewasser) betrug die Standardabweichung $s= \pm 5 \mu \mathrm{g} \mathrm{N} / 1$ (5-cm-Küvette bei $420 \mathrm{~nm})$.

Bei sehr geringen Nitratkonzentrationen wurde die empfindlichere Cadmiumreduktionsmethode nach STRICKLAND et al. [62] angewandt.

Nitritbestimmung:

Nitrit wurde mit Sulfanilamid und N-(1-Naphthyl)-äthylendiamin nach STRIckLAND et al. [62] bestimmt.

\subsection{Bestimmung der organischen Stickstoffkomponenten}

Organische N-Verbindungen kommen im Wasser in suspendierter oder gelöster Form vor. Der an Partikel gebundene organische $\mathrm{N}$ wird als «partikulärer» $\mathrm{N}$ bezeich- 
net. Der im Filtrat $(0,45 \mu \mathrm{m}$ filtriert) erfassbare organische Stickstoff ergibt sich aus der Differenz der Gesamt-N-Konzentration und der $\mathrm{NH}_{4}$-N-Konzentration.

Zur Bestimmung des partikulären Stickstoffs im Wasser werden verschiedene Methoden vorgeschlagen: der Dumas-Aufschluss [9, 37], die Ultraviolettoxydation des organischen Materials zu Nitrat [7] und der Mikro-Kjeldahl-Aufschluss [32, 57, 62].

Der Dumas-Aufschluss verlangt einige Milligramme Algentrockensubstanz. Da grosse Mengen Seewasser filtriert werden müssten, kam diese Methode nicht in Frage.

Bei den Düngexperimenten stieg der Nitratgehalt bis auf $1,5 \mathrm{mg} \mathrm{NO}_{3}-\mathrm{N} / \mathrm{l}$. Hohe Nitratkonzentrationen stören aber die N-Bestimmung mit Hilfe der Ultraviolettoxydation [62]. Zur Auswahl standen noch die Mikro-Kjeldahl-Methoden.

Beim Kjeldahl-Aufschluss nach ScHuId [57] wird der part. N aus der Differenz von Rohwasser und filtriertem Wasser ermittelt; dabei wird nicht berücksichtigt, dass hohe Nitratkonzentrationen die Bestimmung negativ beeinflussen (Abb. 2).

Beim Verfahren nach STRICKLand et al. [61] werden Millipore-Filter mit Magnesiumkarbonat überdeckt, nach der Filtration wird die Magnesiumkarbonatschicht mitsamt dem Plankton in einen Kolben gespült und aufgeschlossen. Nach eigenen Versuchen liess sich das Planktonmaterial manchmal nur schwer quantitativ abspülen.

HOLM-HANSEN [32] trennte die partikuläre Fraktion mit Hilfe von Glasfaserfiltern ab. Leider ist die Porenweite bei Glasfaserfiltern nicht genau definiert. GARsidE et al. [25] zeigten, dass Glasfaserfilter (GF/C Whatman), mit Magnesiumkarbonat bedeckt, in bezug auf den Partikelrückhalt den Membranfiltern ebenbürtig sind.

Zur Bestimmung des part. N im Seewasser wurde deshalb eine Methode erarbeitet, die alle Vorteile der zitierten Methoden in sich vereinigte.

2.221 Bestimmung des partikulären organischen Stickstoffs mit der Kjeldahl-Methode

Bei der angewandten Methode wird die Seewasserprobe durch ein Glasfaserfilter, das man mit einer Magnesiumkarbonatschicht bedeckt, filtriert. Das Filter wird mit-

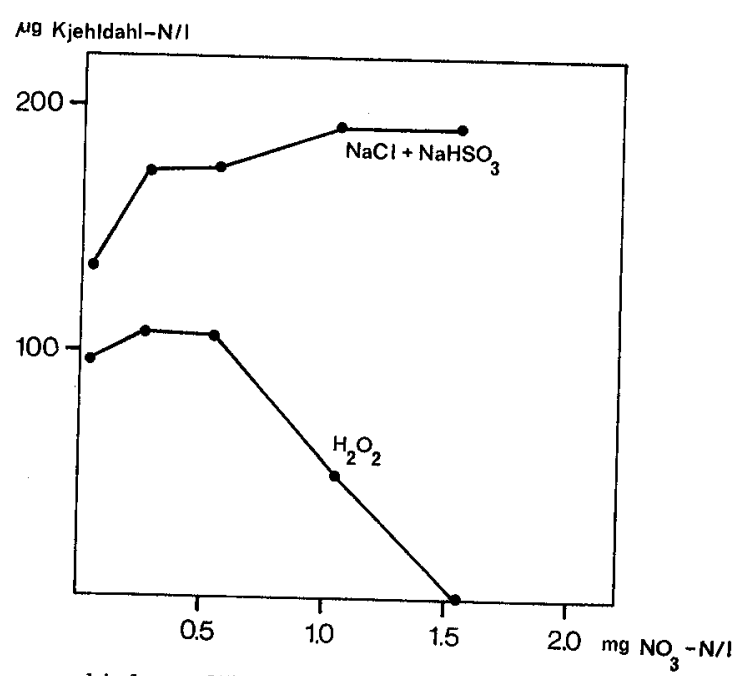

Abb. 2. Der Einfluss verschiedener Nitratkonzentrationen auf die Kjeldahl-Bestimmung von filtriertem Seewasser (Vierwaldstättersee 14. Oktober 1969). 
samt dem Planktonrückstand aufgeschlossen. Nach vorhergehender Dampfdestillation des Aufschlussgutes nach Pregl wird das Ammonium mit Nessler-Reagenz bestimmt.

Um zu testen, ob Stickstoffverunreinigungen durch die Glasfaserfilter in die Proben eingeführt werden, wurden verschiedene Filter aufgeschlossen.

Tab. 1 zeigt, dass nach dem Ausglühen der Filter der N-Wert dem der Schwefelsäure entspricht.

Vergleichsweise wurde Wasser aus dem bakterienreichen Rotsee mit der Glasfaserfiltermethode und der Methode nach STRICKLAND et al. [61] analysiert.

Tab. 2 zeigt, dass die mit beiden Methoden erhaltenen Werte identisch sind. Bei der Filtration durch bedeckte Glasfaserfilter wird also praktisch alles zurückgehalten, was grösser als $0,5 \mu \mathrm{m}$ ist.

Analysenvorschrift zur Bestimmung des partikulären organischen Stickstoffs mit Glasfaserfiltern:

Die Glasfaserfilter (GF/C Whatman, Durchmesser 5,5 cm) werden vor Gebrauch im Muffelofen während 2 Stunden bei $500^{\circ} \mathrm{C}$ ausgeglüht und nachher mit $\mathrm{NH}_{4^{-}}$ freiem Wasser gewaschen.

Tab. 1. Vergleich des $\mathrm{H}_{2} \mathrm{SO}_{4}$-Blindwertes und des Glasfaserfilterblindwertes.

\begin{tabular}{ll}
\hline & Extinktion $440 \mathrm{~nm}(10-\mathrm{cm}-\mathrm{Küvette})$ \\
\hline $\begin{array}{l}\text { Nessler-Reagenzblindwert } \\
(4 \mathrm{ml} \text { in } 100 \mathrm{ml} \text { Wasser) }\end{array}$ & 0,025 \\
\hline $\begin{array}{l}\text { Schwefelsäureblindwert } \\
(2 \mathrm{ml})\end{array}$ & 0,079 \\
\hline & 0,066 \\
& 0,096 \\
& 0,098 \\
Glasfaserfilter (GF/C Whatman) & 0,083 \\
mit Magnesiumkarbonat bedeckt & 0,081 \\
& 0,083 \\
& 0,078 \\
\hline
\end{tabular}

Tab. 2. Vergleich zwischen Glasfaserfiltermethode und der Methode nach Strickland et al. [61]. Rotsee 14. August 1969. Durchschnittswerte aus zwei Bestimmungen.

\begin{tabular}{lll}
\hline Tiefe & $\begin{array}{l}\text { Partikulärer Kjeldahl-N } \mu g / 1 \\
\text { Glasfaserfiltermethode }\end{array}$ & Magnesiumkarbonatschicht (Millipore HA filtriert) \\
\hline 0 & 250 & 275 \\
1 & 230 & 230 \\
2,5 & 254 & 238 \\
5 & 396 & 366 \\
7,5 & 472 & 436 \\
14 & 534 & 508 \\
\hline
\end{tabular}


Das Filter wird auf einem Millipore-Filterhalter fixiert, mit etwa $30 \mathrm{ml}$ N-freiem Wasser und $5 \mathrm{ml}$ Magnesiumhydroxidkarbonat-Suspension (2\%, p.A. Merck, gepulvert leicht) überschichtet, ohne ein Vakuum anzulegen. Dann saugt man bei $1 / 3$ atm das Filter trocken und filtriert die Seewasserprobe, ohne das Vakuum zu unterbrechen.

Das Filter bingt man mit einer Pinzette in einen trockenen Kjeldahl-Kolben und gibt $2 \mathrm{ml} \mathrm{konz}$. Schwefelsäure (p.A. Merck) und drei Tropfen Perhydrol (30 Gew.-\% $\mathrm{H}_{2} \mathrm{O}_{2}$ Merck) zu.

Nach Vorschlag von ScHmid [57] wurden die $250 \mathrm{ml}$ Kjeldahl-Kolben (mit NS 29/32) jeweils sofort mit Aufsätzen verschlossen, womit Störeinflüsse aus der Luft und Verluste vermieden werden können.

Den Kolben verschliesst man sofort mit dem Aufsatz, den innern und äusseren

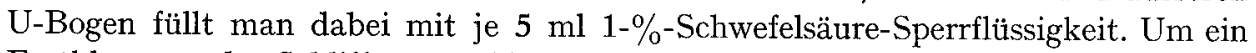
Festklemmen der Schliffe zu verhindern, empfiehlt es sich, den Schliffkern des Aufsatzes mit einer Teflon-Manschette (Fisons Scientific Apparatus Ltd., London) zu überziehen.

Der Kjeldahl-Aufschluss erfolgt bei $310^{\circ} \mathrm{C}$ auf einem Infrabrenner während 30 Minuten. Nach dem Erkalten fügt man die Sperrflüssigkeit des inneren U-Bogens zum Aufschlussgut und spült den Aufsatzteil und den Kolbenhals mit je $10 \mathrm{ml}$ Wasser, so dass etwa $25 \mathrm{ml}$ Flüssigkeit im Kolben zurückbleiben.

Die Destillationsapparatur wird mit $\mathrm{NH}_{4}$-freiem Wasser gefüllt (2,5 l) und mit $5 \mathrm{ml}$ kaltgesättigter Natriumkarbonatlösung $\left(\mathrm{Na}_{2} \mathrm{CO}_{3}\right.$ p.A. Merck) versetzt. Nach einem Vorlauf von etwa $300 \mathrm{ml}$ werden $10 \mathrm{ml} 32-\%$-Natronlauge ( $\mathrm{NaOH}$ p.A. Merck) der Wasserdampfdestillation unterworfen, dieses Destillat wird verworfen (s. ScHMiD [57], S.252). Dann bringt man den Kolben mit der ersten Probe auf die Destillations-

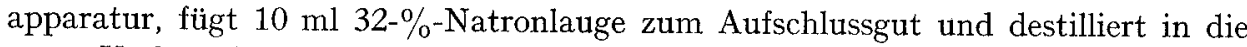
saure Vorlage (30 ml Wasser und 3 Tropfen 10-\%-Schwefelsäure) bis zur 100-mlMarke.

Nach der Destillation fügt man zum Destillat $4 \mathrm{ml}$ Nessler-Reagenz und misst die Extinktion nach 20 Minuten bei $440 \mathrm{~nm}$ gegen destilliertes Wasser in einer 10-cmKüvette.

Da die Schwefelsäure selbst schon Stickstoff enthält, müssen zu jeder Serie zwei Blindproben aufgeschlossen werden. Zur Bestimmung des Blindwertes werden Glasfaserfilter wie eine Probe behandelt. Der Blindwert wird jeweils von den Probenwerten abgezogen.

Bei einer Filtration von $200 \mathrm{ml}$ beträgt der Messbereich $10-400 \mu \mathrm{g}$ partikulärer Kjeldahl-N/1.

Beim äusserst geringen Gehalt von $50 \mu \mathrm{g}$ part. N/1 (Vierwaldstättersee 20. Januar 1969) betrug die Standardabweichung bei einer Filtration von $200 \mathrm{ml} \mathrm{s}= \pm 10 \mu \mathrm{g}$ N/l. Diese hohe Genauigkeit ermöglicht die Bestimmung des part. $\mathrm{N}$ in oligotrophen Gewässern und bei hohen Nitratkonzentrationen, während die Methode nach SCHMID [57] zu starke Streuungen aufweist (Tab. 3).

\subsection{Bestimmung des gelösten organischen Kjeldahl-Stickstoffs}

Bei der Bestimmung des gelösten organischen Stickstoffs im filtrierten Wasser begegnen wir oft Nitratkonzentrationen, die die Konzentration des organischen $\mathrm{N}$ und Ammonium- $N$ übersteigen. Nitrate stören, indem sie eine Abnahme der Kjeldahl- 
Tab. 3. Vergleich zwischen Glasfaserfiltermethode und der Differenzmethode nach ScHmID [57]. Urnersee 5. Februar 1969 (Vollzirkulation). Nitratgehalt $350 \mu \mathrm{g} \mathrm{NO}-\mathrm{N} / 1$.

\begin{tabular}{rll}
\hline & $\mu g$ part. N/1 & \\
Tiefe m & Glasfiltermethode & Rohwasser minus filtriertes Wasser nach ScHMID [57] \\
\hline 0 & 60 & 10 \\
5 & 40 & 40 \\
10 & 50 & 50 \\
15 & 60 & 10 \\
20 & 40 & 20 \\
30 & 50 & 30 \\
50 & 60 & 20 \\
100 & 60 & 0 \\
195 & 90 & 0 \\
\hline
\end{tabular}

Werte bewirken (Abb. 2). Nach Untersuchungen von Prochazkova [47] mit reinen Lösungen kann die $\mathrm{NO}_{3}$-Störung durch Zugabe von Natriumchlorid verhindert werden, wahrscheinlich infolge Bildung von flüchtigen Verbindungen wie NOCl und $\mathrm{NO}_{2} \mathrm{Cl}$. Überwiegt $\mathrm{NO}_{3}-\mathrm{N}$, so gibt man vor dem Aufschluss noch Natriumbisulfit $\mathrm{zu}$.

Aus Abb. 2 ist ersichtlich, dass bei Verwendung von Peroxid für den KjeldahlAufschluss im filtrierten Seewasser immer niedrigere Werte erhalten werden als bei $\mathrm{NaCl}$ - und $\mathrm{NaHSO}_{3}$-Zugabe. Vorversuche mit filtriertem Vierwaldstätterseewasser haben gezeigt, dass, auch bei nichtvollständiger Verbrennung des Ausschlusses, mit $\mathrm{H}_{2} \mathrm{SO}_{4}$ allein höhere $\mathrm{N}$-Werte erhalten werden als bei Verwendung von Peroxid als Oxydationsmittel. Die analytischen Probleme bei der Bestimmung der gelösten organischen N-Verbindungen im Seewasser sind noch nicht befriedigend gelöst. Das zeigte sich auch in der erhöhten Standardabweichung. Bei unseren Untersuchungen wurde nach den Empfehlungen von Prochazkova [47] gearbeitet.

Analysenvorschrift zur Bestimmung des gelösten organischen Stickstoffs im filtrierten Seewasser:

$\mathrm{Zu} 200 \mathrm{ml}$ filtriertem Seewasser $(0,45 \mu \mathrm{m}$ filtriert) gibt man $2 \mathrm{ml} \mathrm{konz.} \mathrm{Schwefel-}$ säure (p.A. Merck) und $1 \mathrm{ml} 5-\%$-Natriumchloridlösung. Man lässt die Proben auf dem Infrabrenner auf etwa $10 \mathrm{ml}$ eindampfen, stellt die Brenner auf $310^{\circ} \mathrm{C}$ ein und gibt dann $1 \mathrm{ml}$ Natriumbisulfit $\left(5 \% \mathrm{NaHSO}_{3}\right) \mathrm{zu}$. Kurz nachdem sich die ersten $\mathrm{SO}_{3}$ Dämpfe gebildet haben, verschliesst man die Kjeldahl-Kolben mit den Aufsätzen. Anschliessend wird während 1 Stunde bei $310^{\circ} \mathrm{C}$ aufgeschlossen.

Die Destillation und Nessler-Zugabe erfolgt wie bei der Bestimmung des part. N. Den Blindwert ermittelt man durch Aufschluss von $2 \mathrm{ml} \mathrm{H}_{2} \mathrm{SO}_{4}, 1 \mathrm{ml} 5-\%-\mathrm{NaCl}$ und $1 \mathrm{ml} 5-\%-\mathrm{NaHSO}_{3}$.

Bei Verwendung von $200 \mathrm{ml}$ filtriertem Wasser beträgt der Messbereich 10-400 $\mu \mathrm{g}$ Kjeldahl-N/l.

Bei einem Gehalt von $130 \mu \mathrm{g} \mathrm{N} / 1$ betrug die Standardabweichung $s= \pm 20 \mu \mathrm{g} \mathrm{N} / 1$ (Filtration von $1.50 \mathrm{ml}$ Vierwaldstätterseewasser, $\mathrm{NO}_{3}$-Gehalt $460 \mu \mathrm{g} \mathrm{N} / 1$ ). 
2.23 Bestimmung des Kjeldahl-Stickstoffs im aufgefangenen Sediment

Bloesch [11] hat das aus der trophogenen Schicht stammende Sediment in verschiedenen Tiefen aufgefangen und die Sedimentation während jeweils 14 Tagen gemessen. Das Sediment wurde bei $50^{\circ} \mathrm{C}$ getrocknet und das Trockengewicht bestimmt.

Für die N-Analyse wurden $20 \mathrm{mg}$ Trockensubstanz in einen trockenen KjeldahlKolben eingewogen und mit $2 \mathrm{ml}$ konz. Schwefelsäure während 30 Minuten aufgeschlossen $\left(310^{\circ} \mathrm{C}\right)$. Für die vollständige Verbrennung fügt man 6 Tropfen Perhydrol zu und schliesst nochmals während 20 Minuten auf. Beim Aufschluss und der anschliessenden Wasserdampfdestillation verfährt man wie bei der Bestimmung des partikulären Stickstoffs. Vor der Nessler-Zugabe verdünnt man das Destillat 10 - bis $20 \mathrm{mal}$ und misst die Extinktion bei $440 \mathrm{~nm}$ in einer 10-cm-Küvette.

\section{Orthophosphat:}

\subsection{Bestimmung der Phosphorkomponenten}

Bestimmung mit der Ammoniummolybdat-Zinnchlorid-Methode nach АмвӥнL et al. [6].

Gesamtphosphor:

Die Gesamt-P-Konzentration wurde nach Schmid et al. [56] bestimmt. Der partikuläre Phosphor ergibt sich aus der Differenz der Gesamt-P-Konzentration im Rohwasser und derjenigen des Filtrats $(0,45 \mu \mathrm{m}$ filtriert).

\subsection{Bestimmung des gelösten Sauerstoffs und des Sulfids}

Sauerstoff:

Bestimmung nach Winkler, modifiziert nach ALsTERBERG [1] (Vorschrift der EAWAG).

Schwefelwasserstoff:

Die quantitative Bestimmung erfolgte colorimetrisch mit Dimethyl-p-phenylendiaminchlorid und Eisen-III-ammoniumsulfat (Vorschrift EAWAG).

\subsection{Bestimmung des anorganischen Gesamtkohlenstoffs}

Der Gehalt an anorganischem Kohlenstoff (gelöstes $\mathrm{CO}_{2}, \mathrm{HCO}_{3}^{-}, \mathrm{CO}_{3}{ }^{2-}$ ) wurde mit Hilfe des pH-Wertes (pH-Gerät Radiometer Typ PHM26 mit Glaselektrode) und der Alkalinität nach HARvEY [29] berechnet.

Alkalinität (Säurebindungsvermögen):

$100 \mathrm{ml}$ Probewasser werden mit 0,1 N Salzsäure gegen Methylorange als Indikator titriert. Die Titration erfolgt dabei unter Stickstoffstrom, dadurch wird das gebildete freie $\mathrm{CO}_{2}$ ausgetrieben.

\subsection{Biologische Untersuchungsmethoden}

\subsection{Produktionsmessung mit der $\mathrm{C}^{\mathbf{1 4}}$-Methode}

Für den $\mathrm{C}^{14}$-Ansatz füllte man $125 \mathrm{ml}$ Jenaer Flaschen ab. $\mathrm{Zu}$ diesen Flaschen fügte man $1 \mathrm{ml}$ sterile, radioaktive $\mathrm{NaHC}^{14} \mathrm{O}_{3}$-Lösung (etwa 6 Mikrocurie). Die Proben wurden jeweils von 10 bis $14 \mathrm{Uhr}$ in den entsprechenden Tiefen im See exponiert. Nachher filtrierte man $25 \mathrm{ml}$ (Sartorius Membranfilter 0,22 $\mu \mathrm{m}$ ) und klebte die Filter 
mit dem Plankton mit "Rubber-Cement» in Metallschälchen. Um die Filter von anorganischen $\mathrm{C}^{\mathbf{1 4}}$-Verbindungen $\mathrm{zu}$ befreien, wurden sie während 20 Minuten rauchender Salzsäure ausgesetzt.

Die Ampullenaktivität wurde, wie bei VOLLENwEIdER [77] beschrieben, mit der Bariumkarbonatmethode bestimmt.

Die Aktivität der Planktonfilter wurde in der Radiologischen Abteilung an der EAWAG mit dem Methandurchflusszähler (Firma Frieseke und Hoepfner) gemessen.

\subsection{Planktonuntersuchungen}

Die qualitativen und quantitativen Planktonuntersuchungen wurden mit dem Umkehrmikroskop nach UTERMÖHL [74] ausgeführt.

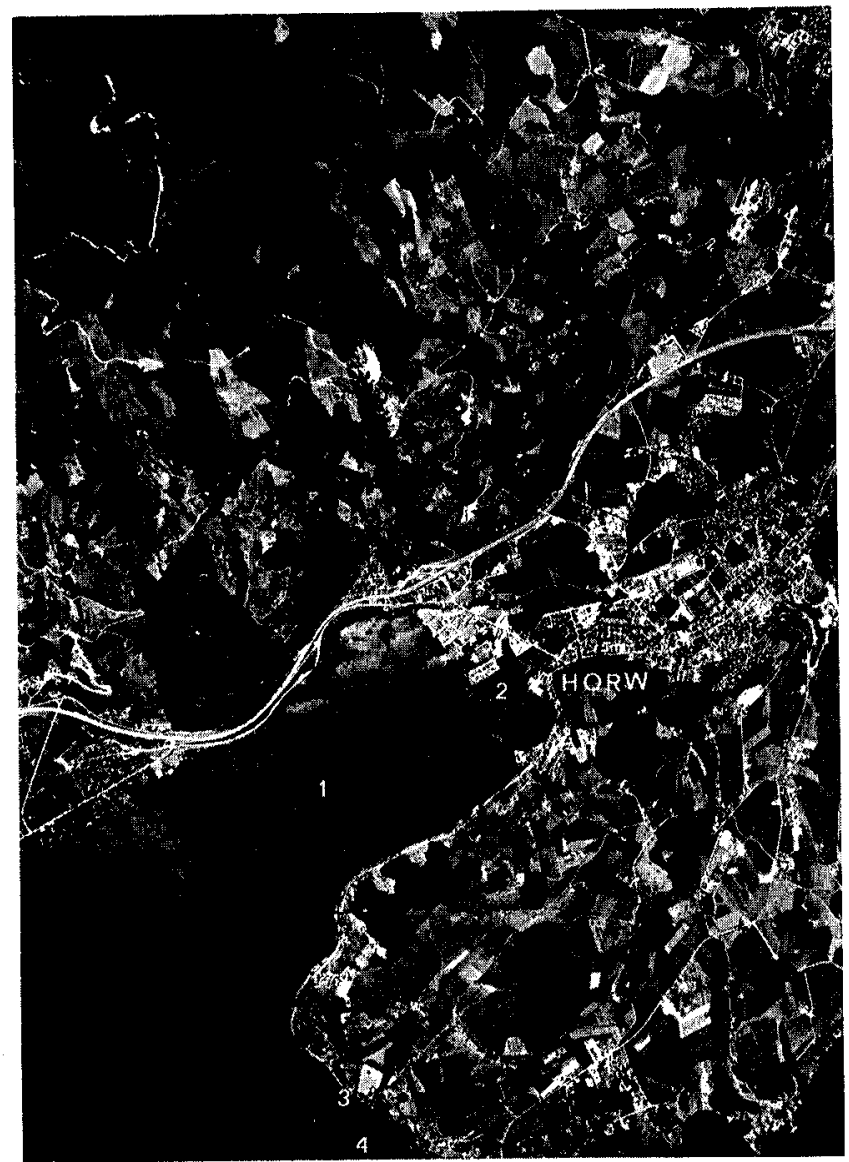

Abb. 3. Horwer Bucht des Vierwaldstättersees (Aufnahme der Swissair Photo AG, Zürich). 1 Probenahmestelle, 2 Horwer Bach, 3 Hydrobiologisches Labor Kastanienbaum, 4 Expositionsstelle für die Nährstofftestzellen. 


\section{Resultate der Seeuntersuchungen}

\subsection{Orographie und Probenahmestelle}

Vierwaldstättersee (Horwer Bucht)

Die Morphologie des Vierwaldstättersees ist bei AмвüHL [5] beschrieben.

Die untersuchte Stelle liegt in der Horwer Bucht. Das fast rechteckige Becken von $1 \times 1,5 \mathrm{~km}$ Uferlänge ist maximal $72 \mathrm{~m}$ tief, das Volumen beträgt $72 \cdot 10^{6} \mathrm{~m}^{3}$. Die genauen Isobathenflächen sind bei GÄCHTER [24] angegeben.

In den Jahren 1969/70 wurden monatlich an dem in Abb. 3 bezeichneten Punkt mit der Friedinger-Schöpfflasche aus folgenden Tiefen Proben entnommen : 0, (1), 2,5, 7,5, $10,12,5,15,25,35,45$ und $60 \mathrm{~m}$. Die Proben direkt über dem Seesediment wurden mit dem Schlammlot [80] gehoben, dabei wurde das in der Plexiglasröhre überstehende Wasser mit einem Heber abgesaugt. Die maximale Tiefe beträgt an dieser Stelle $62 \mathrm{~m}$.

Rotsee

Der Rotsee liegt in einer windstill gelegenen Mulde nördlich von Luzern. Bei einer Länge von 2,5 km, einer Breite von $0,15-0,25 \mathrm{~km}$ und einer maximalen Tiefe von $16 \mathrm{~m}$ beträgt das Volumen $4,3 \cdot 10^{6} \mathrm{~m}^{3}$, die mittlere Tiefe ist $9 \mathrm{~m}$ [38].

Bis zum Jahre 1933 wurde der See durch die Abwässer des ganzen anliegenden Stadtquartiers belastet. Ein Teil der Abwässer wurde dann in einer Sammelanlage mechanisch gereinigt und direkt in den Auslauf des Sees geleitet. Seit Juni 1969 werden alle Abwässer vom See weggeleitet. In den Jahren 1969/70 wurde monatlich am in Abb. 4 bezeichneten Punkt aus folgenden Tiefen Proben entnommen: 0, 1, 2,5, $5,7,5$ und $14 \mathrm{~m}$.

Horwer Bucht

\subsection{Thermik}

In Abb. 5 ist der jahreszeitliche Verlauf der Temperatur während der Untersuchungsperiode festgehalten. Während der Vollzirkulation im Februar betrug die

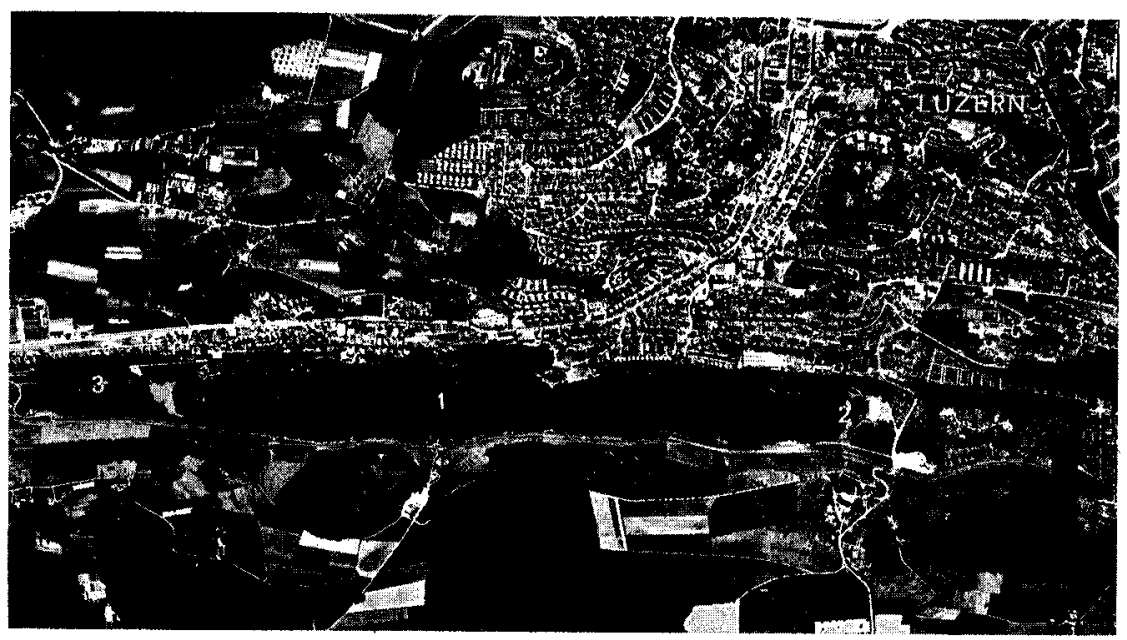

Abb. 4. Rotsee (Aufnahme der Swissair Photo AG, Zürich). 1 Probenahmestelle, 2 Reuss-Stolleneinlauf, 3 Auslauf. 


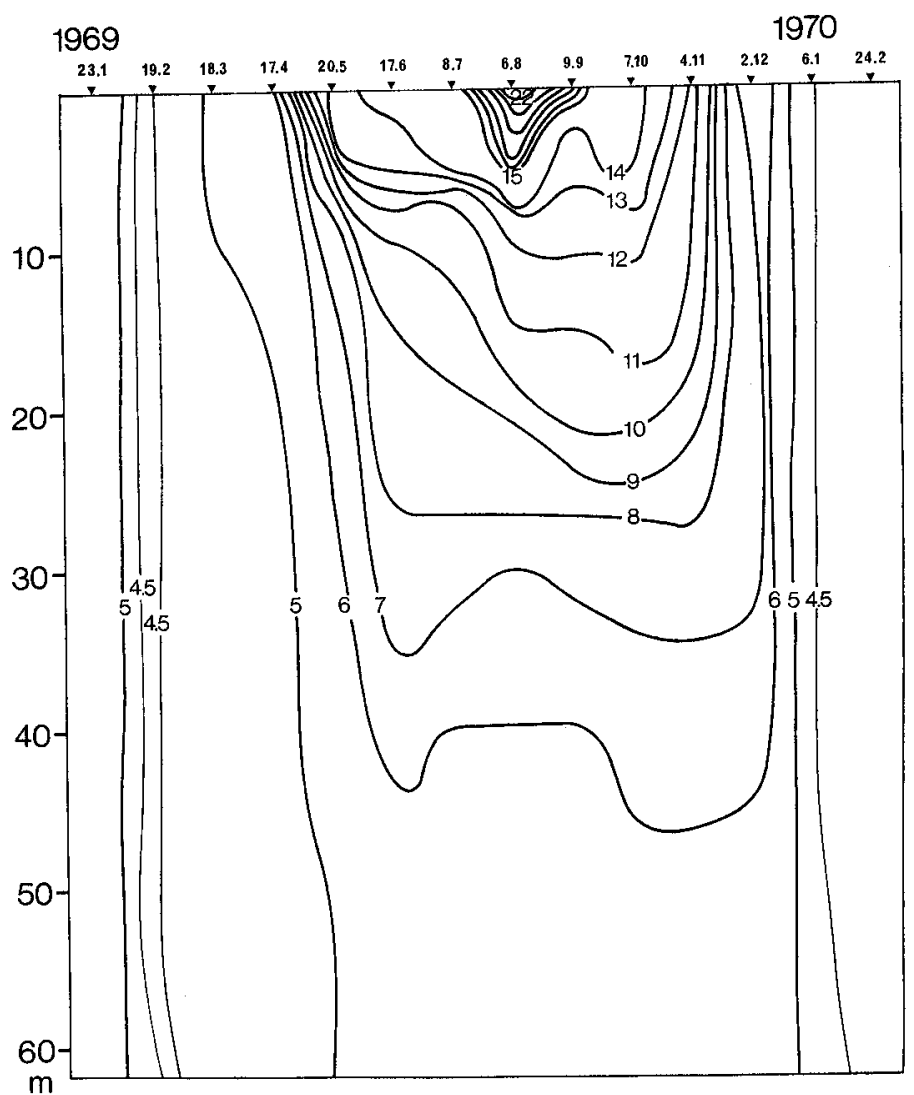

Abb. 5. Isothermen der Horwer Bucht $\left({ }^{\circ} \mathrm{C}\right)$.

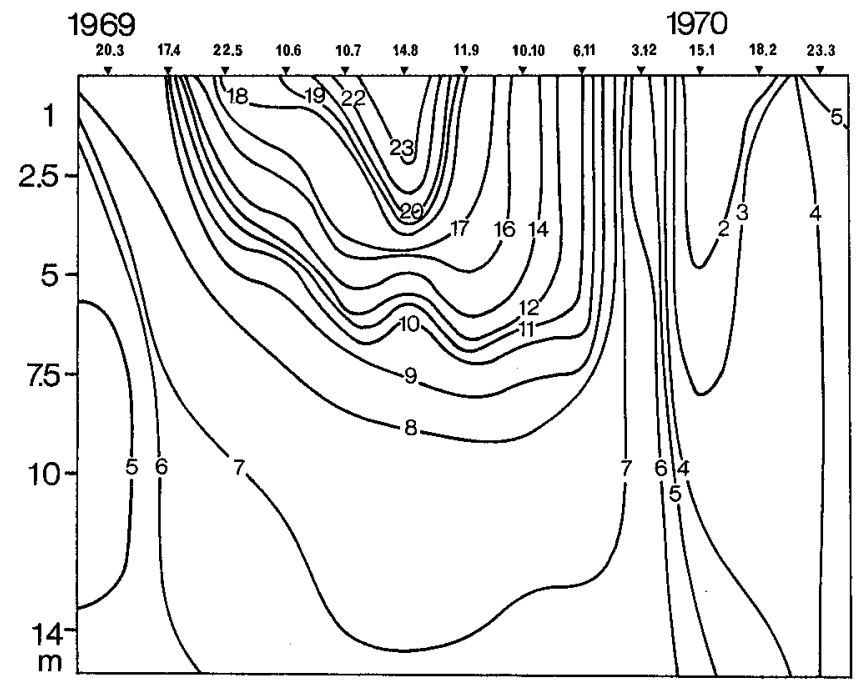

Abb. 6. Isothermen des Rotsees $\left({ }^{\circ} \mathrm{C}\right)$. 
Temperatur $4,5^{\circ} \mathrm{C}$. Bis zum Ende der Sommerstagnation reichte der Temperaturanstieg bis in $50 \mathrm{~m}$ Tiefe. Unterhalb dieser Tiefe blieb die Temperatur während des ganzen Jahres konstant. Die höchsten Temperaturen wurden im August mit 22,7 ${ }^{\circ} \mathrm{C}$ gemessen.

\section{Rotsee}

In Abb. 6 sind die Isothermen des Rotsees dargestellt. Maximale Temperaturen wurden im August $\left(23,5^{\circ} \mathrm{C}\right)$ gemessen. Die $8-^{\circ} \mathrm{C}$-Isotherme reichte im Gegensatz zur Horwer Bucht $(25 \mathrm{~m})$ nur bis in $8 \mathrm{~m}$ Tiefe, das Metalimnion (Thermokline) lag während der Sommerstagnation in 2 bis $6 \mathrm{~m}$ Tiefe.

In der Dezember-Serie wurde in den oberen Wasserschichten $5^{\circ} \mathrm{C}$, im Tiefwasser $6^{\circ} \mathrm{C}$ gemessen. Eine Erklärung dazu finden wir im höheren Salzgehalt des Tiefenwassers und die dadurch bedingte Dichtezunahme. In den Monaten Januar und Februar war der Rotsee von einer bis $10 \mathrm{~cm}$ dicken Eisschicht bedeckt.

In Abb. 7 sind für beide Seen die maximalen Temperaturdifferenzen pro $1 \mathrm{~m}$ Wasserschicht aufgetragen. Die Temperaturschichtung liefert gleichzeitig eine Aussage über die Dichteschichtung und somit auch über den Grad der Absperrung der hypolimnischen Schichten vom Epilimnion.

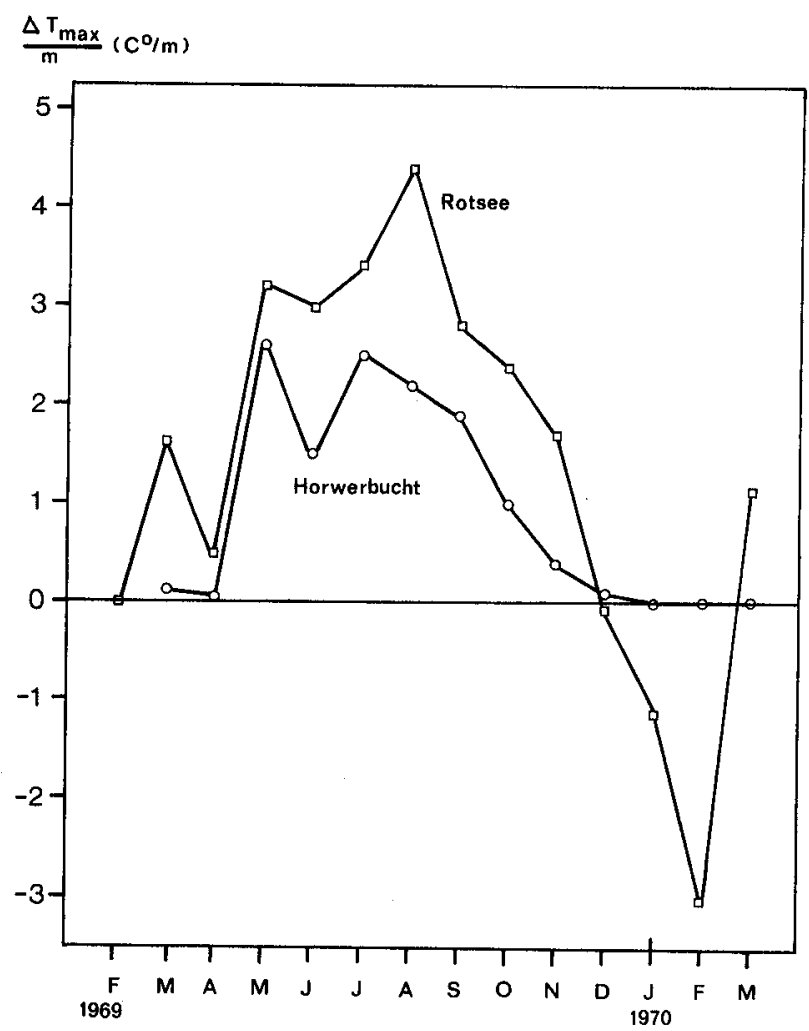

Abb. 7. Maximaler Temperaturgradient der Horwer Bucht und des Rotsees. 
Auf Grund der gemessenen Temperaturdifferenzen ist der Rotsee viel stabiler geschichtet als die Horwer Bucht. Der hohe Salzgehalt im Tiefenwasser und die dadurch bedingte Dichtezunahme verhindert im Rotsee wahrscheinlich auch bei Homothermie eine Vollzirkulation, so dass er als fakultativ meromiktische angesehen werden muss.

\subsection{Lichtverhältnisse}

Mit Hilfe der Lichtkomponente, die den kleinsten vertikalen Extinktionskoeffizienten aufweist, also am tiefsten ins Wasser eindringt, lässt sich die euphotische (trophogene) Schicht abschätzen. Nach RHODE [49] korrespondiert normalerweise die Tiefe, in der noch $1 \%$ der Oberflächenintensität des grünen Lichtes gemessen wird, mit der Kompensationstiefe, das heisst unterhalb dieser Tiefe ist während 24 Stunden die Respiration grösser als die Assimilation.

In den Tab. 4 und 5 sind die Sichttiefen und die 1-\%-Grenzen für verschiedene Spektralbereiche zusammengestellt.

In der Horwer Bucht drang das grüne Licht, gefolgt von Blau, am tiefsten ein. Die 1-\%-Grenze für VG9 variierte zwischen 4,3 und $19,0 \mathrm{~m}$.

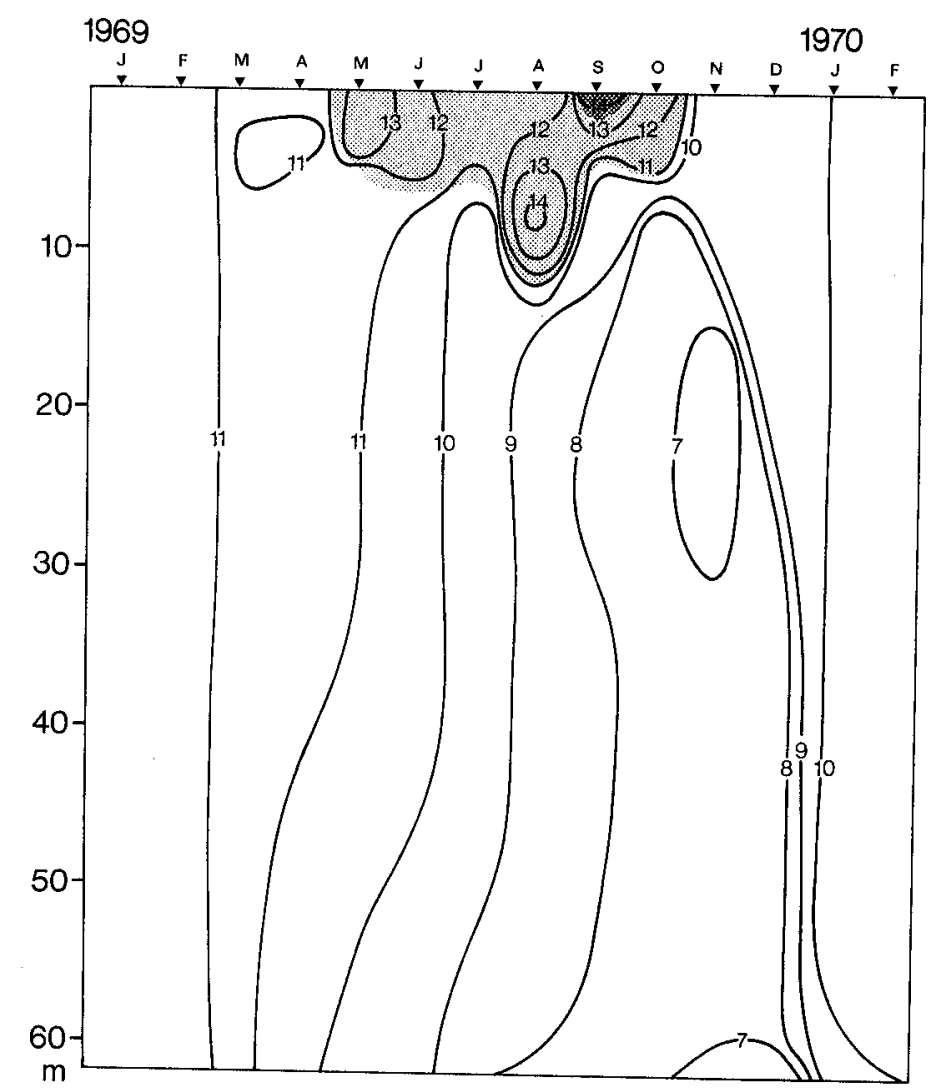

Abb. 8. Sauerstoff ( $\mathrm{mg} \mathrm{O}_{2} / \mathrm{l}$ ) der Horwer Bucht. Schwacher Punktraster $=100 \%$ Sättigung. Starker Punktraster $=150 \%$ Sättigung. 


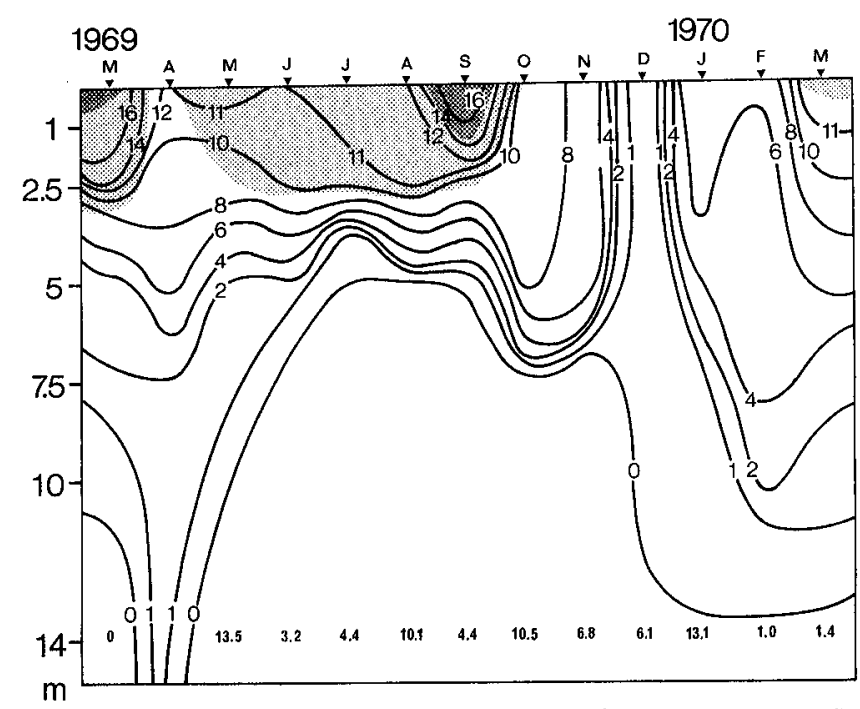

Abb. 9. Sauerstoff ( $\mathrm{mg} \mathrm{O}_{2} / 1$ und Schwefelwasserstoff $\left(\mathrm{mg} \mathrm{S}^{2-} / 1\right)$ des Rotsees. Schwacher Punktraster $=100 \%$ Sättigung, starker Punktraster $=150 \%$. Schwefelwasserstoff nur in $14 \mathrm{~m}$ angegeben.

Grünes Licht drang auch im Rotsee immer am tiefsten ein, dicht gefolgt von Rot. Die 1-\%-Grenze für VG9 schwankte zwischen 3,7 und 9,2 m.

Bei den Sichttiefen ist auffallend, dass im Mai/Juni und September/Oktober die Werte im Rotsee grösser waren als in der Horwer Bucht.

\subsection{Sauerstoff}

In Seen besteht eine enge Beziehung zwischen Sauerstoffgehalt und den biologischen Produktions- und Abbauprozessen. Durch die Ausbildung der thermischen Schichtung wird in Seen temperierter Zonen der Gasaustausch zwischen Epi- und Hypolimnion unterbunden. Da die im Epilimnion produzierte Biomasse langsam ins Hypolimnion absinkt und zersetzt wird, kann die dabei auftretende Sauerstoffzehrung als Mass der Produktion und indirekt der Nährstoffversorgung dienen.

\section{Horwer Bucht}

Der Sauerstoffgehalt (Abb. 8) am Ende der Vollzirkulation (März) betrug 11,5 $\mathrm{mg} / \mathrm{l}$. Über Grund wurde am Ende der Sommerstagnation (November) noch $6,5 \mathrm{mg} / \mathrm{l}$ gemessen, die Sauerstoffzehrung betrug hier also $5 \mathrm{mg} / 1$.

Die epilimnischen Sauerstoffmaxima fallen mit den höchsten partikulären Phosphor- und Stickstoffkonzentrationen zusammen. Das Sauerstoffmaximum in 7,5 bis $10 \mathrm{~m}$ im August wird dabei durch die Photosyntheseaktivität eingeschichteter Oscillatoria rubescens bewirkt. Im November zeigte sich ein metalimnisches Sauerstoffminimum von $6,3 \mathrm{mg} / \mathrm{l}$, wahrscheinlich lässt sich dieses Minimum auf die Abbauaktivität von Bakterien zurückführen, die direkt unter der photosynthetischen Schicht das anfallende Planktonmaterial teilweise mineralisieren.

\section{Rotsee}

Epilimnische Sauerstoffmaxima von $16 \mathrm{mg} \mathrm{O}_{2} / 1$ wurden im März und September gemessen (Abb. 9). Im Hypolimnion wurde nur im April etwa $1 \mathrm{mg} \mathrm{O} / 2$ gemessen, 


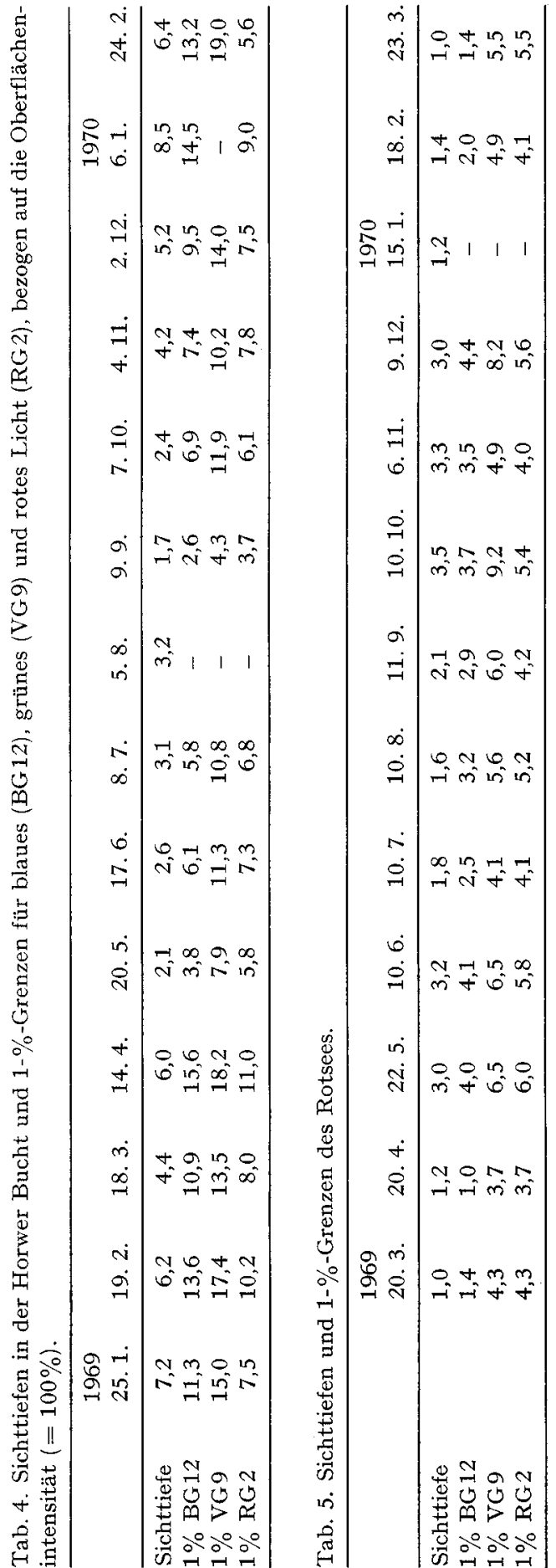

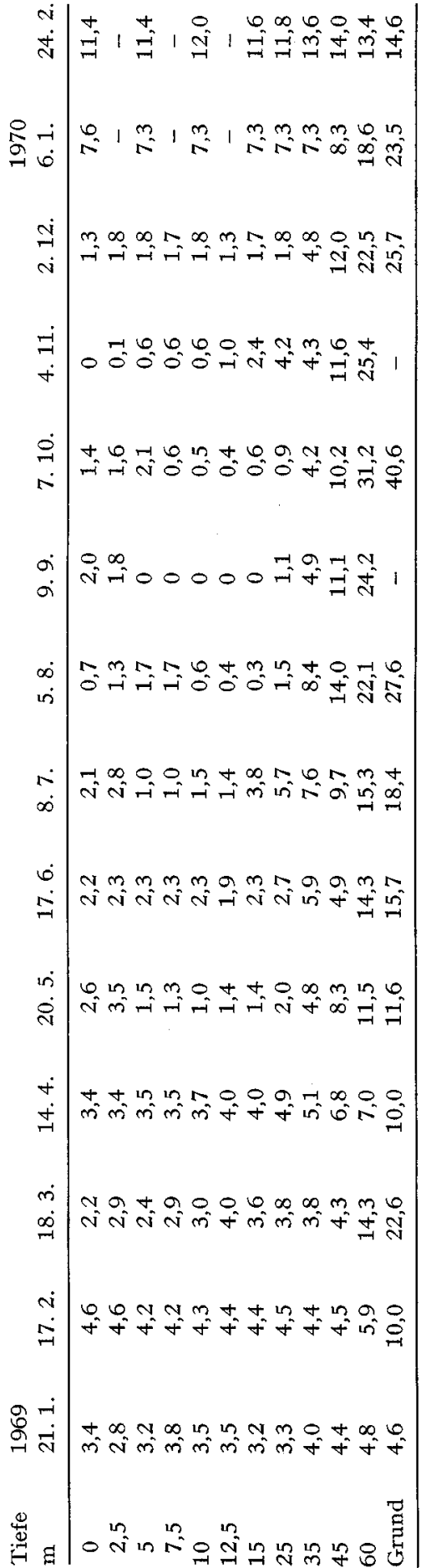




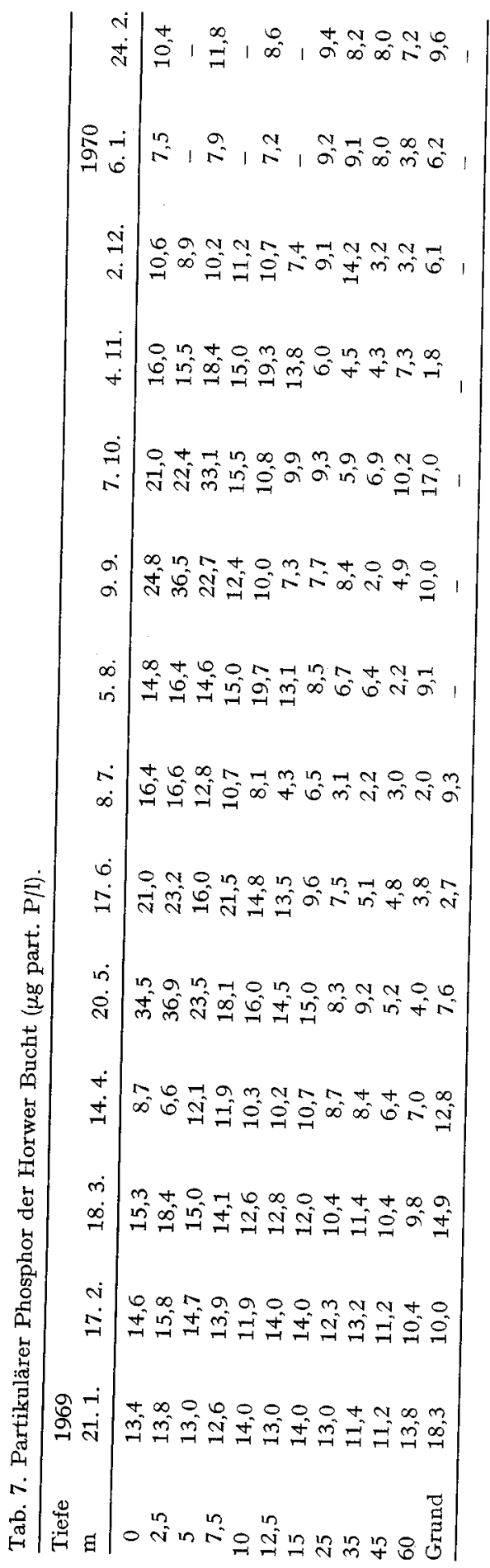

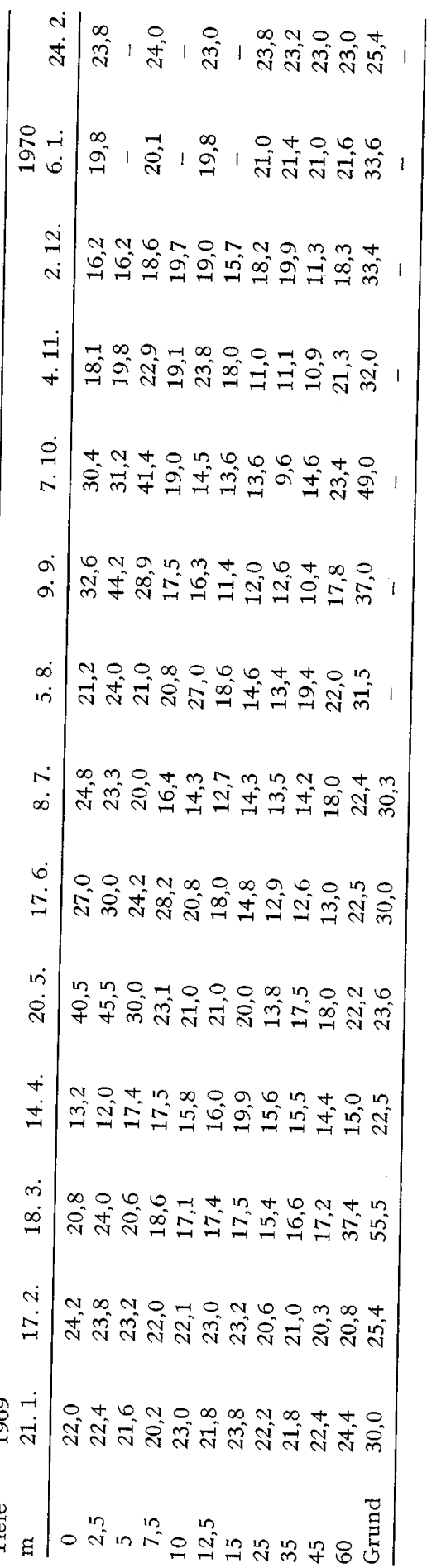


sonst herrschten anaerobe Verhältnisse. Der Sauerstoffschwund reichte im Sommer bis auf $5 \mathrm{~m}$ Tiefe, gleichzeitig konnte man beträchtliche Mengen an Schwefelwasserstoff nachweisen.

\section{Horwer Bucht}

\subsection{Phosphorkomponenten}

Den Phosphorkreislauf in der Horwer Bucht und die Beziehung zur planktischen Primärproduktion hat GÄCHTER [24] ausführlich dargestellt. Aus direkten Messungen der Primärproduktion im See und in Plastikbehältern, die im See exponiert wurden, konnte eine enge Beziehung zwischen Primärproduktion und Gesamtphosphorkonzentration nachgewiesen werden. Die in den Tab. 6, 7 und 8 zusammengestellten Werte für Phosphat, partikulären Phosphor und Gesamt-P mögen zur Charakterisierung des Sees während der Untersuchungsperiode dienen.

Die Phosphatkonzentrationen während der Vollzirkulation betrugen im Februar 1969 4,5 $\mu \mathrm{g}$ und im Februar 1970 11,5 $\mu \mathrm{g} \mathrm{PO}_{4}-\mathrm{P} / 1$, dabei muss aber berücksichtigt werden, dass der Gesamt-P in beiden Jahren etwa $23 \mu \mathrm{g} P / 1$ betrug. Epilimnische Phosphatminima wurden in den Monaten August bis November gemessen.

Hohe Konzentrationen an part. P traten im Frühjahr (Mai) und Herbst (September/Oktober) auf. Im Mai und September wurde in 2,5 m Maxima von $37 \mu g$ part. P/1 gemessen.

\section{Rotsee}

Die Konzentrationen der verschiedenen P-Komponenten wurden von BLoEsch [11.] monatlich bestimmt und sind in den Tab. 9, 10 und 11 zusammengestellt.

Zum Zeitpunkt maximaler Zirkulation (Februar 1970) betrug der Phosphatgehalt in den oberen Schichten etwa $200 \mu \mathrm{g} \mathrm{PO}_{4}-\mathrm{P} / 1$ und im Mittel über die ganze Tiefe $320 \mu \mathrm{g} \mathrm{P} / 1$. Die epilimnischen Phosphatminima (weniger als $5 \mu \mathrm{g} \mathrm{P} / 1$ ) reichten im Juli/August bis in $5 \mathrm{~m}$ Tiefe. In $14 \mathrm{~m}$ Tiefe zeichnete sich vom April 1969 bis Januar 1970 eine Phosphatanreicherung von $500 \mu \mathrm{g}$ auf $1600 \mu \mathrm{g} \mathrm{P} / 1 \mathrm{ab}$.

Im Epilimnion wurden partikuläre P-Konzentrationen von über $100 \mu \mathrm{g} \mathrm{P} / 1 \mathrm{im}$ März/April und unter Eis im Januar/Februar gemessen. Im Mai und September fielen die Konzentrationen des part. $\mathrm{P}$ in der Schicht maximaler Produktion unter die entsprechenden Konzentrationen der Horwer Bucht. Im Rotsee wurde während der Sommerstagnation eine ausgeprägte Verarmung an Gesamt-P im Epilimnion beobachtet.

\subsection{Stickstofkomponenten}

\subsection{Anorganische N-Komponenten}

In sauerstoffreichen Gewässern liegt der Hauptteil des assimilierbaren anorganischen Stickstoffs als Nitrat vor. Dieser +5 wertige Stickstoff muss von den Algen zuerst in die - 3wertige Form des $\mathrm{NH}_{4}$ übergeführt werden, bevor der Stickstoff in die Aminosäuren, Säureamide und anderen Molekültypen wie Nucleotide und Pyrrole eingebaut werden kann. Die meisten Algen, die anorganischen $\mathrm{N}$ assimilieren, sind befähigt, $\mathrm{NO}_{3}, \mathrm{NO}_{2}$ und $\mathrm{NH}_{4}$ zu verwerten und erreichen damit gleiches Wachstum [13].

Hohe Nitrit- und Ammoniumkonzentrationen können zwar hemmend wirken, aber schädigende Konzentrationen kommen in natürlichen Gewässern selten vor. 
ウి|

ำ

윰 멈

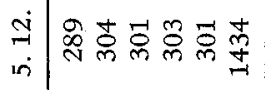

멈

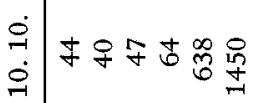

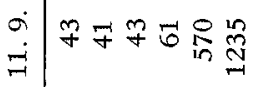




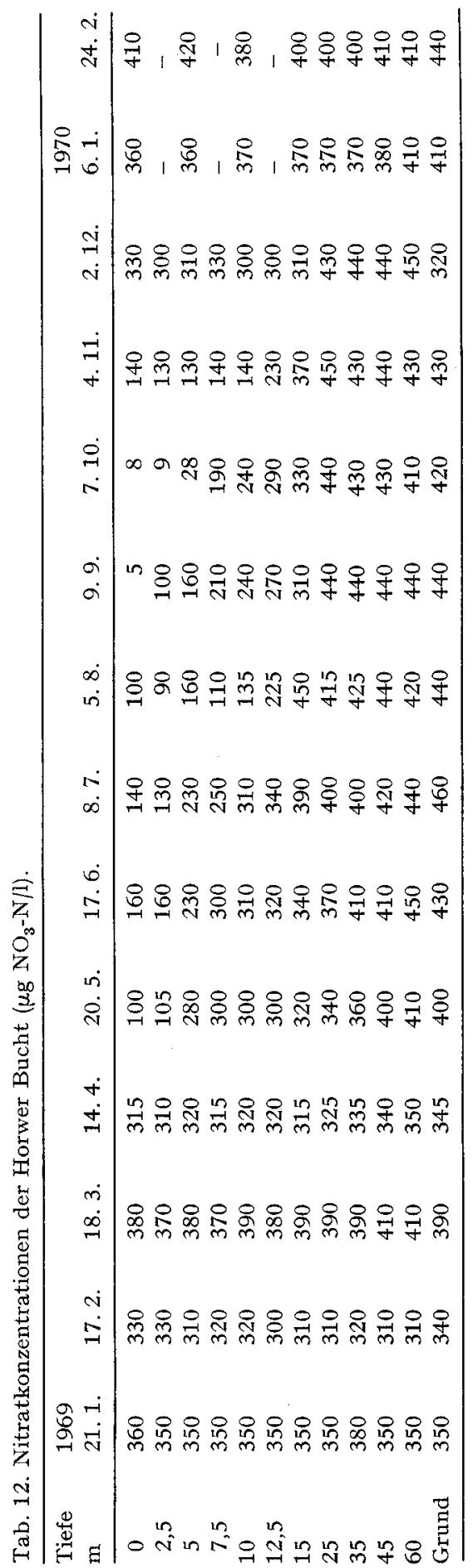

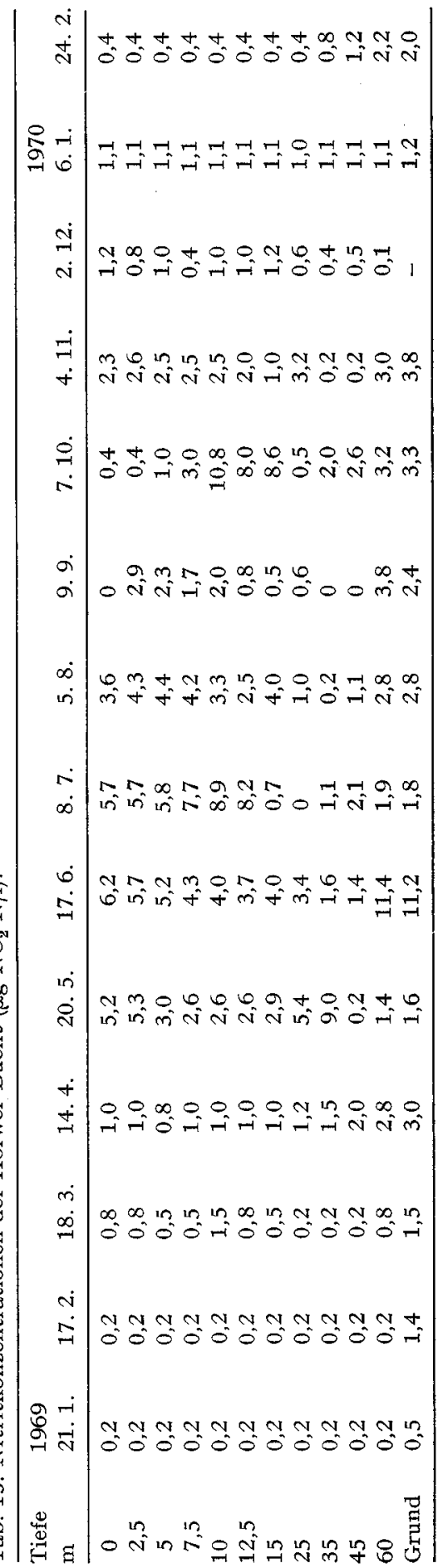




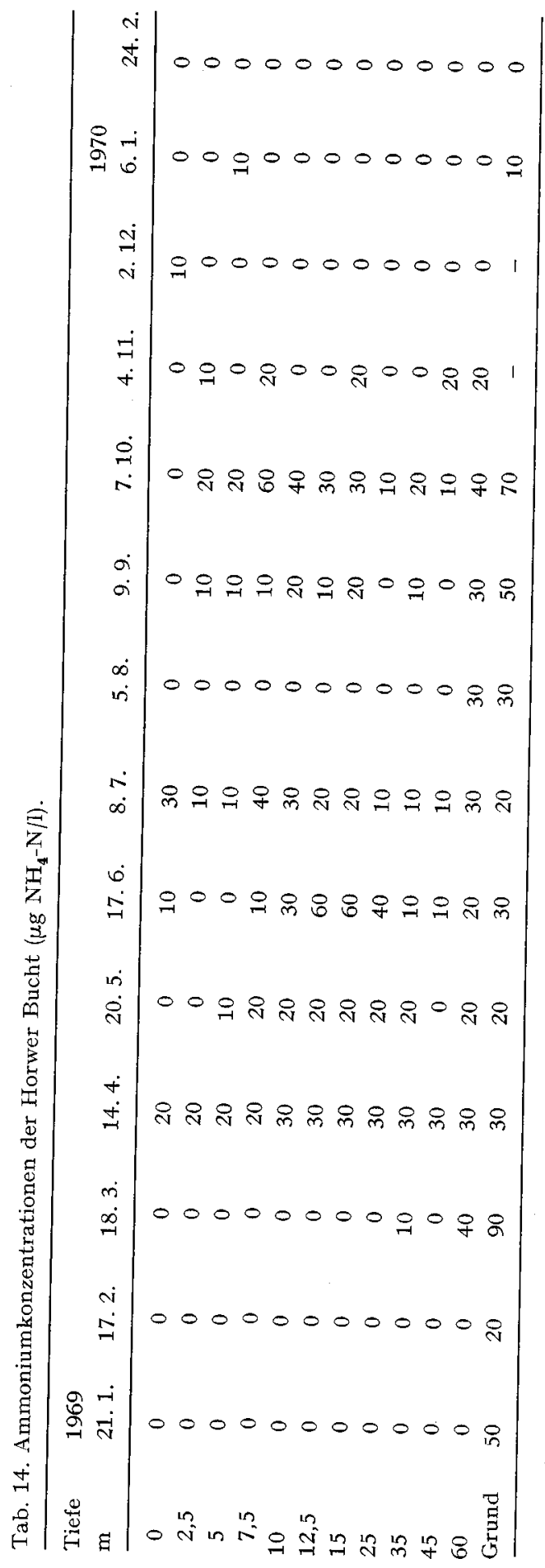


SYRETT [65] zeigte, dass hungernde Chlorellazellen sich bei Zugabe äquivalenter N-Mengen mit Ammonium schneller erholten als mit Nitrat. Ist die Energie begrenzt (z.B. schwache Lichtintensitäten), ist das Wachstum mit Ammonium-N effektiver als mit Nitrat-N.

Diese physiologischen Feststellungen zeigen, dass bei der Frage, ob anorganische $\mathrm{N}$-Verbindungen in einem See wachstumsbegrenzend wirken, jeweils die Konzentrationen von $\mathrm{NO}_{3}, \mathrm{NO}_{2}$ und $\mathrm{NH}_{4}$ untersucht werden müssen.

\section{Horwer Bucht}

Die exakten Analysenwerte für die anorganischen $\mathrm{N}$-Verbindungen sind in den Tab. 12, 13 und 14 zusammengestellt.

\section{Nitrat:}

$\mathrm{Abb} .10$ zeigt die zeitlichen Veränderungen der Nitratkonzentrationen in den verschiedenen Seetiefen. Die Konzentration während der Zirkulationszeit betrug etwa $400 \mu \mathrm{g} \mathrm{NO}-\mathrm{N} / 1$. Ab April beginnt die epilimnische Nitratzehrung. Bis zum Ende der Sommerstagnation sank in der Schicht maximaler Produktion die Nitrat-

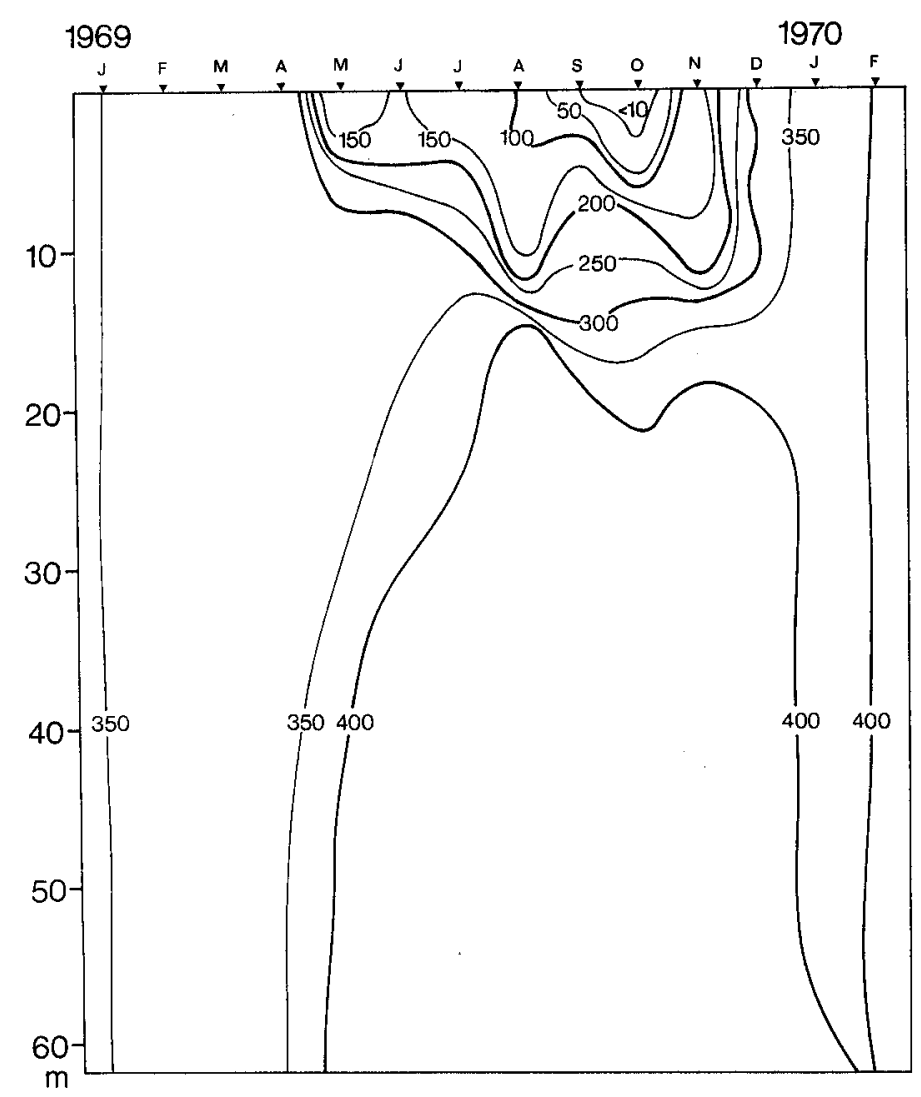

Abb. 10. Nitratkonzentration $\left(\mu \mathrm{g} \mathrm{NO}_{3}-\mathrm{N} / 1\right)$ der Horwer Bucht. 
konzentration bis auf $4 \mu \mathrm{g} / \mathrm{l}$, wobei gleichzeitig nur $1 \mu \mathrm{g} \mathrm{NO}_{2}-\mathrm{N} / \mathrm{l}$ und kein $\mathrm{NH}_{4}-\mathrm{N}$ nachgewiesen werden konnte (Tab. 15).

Unterhalb von $20 \mathrm{~m}$ fand eine Nitratanreicherung statt, die vom April bis zum Oktober etwa $100 \mu \mathrm{g} \mathrm{NO}_{3}-\mathrm{N} / 1$ betrug.

Tab. 15. Nitratminimum der Horwer Bucht (19.9.69).

\begin{tabular}{llllcccrr}
\hline Tiefe $(\mathrm{m})$ & 0 & 1 & 2,5 & 5 & 7,5 & 10 & 12,5 & 15 \\
$\mathrm{NO}_{3}-\mathrm{N} \mu \mathrm{g} / 1$ & 5 & 4 & 4 & 23 & 133 & 180 & 250 & 260 \\
$\mathrm{NO}_{2}-\mathrm{N} \mu \mathrm{g} / 1$ & 1 & 1 & 1 & 1 & 1,4 & 1,4 & 1,6 & 1 \\
$\mathrm{NH}_{4}-\mathrm{N} \mu \mathrm{g} / 1$ & 0 & 0 & 0 & 0 & - & - & - & - \\
\hline
\end{tabular}

\section{Nitrit:}

Die zeitlichen und räumlichen Veränderungen der Nitritkonzentrationen in der Horwer Bucht zeigt Abb. 11.

Nitrit ist das erste $Z$ wischenprodukt bei der Nitratassimilation. Das epilimnische Maximum vom Mai bis in den August ist möglicherweise auf starke Nitratassimilation

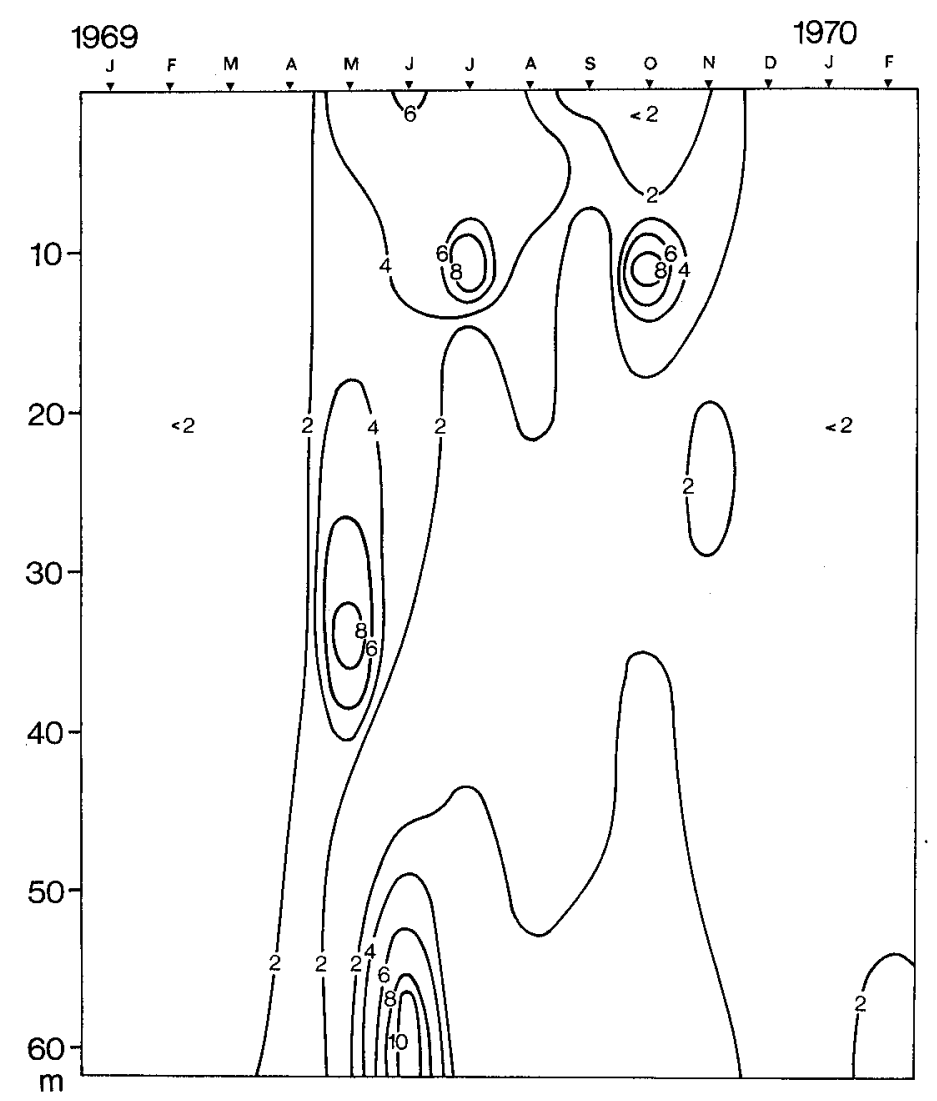

Abb. 11. Nitritkonzentration $\left(\mu \mathrm{g} \mathrm{NO}_{2}-\mathrm{N} / \mathrm{l}\right)$ der Horwer Bucht. 
zurückzuführen. Die Maxima in $11 \mathrm{~m}$ im Juli und Oktober lagen im Bereich der optischen Kompensationstiefe, wahrscheinlich spielten sich hier Nitrifikationsprozesse ab. Über Grund wurde im Juni 11,5 $\mu \mathrm{g} \mathrm{NO} \mathrm{N}_{2}-\mathrm{N} / 1$ gemessen, dieses Maximum fällt mit dem Ende der Frühjahrproduktionsspitze zusammen, das anfallende organische Material wurde also weiter mineralisiert und der Nitritanstieg deutet wieder auf Nitrifikation hin.

\section{Ammonium:}

Die Ammoniumkonzentrationen in der Horwer Bucht waren gering. Während der Sommerstagnation konnte man Spuren nachweisen, aber nur in den bodennahen Schichten wurden höhere Konzentrationen ermittelt.

\section{Rotsee}

Nitrat:

Die höchsten Nitratkonzentrationen (Abb. 12) wurden jeweils im März gemessen (bis $720 \mu \mathrm{g} \mathrm{NO} \mathrm{N}_{3} \mathrm{~N} / \mathrm{l}$ ). Durch die Zirkulation wird Sauerstoff in die tieferen Schichten eingetragen, dabei wird durch Nitrifikationsprozesse das Ammonium zu Nitrat oxydiert. Epilimnische $\mathrm{NO}_{3}$-Minima (weniger als $50 \mu \mathrm{g} \mathrm{N} / \mathrm{l}$ ) bildeten sich vom August bis in den Dezember aus, im August fiel bis in 2,5 $\mathrm{m}$ Tiefe der $\mathrm{NO}_{3}$-Gehalt auf Null. Da im Tiefenwasser anaerobe Verhältnisse herrschten, trat Nitrat im Hypolimnion nur in Spuren auf.

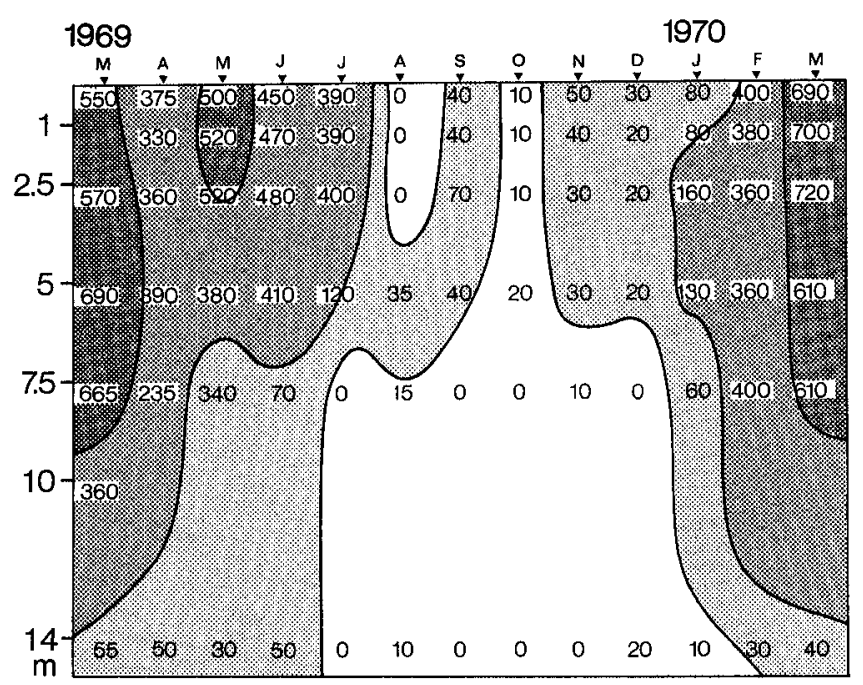

Abb. 12. Nitratkonzentration $\left(\mu g \mathrm{NO}_{3}-\mathrm{N} / 1\right)$ des Rotsees.

\section{Ammonium:}

Von den anorganischen N-Komponenten machte im Rotsee das Ammonium den grössten Anteil aus (Abb. 13), so wurde im Dezember bis in 7,5 m Tiefe etwa 1300 $\mu \mathrm{g} \mathrm{NH}_{4}-\mathrm{N} / 1$ gemessen. Ein erstes Mal wurde Ammonium im Mai an der Oberfläche aufgezehrt, während der $\mathrm{NO}_{3}$-Gehalt $500 \mu \mathrm{g} \mathrm{N} / 1$ betrug, man darf hier also auf eine bevorzugte $\mathrm{NH}_{4}$-Aufnahme durch das Phytoplankton schliessen. Im September/ 
Oktober fiel in der Produktionsschicht der Ammoniumgehalt auf Null. Über Grund fand vom April 1969 (2600 $\mu \mathrm{g} \mathrm{N} / \mathrm{l})$ bis in den Januar $1970(9100 \mu \mathrm{g} \mathrm{N} / \mathrm{l})$ eine Ammoniumanreicherung statt.

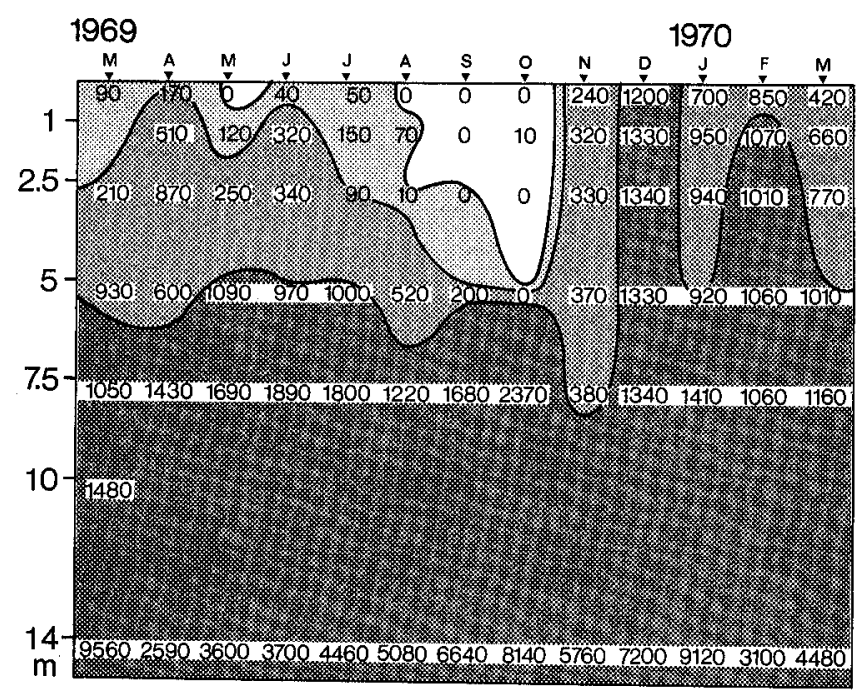

Abb. 13. Ammoniumkonzentration $\left(\mu \mathrm{g} \mathrm{NH}_{4}-\mathrm{N} / 1\right)$ des Rotsecs.

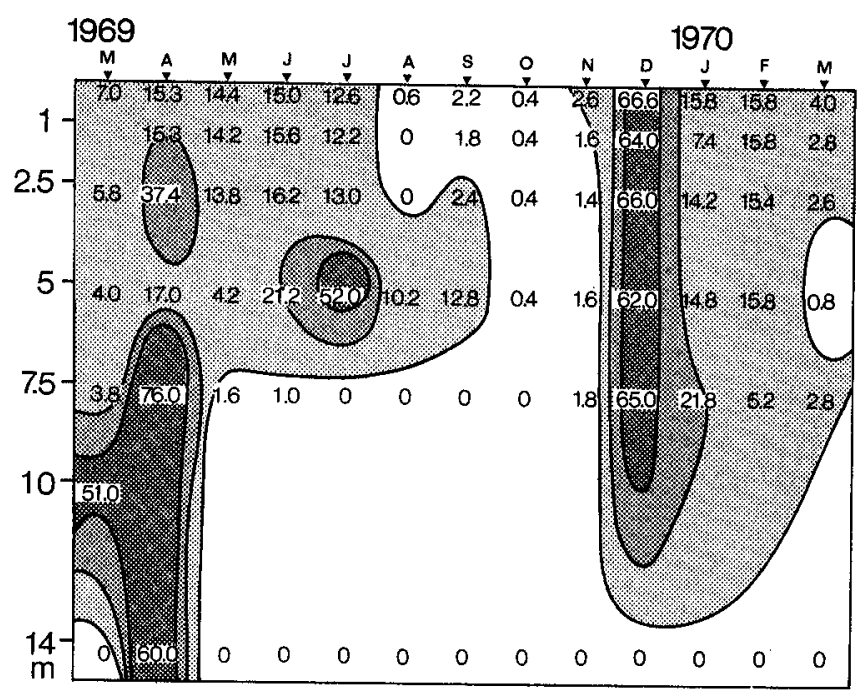

Abb. 14. Nitritkonzentration $\left(\mu \mathrm{g} \mathrm{NO}_{2}-\mathrm{N} / \mathrm{I}\right)$ des Rotsees.

\section{Nitrit:}

Hohe Nitritkonzentrationen wurden im April und Dezember gemessen (Abb. 14). In der Dezember-Serie wurde wahrscheinlich gerade der erste Nitrifikationsschritt 
$\left(\mathrm{NH}_{4} \rightarrow \mathrm{NO}_{2}\right)$ erfasst, denn gegenüber $20 \mu \mathrm{g} \mathrm{NO}_{3}-\mathrm{N} / 1$ betrug die $\mathrm{NO}_{2}$-Konzentration $60 \mu g \mathrm{NO}_{2}-\mathrm{N} / 1$.

Zusammenfassend kann gesagt werden, dass sich im Epilimnion vom August bis in den November für alle anorganischen N-Komponenten ein ausgeprägtes Minimum ausgebildet hat.

\subsection{Organische N-Komponenten}

Untersuchungen über den jahreszeitlichen Verlauf des partikulären und gelösten organischen Stickstoffs in Seen liegen nur wenige vor (Tab. 16). Meist wird auf die Arbeit von Domogalla et al. [14] verwiesen; bei diesen Untersuchungen wurde im Lake Mendota an der Oberfläche immer mehr gelöster organischer $\mathrm{N}$ als part. $\mathrm{N}$ nachgewiesen, auch bei KRoGH et al. [35] und Postma [46] überwog der gelöste organische N-Anteil.

Tab. 16. Partikulärer und gelöster organischer $N$ einiger Seen ( $\mu g \mathrm{~N} / \mathrm{l})$.

\begin{tabular}{lrr} 
& Part. N & \multicolumn{1}{c}{$\begin{array}{c}\text { Gelöster } \\
\text { org. N }\end{array}$} \\
\hline Lake Mendota 1923/24 Oberfläche [14] & $50-240$ & $440-940$ \\
Furesee [35] & $30-190$ & $440-640$ \\
Ysel Lake (Stelle 5) [46] & $250-1400$ & $590-1840$ \\
Lake Smith (Oberfläche) [10] & $80-750$ & \\
Bodensee (Obersec) [34] & $10-160$ & $50-150$ \\
Vierwaldstättersee (2,5 m) & & \\
Kreuztrichter [5] & $40-310$ & $80-180$ \\
Horwer Bucht & $70-390$ & $270-660$ \\
Rotsee (1 m) & $180-1200$ & \\
\hline
\end{tabular}

\subsection{Partikulärer Stickstoff}

\section{Horwer Bucht}

Die zeitliche und räumliche Verteilung des partikulären Kjeldahl-N zeigt Abb.15.

Die einzelnen Analysenwerte sind in Tab. 17 zusammengestellt.

Während der Zirkulationszeit lagen die Konzentrationen des part. N über die ganze Seetiefe bei etwa 50-70 $\mathrm{g}$ N/1. Im Epilimnion trat im Mai ein erstes Maximum von über $350 \mu \mathrm{g} N / 1$ auf. Im Hochsommer nahm in den oberen Schichten der part. N ab, nur in $10 \mathrm{~m}$ bildete sich durch die Einschichtung von Oscillatoria rubescens ein Maximum von $420 \mu \mathrm{g} \mathrm{N} / \mathrm{l}$ aus.

Das Hypolimnion verarmte während der Sommerstagnation an part. N. Wir erfassten nur noch Material, das sich auf dem Sedimentationsweg befand und in Bakterien und Zooplankton gebundenen Stickstoff. Im September stieg die Konzentration des part. $\mathrm{N}$ in den oberflächennahen Schichten erneut bis auf $390 \mu \mathrm{g} \mathrm{N} / 1$ an, wahrscheinlich bewirkt durch eine erhöhte Zufuhr von Nährstoffen, sei es durch die beginnende Herbstteilzirkulation oder die starken Regenmengen von $220 \mathrm{~mm}$ im Monat August (Jahresmittel 1969: $1116 \mathrm{~mm}$ ).

Rotsee

Abb. 16 zeigt die jahreszeitlichen Veränderungen des part. $N$ in den verschiedenen Tiefen des Rotsees. Mehr als $500 \mu \mathrm{g}$ N/1 wurde im Epilimnion im April 1969, unter 


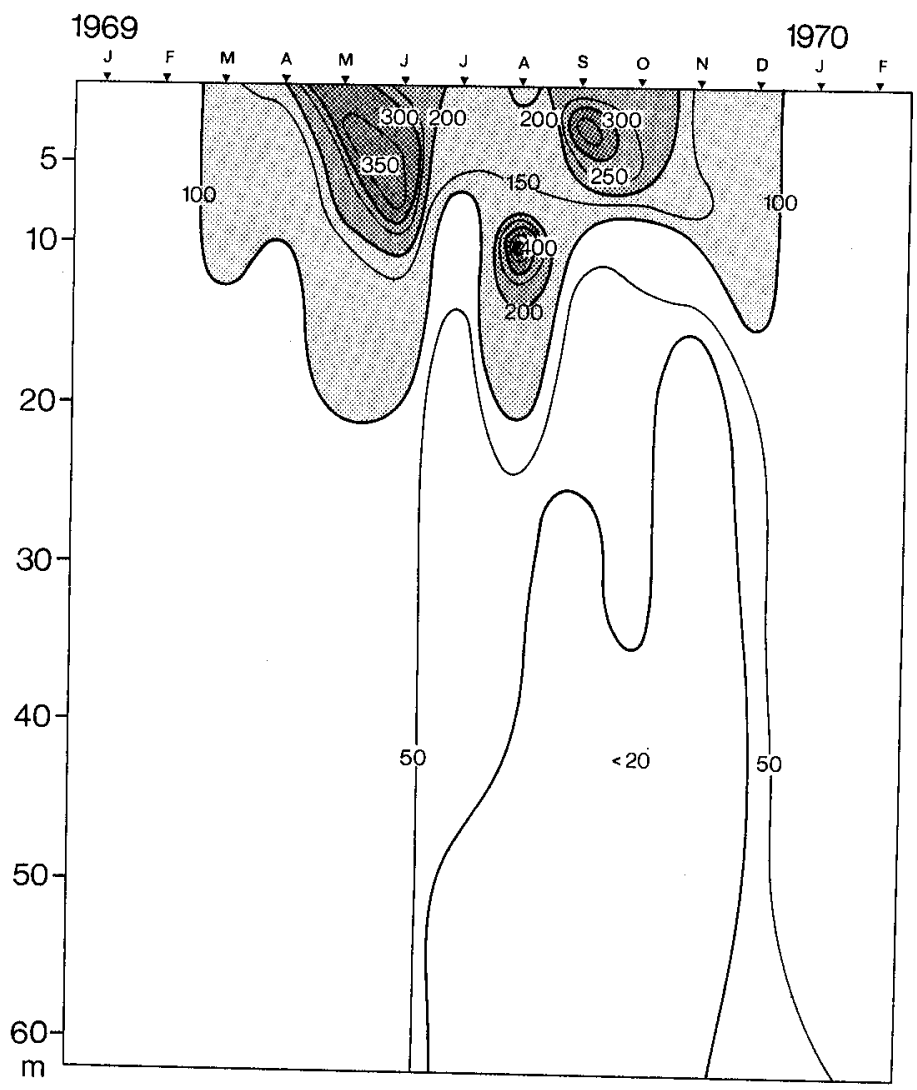

Abb. 15. Partikulärer KjeldahI-N ( $\mu$ g N/I) der Horwer Bucht.

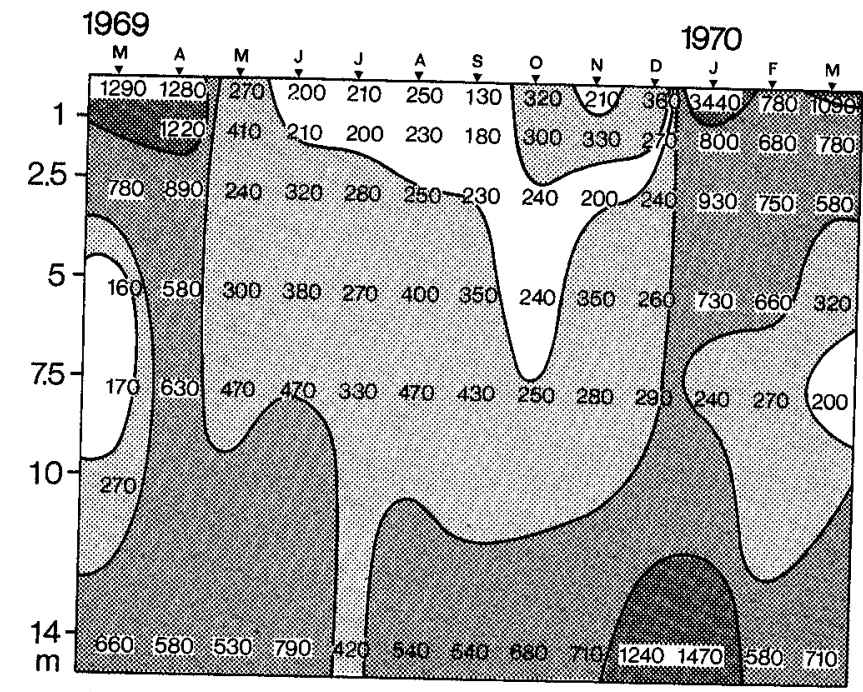

Abb. 16. Partikulärer Kjeldahl-N ( $\mu \mathrm{g}$ N/l) des Rotsees. 
Eis im Januar/Februar und im März 1970 gemessen, dabei wurde in den oberen Schichten gleichzeitig mehr als $1000 \mu \mathrm{g} \mathrm{N} / 1$ ermittelt. Der hohe Wert von $3440 \mu \mathrm{g}$ part. N/1 im Januar wurde durch eine starke Ansammlung von Cryptomonas Marssonii direkt unter der Eisdecke bewirkt.

Nach der starken Phytoplanktonentwicklung im Frühjahr trat im Epilimnion eine Verarmung an part. $\mathrm{N}$ ein, die Werte fielen teilweise unter die entsprechenden in der Horwer Bucht. Unterhalb der jeweiligen optischen Kompensationstiefe war der partikuläre N-Gehalt immer hoch, in $14 \mathrm{~m}$ wurde im Dezember/Januar über $1000 \mu \mathrm{g}$ partikulärer Kjeldahl-N/1 ermittelt. Der erfasste Stickstoff muss also hauptsächlich in Bakterien gebunden sein. In $14 \mathrm{~m}$ Tiefe wurde in den Monaten März/Dezember 1969 und Januar/März 197027 und $17 \cdot 10^{7}$ bzw. 37 und 10 $10^{7}$ Thiopedia-roseaZellen pro Liter ausgezählt.

In der Tab. 20 ist der im Zeitpunkt der Untersuchung vorhandene part. $\mathrm{N}$ unter $1 \mathrm{~m}^{2}$ Seeoberfläche bei Berücksichtigung der trophogenen Schicht und der gesamten Wassersäule berechnet worden, um ein indirektes Mass für die augenblicklich vorhandene Biomasse (standing crop) zu erhalten. In der Horwer Bucht wurde im Juni mit 3,91 g part. $\mathrm{N} / \mathrm{m}^{2}(0-15 \mathrm{~m})$ und 7,28 g part. $\mathrm{N} / \mathrm{m}^{2}(0-60 \mathrm{~m})$ der Höchstwert erreicht.

Die Standing crop in der trophogenen Schicht $(0-5 \mathrm{~m})$ des Rotsees war während der Sommerstagnation kleiner als in der Horwer Bucht, im April 1969 und Januar 1970 wurden hingegen $5,90 \mathrm{bzw} .5,47 \mathrm{~g} \mathrm{~N} / \mathrm{m}^{2}$ gemessen.

\subsection{Gelöster organischer Stickstoff}

Die Konzentrationen des gelösten organischen Stickstoffs schwankten in der Horwer Bucht zwischen 20-210 $\mu \mathrm{g} \mathrm{N} / 1$, der mittlere Bereich lag bei 70-130 $\mu \mathrm{g} \mathrm{N} / \mathrm{l}$. Während der Stagnationsperiode wurde vielfach in 15 bis $45 \mathrm{~m}$ Tiefe ein Minimum festgestellt (Tab. 18). Vergleicht man den Gehalt an gelöstem organischem $\mathrm{N}$ unter $1 \mathrm{~m}^{2}$ Seeoberfläche $(0-15 \mathrm{~m})$ mit demjenigen an part. $\mathrm{N}$, dann überwiegt nur in den Wintermonaten eindeutig der gelöste organische Stickstoff (Tab. 20).

Im Rotsee wurden beträchtliche Mengen an gelöstem organischem Stickstoff ermittelt $(100-1440 \mu \mathrm{g} \mathrm{N} / 1)$. Im Epilimnion fielen die Werte vom August bis Dezember eindeutig niedrig aus (Tab. 19).

Beim hohen Wert im Dezember $(0 \mathrm{~m})$ muss berücksichtigt werden, dass durch die Filtration der zahlreich vorhandenen Flagellaten, deren Zellen teilweise zerstört wurden, das Filtrat enthielt also beträchtliche Mengen an Zellextrakten.

Vom Mai bis Dezember übertraf der Gehalt an gelöstem organischem N unter $1 \mathrm{~m}^{2}$ Seeoberfläche $(0-5 \mathrm{~m})$ denjenigen des partikulären Stickstoffs. Im Gegensatz zur Horwer Bucht überwiegt dagegen im Winter der partikuläre Stickstoff (Tab. 20).

Bei Domogalla et al. [14], Krogh et al. [35] und Postma [10] überwiegten die Konzentrationen des gelösten organischen $\mathrm{N}$ diejenigen des part. $\mathrm{N}$ beträchtlich. Da zur Bestimmung der N-Komponenten verschiedene Trenn- und Analysenverfahren angewandt wurden, sind die Werte aus der Literatur mit unseren Analysenwerten nicht streng vergleichbar.

\subsection{Stickstoffsedimentation}

Um eine Aussage über die Stickstoffsedimentation aus der trophogenen Schicht machen zu können, wurde im Rotsee das in $5 \mathrm{~m}$ Tiefe und in der Horwer Bucht das 


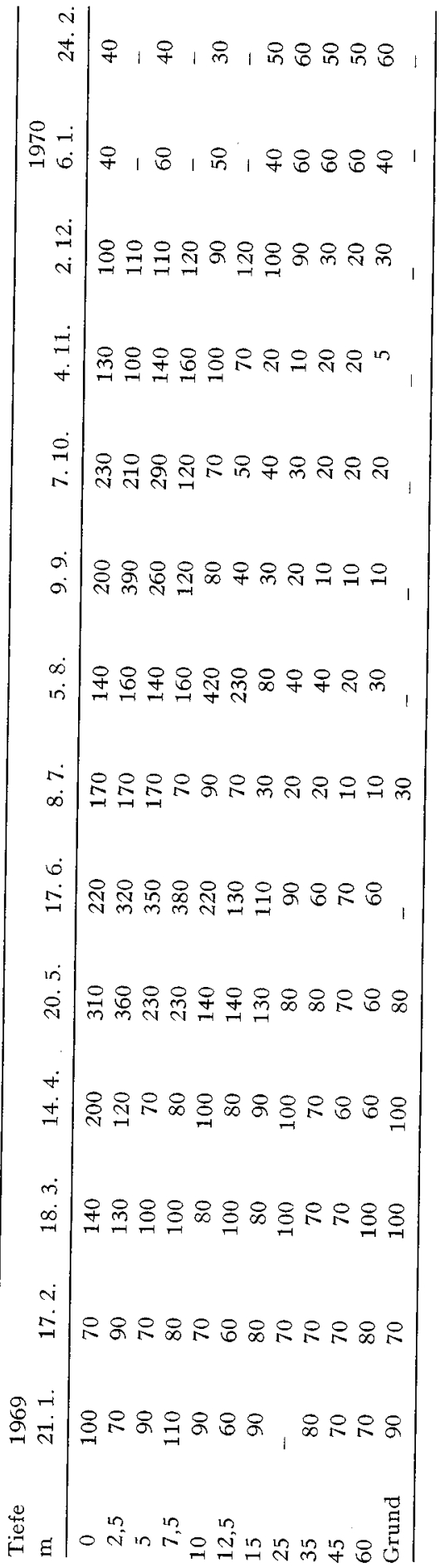

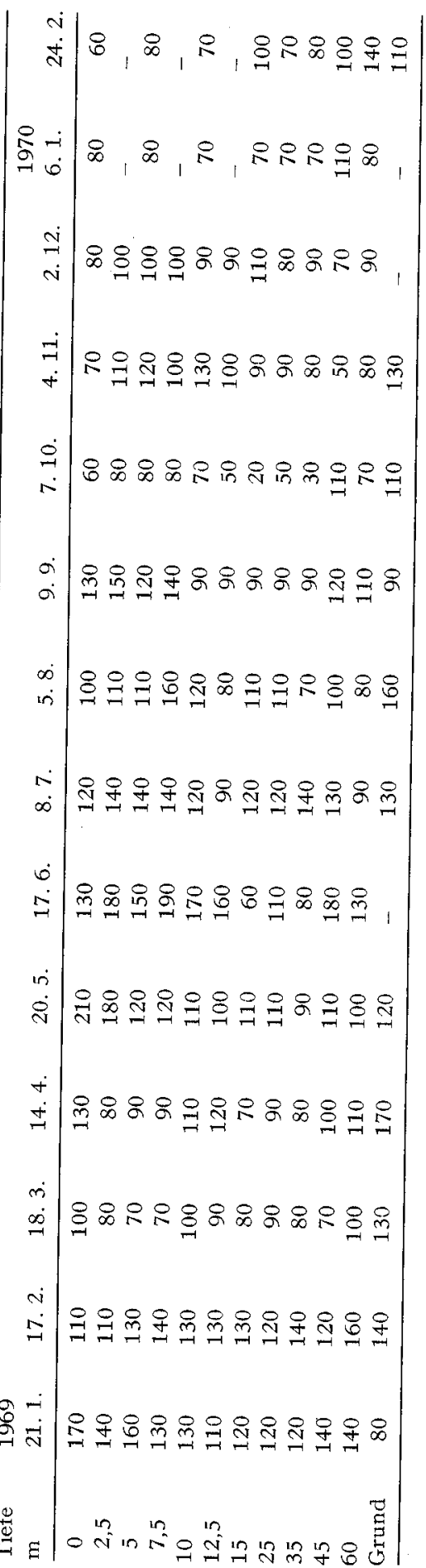




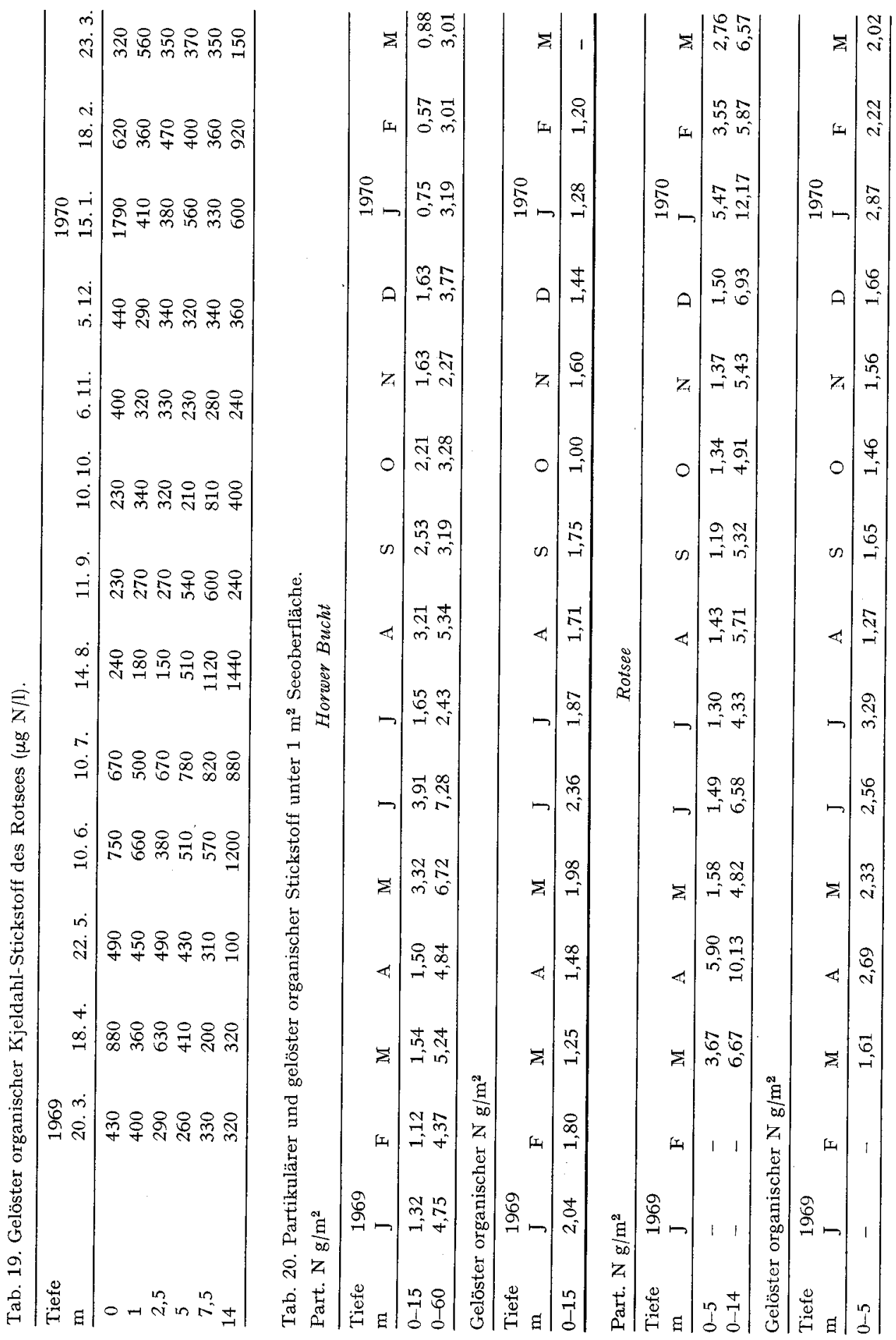


in $15 \mathrm{~m}$ Tiefe aufgefangene Sediment analysiert. Die Sedimentation wurde in Abschnitten von 14 Tagen gemessen [11]. Die Abb. 17 und 18 zeigen die Sedimentationsraten für Trockensubstanz ( $\mathrm{g} \mathrm{TS} / \mathrm{m}^{2}$ und Tag) und für Stickstoff $\left(\mathrm{mg} \mathrm{N} / \mathrm{m}^{2}\right.$ und Tag). In der Horwer Bucht schwankte der $\mathrm{N}$-Anteil pro Trockengewicht von 0,3 bis $1,4 \%$. Während der Sommerstagnation war die N-Sedimentation mit etwa $30 \mathrm{mg} \mathrm{N} / \mathrm{m}^{2}$ und Tag erstaunlich konstant.

Im Rotsee schwankte der N-Anteil pro Trockengewicht von 0,7 bis $4,8 \%$. Mit der Ausbildung einer ausgeprägten thermischen Schichtung erreichte die Sedimentation

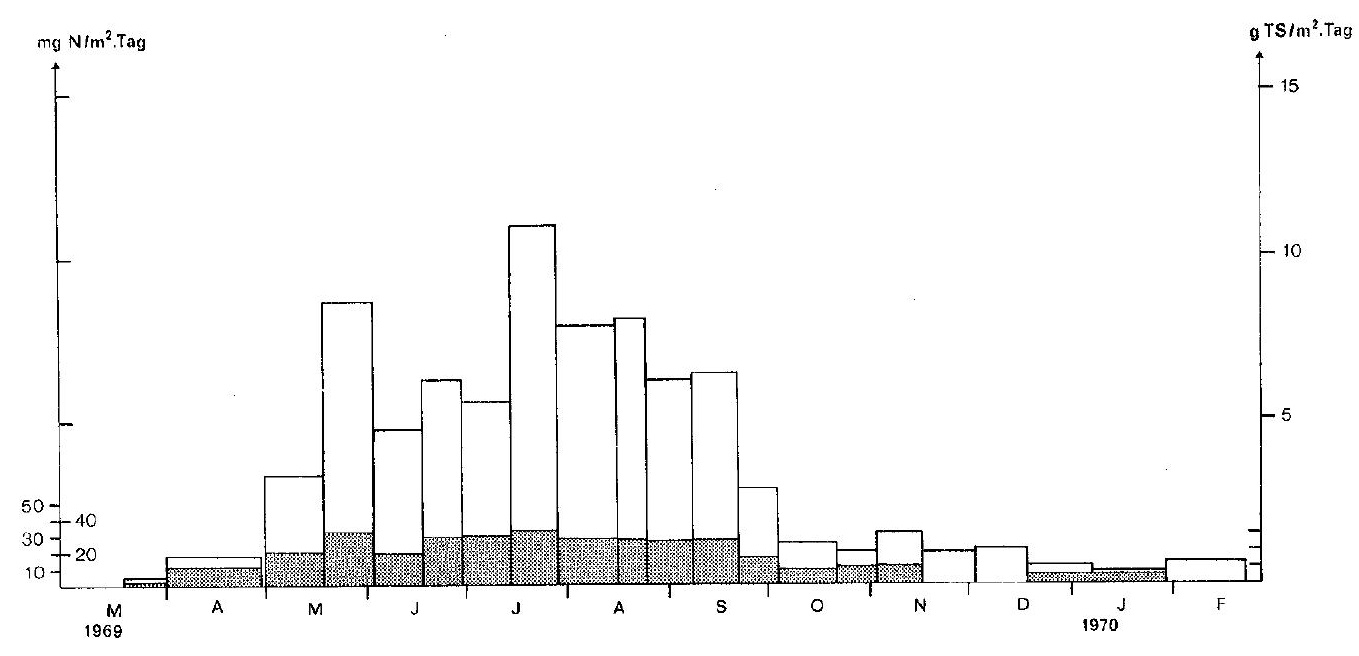

Abb. 17. N-Sedimentation (mg N/m². Tag) und Sedimentationsraten des Trockengcwichtes (g TS $/ \mathrm{m}^{2}$. Tag) nach BLowsch [11] in $15 \mathrm{~m}$ Tiefe.

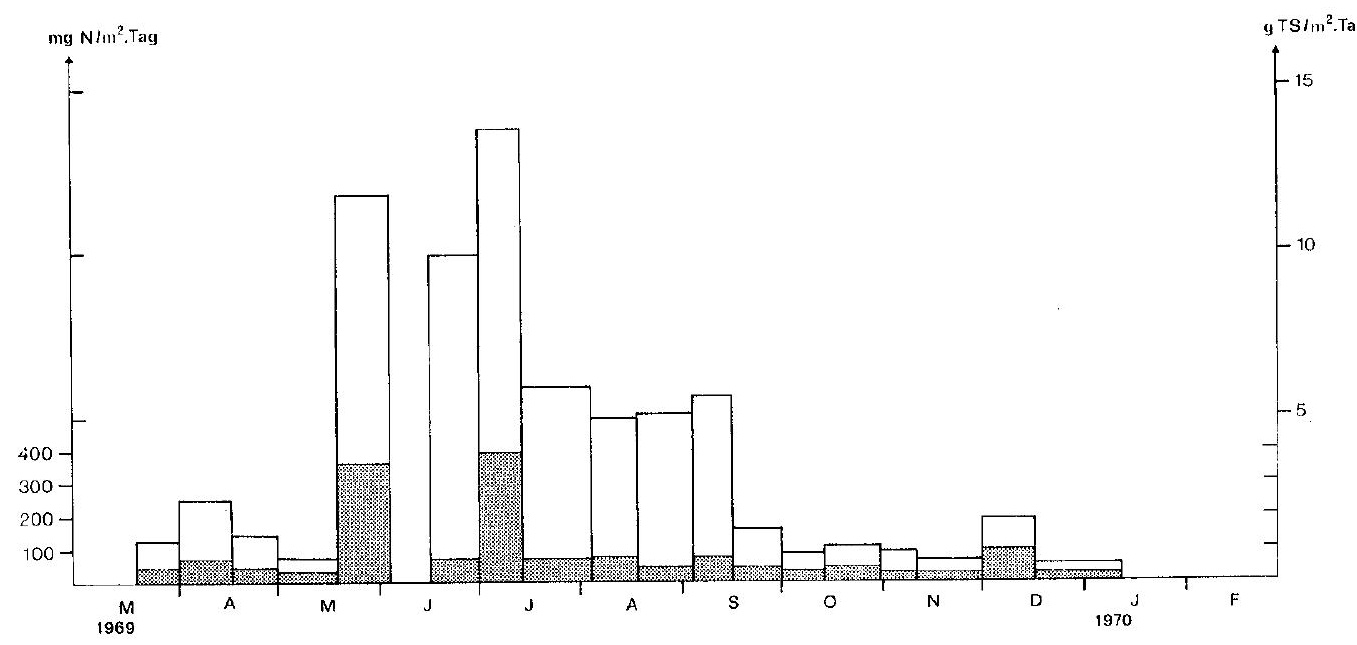

Abb. 18. N-Sedimentation ( $\mathrm{mg} \mathrm{N} / \mathrm{m}^{2} \cdot$ Tag) und Sedimentationsraten des Trockengewichts (g TS $/ \mathrm{m}^{2}$. Tag) nach Bloesch $[11]$ in $5 \mathrm{~m}$ Tiefe des Rotsees. 
mit fast $400 \mathrm{mg} \mathrm{N} / \mathrm{m}^{2}$ und Tag den Höchstwert, am Ende der Sommerstagnation wurde nur eine solche von $24 \mathrm{mg} \mathrm{N} / \mathrm{m}^{2}$ und Tag gemessen.

Thomas $[67,68]$, BAchofeN [8] und Toyoda et al. [72] haben die N-Sedimentationsraten in $20 \mathrm{~m}$ Tiefe gemessen, ihre Werte sind mit unseren Angaben in Tab. 21 verglichen.

Tab. 21. N-Sedimentationsraten einiger Seen.

\begin{tabular}{lc}
\hline & $\begin{array}{c}\text { g N/m2 } \\
\text { und Jahr }\end{array}$ \\
\hline Ägerisee 1951 (oligotroph) [67] & 0,8 \\
Lake Biwa 1963/64, Japan [72] & 1,5 \\
Vierwaldstättersee: Horwer Bucht 1969 (mesotroph) & 5,7 \\
Türlersee 1952/53 (mesotroph), meromiktisch [68] & 11,3 \\
Pfäffikersee 1951 (eutroph) [67] & 2,1 \\
Greifensee 1951 (eutroph) [67] & 1,9 \\
Hallwilersee 1958/59 (eutroph) [8] & $20,1 / 12,0$ \\
Baldeggersee 1958/59 (eutroph) [8] & $13,4 / 12,2$ \\
Rotsee 1969 (polytroph) & 28,1 \\
\hline
\end{tabular}

Werden die niederen Sedimentationsraten für den eutrophen Pfäffiker- und Greifensee nicht berücksichtigt, dann lässt sich eine Beziehung zwischen Trophiegrad und N-Sedimentation herstellen. Der als polytroph zu bezeichnende Rotsee weist dann die höchste N-Sedimentation auf.

Tab. 22. N-Sedimentationsraten des Rotsees (in $\mathrm{mg} \mathrm{N} / \mathrm{m}^{2} \cdot$ Tag und N-Anteil des Trockengewichtes in \%).

\begin{tabular}{|c|c|c|c|c|c|c|}
\hline & $\begin{array}{l}\text { Tiefe } 2,5 \mathrm{~m} \\
\mathrm{mg} \\
\mathrm{N} / \mathrm{m}^{2} \cdot \mathrm{Tag}\end{array}$ & $\%$ & $\begin{array}{l}\text { Tiefe } 5 \mathrm{~m} \\
\mathrm{mg} \\
\mathrm{N} / \mathrm{m}^{2} \cdot \mathrm{Tag}\end{array}$ & $\%$ & $\begin{array}{l}\text { Tiefe } 14 \mathrm{~m} \\
\mathrm{mg} \\
\mathrm{N} / \mathrm{m}^{2} \cdot \mathrm{Tag}\end{array}$ & $\%$ \\
\hline 20. März bis 1. April 1969 & 39,6 & 2,7 & 43,6 & 3,4 & 34,3 & 2,9 \\
\hline 1. April bis 17. April 1969 & - & - & 72,1 & 2,9 & - & - \\
\hline 17. April bis 1. Mai 1969 & 26,5 & 2,7 & 45,0 & 3,1 & 51,8 & 3,5 \\
\hline 1. Mai bis 19. Mai 1969 & - & - & 32,3 & 4,3 & - & - \\
\hline 19. Mai bis 4. Juni 1969 & 304,0 & 3,1 & 361,0 & 3,1 & 235,0 & 2,7 \\
\hline 16. Juni bis 1. Juli 1969 & 62,2 & 0,6 & 71,3 & 0,7 & 34,7 & 0,6 \\
\hline 1. Juli bis 14. Juli 1969 & - & - & 397,0 & 2,9 & - & - \\
\hline 14. Juli bis 4. August 1969 & 98,7 & 1,2 & 70,7 & 1,2 & 68,4 & 1,2 \\
\hline 4. August bis 18. August 1969 & - & - & 76,1 & 1,5 & - & - \\
\hline 18. August bis 3. September 1969 & 85,2 & 1,3 & 46,0 & 0,9 & 65,2 & 1,2 \\
\hline 3. September bis 19. September 1969 & - & - & 72,7 & 1,3 & - & - \\
\hline 16. September bis 1. Oktober 1969 & 40,7 & 2,6 & 41,7 & 2,6 & 38,5 & 2,9 \\
\hline 1. Oktober bis 1.4. Oktober 1969 & - & - & 31,9 & 3,6 & - & - \\
\hline 14. Oktober bis 30. Oktober 1969 & 42,9 & 4,3 & 43,4 & 4,2 & 29,9 & 4,3 \\
\hline 30. Oktober bis 14. November 1969 & - & - & 24,3 & 2,6 & - & - \\
\hline 14. November bis 1. Dezember 1969 & 21,7 & 3,9 & 22,4 & 3,6 & 35,7 & 4,2 \\
\hline 1. Dezember bis 17 . Dezember 1969 & - & - & 91,9 & 4,8 & - & - \\
\hline 17. Dezember bis 1. Januar 1970 & 17,8 & 4,3 & 24,8 & 4,9 & 34,3 & 4,8 \\
\hline
\end{tabular}


In Tab. 22 sind die Sedimentationsraten des Rotsees für verschiedene Tiefen angegeben. Die N-Sedimentation in $14 \mathrm{~m}$ wich im allgemeinen nicht stark von derjenigen in 2,5 und $5 \mathrm{~m}$ Tiefe ab, im Maximum war sie um 50\% geringer als in $5 \mathrm{~m}$.

\subsection{Primärproduktion}

Die Neubildung organischer Substanz (Primärproduktion) in Gewässern hängt von der Photosynthese der autotrophen Organismen ab.

Bei der Photosynthese wird unter Ausnützung der Lichtenergie Kohlensäure reduziert. Von der Photosynthese ist auch die Assimilation der anorganischen N-Verbindungen abhängig. Messungen der Photosyntheseraten sind also indirekt auch Messungen der N-Aufnahme. Nach der Gleichung von Stumm [63] gilt, dass bei ausgeglichenem Wachstum bei der Assimilation von 106 Kohlenstoffatomen 16 Stickstoffatome in das Protoplasma eingebaut werden. Die Parallelität zwischen Kohlenstoffund Stickstoffaufnahme wurde experimentell von DugDaLe et al. [15] mit der $\mathrm{C}^{\mathbf{1 4}}$ und $\mathrm{N}^{15}$-Methode im Meer festgestellt.

Die Assimilationsraten sind in den Tab. 23 und 24 zusammengestellt. Die Kohlenstoff-Fixierung in der verdunkelten Flasche wurde jeweils abgezogen.

Die maximalen Photosyntheseraten der Horwer Bucht wurden meist in 1 bis $2,5 \mathrm{~m}$ Tiefe gemessen. Über $50 \mathrm{mg} \mathrm{C} \mathrm{C}_{\text {ass }} / \mathrm{m}^{3}$ und Stunde wurden im Mai und August/ September/Oktober gemessen. Im August wurde in $10 \mathrm{~m}$ Tiefe ein zweites Assimilationsmaximum von $31 \mathrm{mg} \mathrm{C}$ ass $/ \mathrm{m}^{3}$ und Stunde erreicht, dieser hohe Wert lässt sich durch die Einschichtung von Oscillatoria rubescens erklären.

Die Primärproduktion wurde im Rotsee von SchegG [55] gemessen. Die Photosynthesemaxima lagen meist in 0 bis $1 \mathrm{~m}$ Tiefe, während in $5 \mathrm{~m}$ im allgemeinen weniger als $10 \%$ der maximalen Photosyntheserate gemessen wurde. Mehr als 200 $\mathrm{mg} \mathrm{C}$ ass $/ \mathrm{m}^{3}$ und Stunde wurden an der Oberfläche im März/April 1969 und im Januar 1970 unter Eis erreicht.

Die Assimilationsleistung unter $1 \mathrm{~m}^{2}$ Seeoberfläche $\left(\mathrm{mg} \mathrm{C} / \mathrm{m}^{2} \cdot \mathrm{h}\right)$ wurde planimetrisch bestimmt. Bei der Horwer Bucht wurde eine Wassersäule von $15 \mathrm{~m}$, beim Rotsee eine solche von $5 \mathrm{~m}$ berücksichtigt. Für beide Seen liegen auch $\mathrm{C}^{14}$-Messungen von früheren Jahren vor, die Resultate der verschiedenen Messungen $[24,54,58]$ enthält die Tab. 25.

Die Horwer Bucht zeichnet sich durch deutliche Frühlings- und Spätsommermaxima aus. Weiter kann festgestellt werden, dass sich gegenüber den Jahren 1966/67 die Produktion pro $1 \mathrm{~m}^{2}$ Seeoberfläche etwa verdoppelt hat, dabei muss aber berücksichtigt werden, dass 1969/70 nicht die gleiche Seestelle untersucht wurde.

Für den Rotsee gilt, dass die grössten Photosyntheseleistungen im Frühjahr kurz nach der Zirkulation eintreten. Die Monatswerte der verschiedenen Jahre dürfen aber hier nicht streng verglichen werden, da die Expositionszeiten und auch die Expositionsdauer stark variierten. Die Jahresassimilationsleistung betrug in der Horwer Bucht $457 \mathrm{~g}$ und im Rotsee $637 \mathrm{~g} \mathrm{C}_{\text {ass }} / \mathrm{m}^{2}$.

\subsection{Plankton der Horwer Bucht}

In Tab. 26 sind die Auszählresultate für die 2,5 m Tiefenstufe der Horwer Bucht während eines Jahres zusammengestellt. Es wurden nur die hauptsächlichsten Planktonarten berücksichtigt. 
$33 / 1,1971$

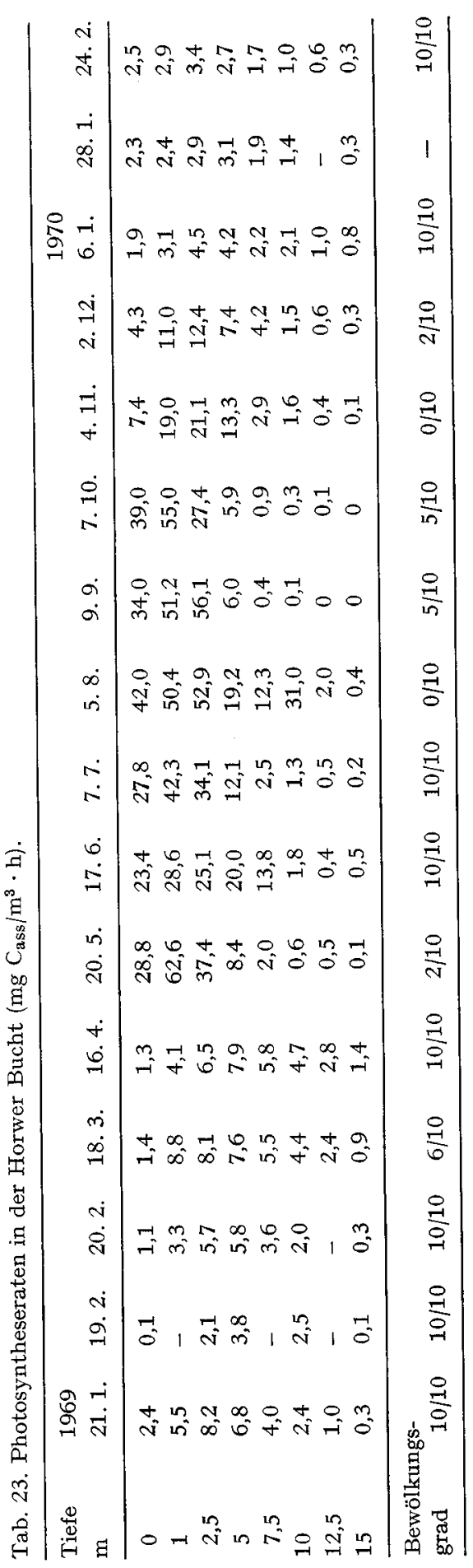

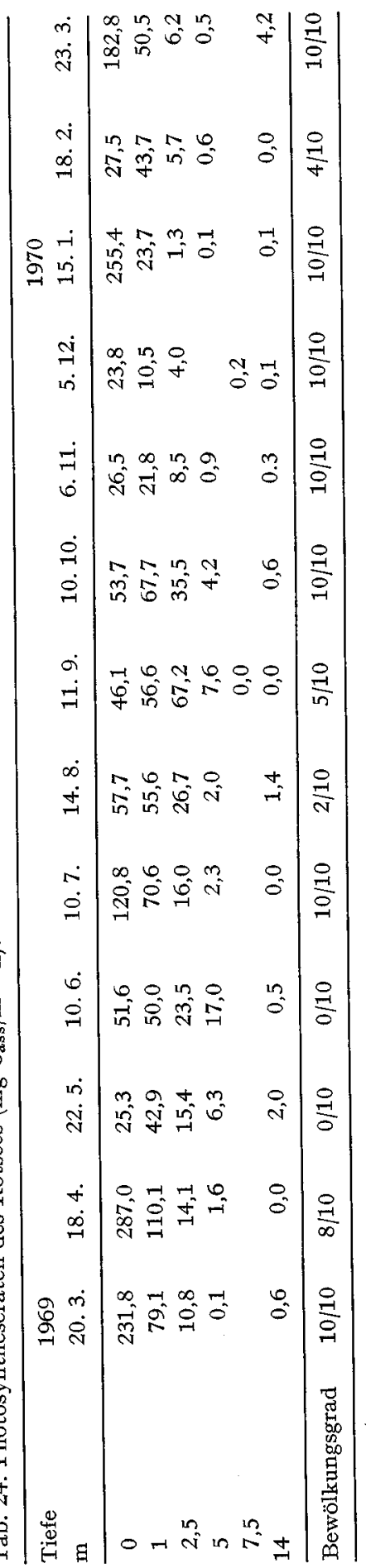



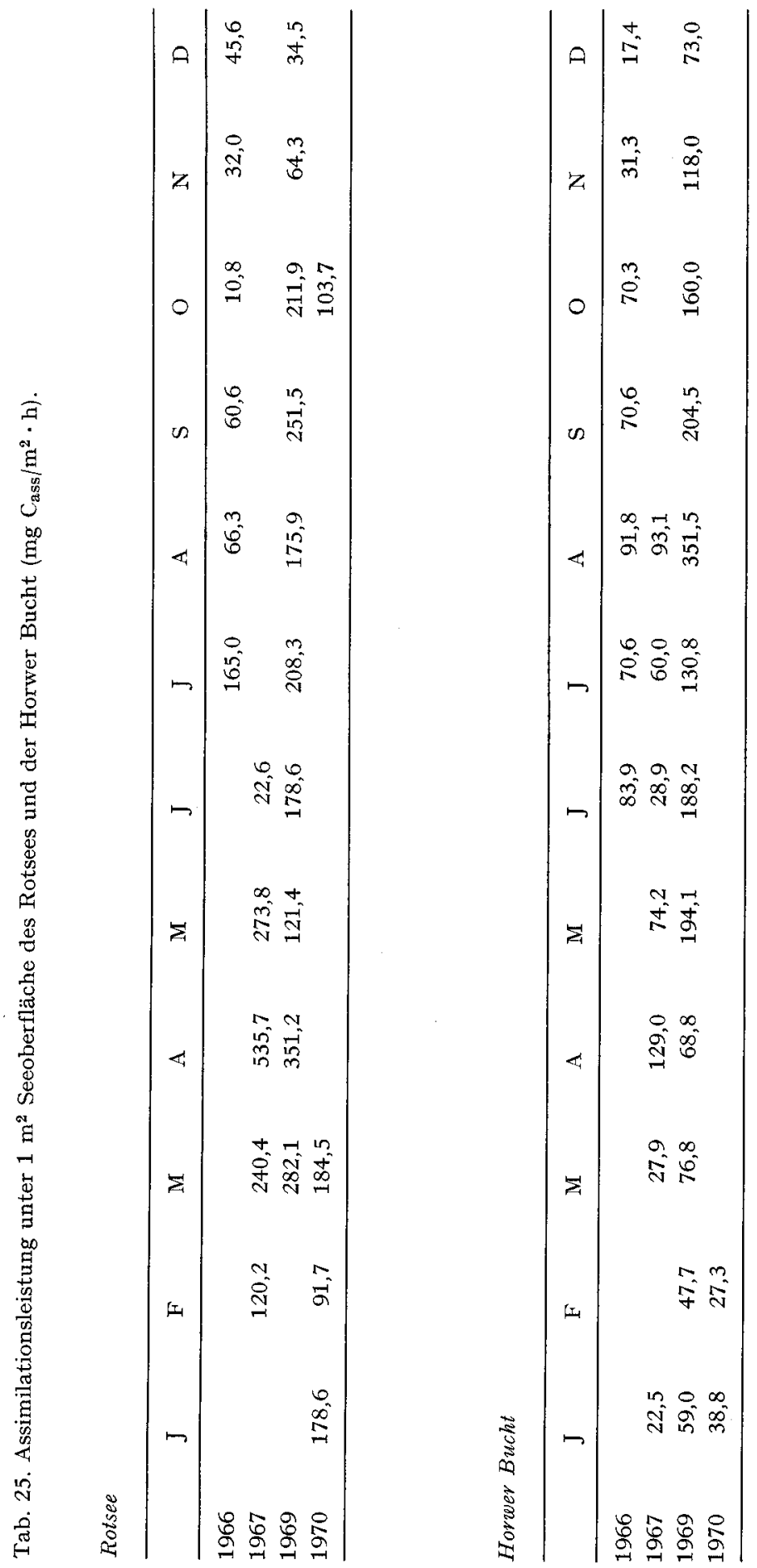


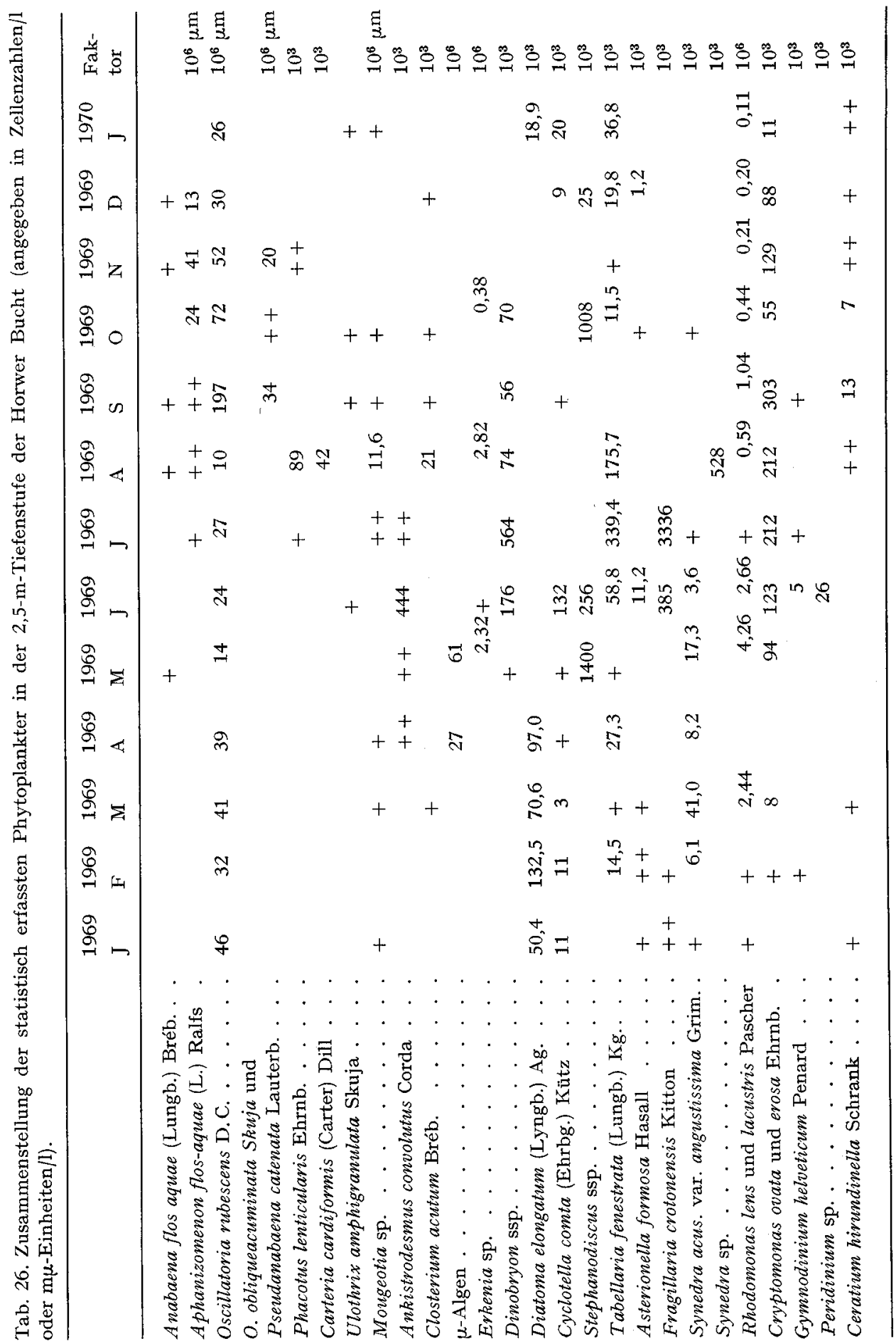


Von den Blaualgen war Oscillatoria rubescens immer vorhanden. Die hohe Fädenzahl im September wurde durch Zirkulation der Wassermassen, in denen Oscillatoria rubescens eingeschichtet war, bewirlst. Im Herbst trat zur Zeit der niedrigsten Konzentrationen an anorganischem $\mathrm{N}$ Aphanizomenon flos aquae zum ersten Male in der Horwer Bucht auf, dabei bildeten sich an der Wasseroberfläche bis in den November «Blüten». In den Proben der Monate September und November wurden noch Oscillatoria obliqueacuminata und Pseudanabaena catenata ausgezählt.

Die als " $\mu$-Algen» bezeichneten kugeligen Algen von etwa 1-2 $\mu \mathrm{m}$ Durchmesser waren vor allem im April und Mai sehr häufig.

Von den Diatomeen waren Diatoma elongatum hauptsächlich im Winter vertreten, während Cyclotella comta im Juni, Tabellaria fenestrata und Fragillaria crotonensis im Juli ihr Maximum erreichten.

Die Flagellaten Rhodomonas lens, $R$. lacustris, Cryptomonas ovata und $C$. erosa waren praktisch immer vorhanden.

Auf die Planktonzusammensetzung des Rotsees während der Untersuchungsperiode wird ScHEGG [55] noch genauer eingehen.

\section{Experimentelle Düngversuche im Vierwaldstättersee}

Bei Seeuntersuchungen beobachtet man, dass neben den Phosphaten auch Nitrate unter die analytische Nachweisbarkeit fallen. Es interessierte uns daher, ob neben dem Phosphor nicht auch Stickstoff wachstumsbegrenzend wirke.

Um die Wirkung von zugesetztem Stickstoff unter möglichst natürlichen Bedingungen studieren zu können, wurde mit den «Nährstofftestzellen» (NTZ) nach GÄcHTER [24] gearbeitet. Das sind durchsichtige Plastikzylinder von 14001 Volumen, die an einer Aufhängevorrichtung in derjenigen Tiefe exponiert wurden, in der im Vierwaldstättersee im allgemeinen maximale Assimilationsraten $\mathrm{zu}$ erwarten sind $(2,5 \mathrm{~m})$.

Vier Nährstofftestzellen wurden jeweils an der in Abb. 3 bezeichneten Stelle exponiert. Die erste NTZ enthielt als Vergleichsprobe ungedüngtes Seewasser, die übrigen wurden mit $\mathrm{NaNO}_{3}$ (p.A. Merck) soweit angereichert $(150,450$ und $1200 \mu \mathrm{g}$ $\left.\mathrm{NO}_{3}-\mathrm{N} / \mathrm{l}\right)$, dass sich Konzentrationen einstellten, wie sie in Seen von verschiedenem Trophiegrad anzutreffen sind [76]. Nach einigen Tagen Versuchsdauer wurde zusätzlich noch mit Phosphat gedüngt $\left(\mathrm{NaH}_{2} \mathrm{PO}_{4} \cdot 2 \mathrm{H}_{2} \mathrm{O}\right.$ p.A. Merck).

Bei der Probenahme wurde aus vier verschiedenen Tiefen der NTZ Wasser entnommen und daraus eine Mischprobe hergestellt. Ein Teil der Probe wurde mit radioaktiver $\mathrm{NaHC}^{14} \mathrm{O}_{3}$-Lösung versetzt und während 6 Stunden $(9-15 \mathrm{Uhr}$ ) neben den Nährstofftestzellen im See in 2,5 m Tiefe exponiert. Durch chemische Analysen wurden folgende Komponenten erfasst:

- partikulärer Kjeldahl-Stickstoff,

- Nitrat,

- Nitrit,

- Ammonium.

Ammonium konnte jeweils nur in Spuren (weniger als $20 \mu \mathrm{g} \mathrm{NH}_{4}-\mathrm{N} / 1$ ) nachgewiesen werden. 


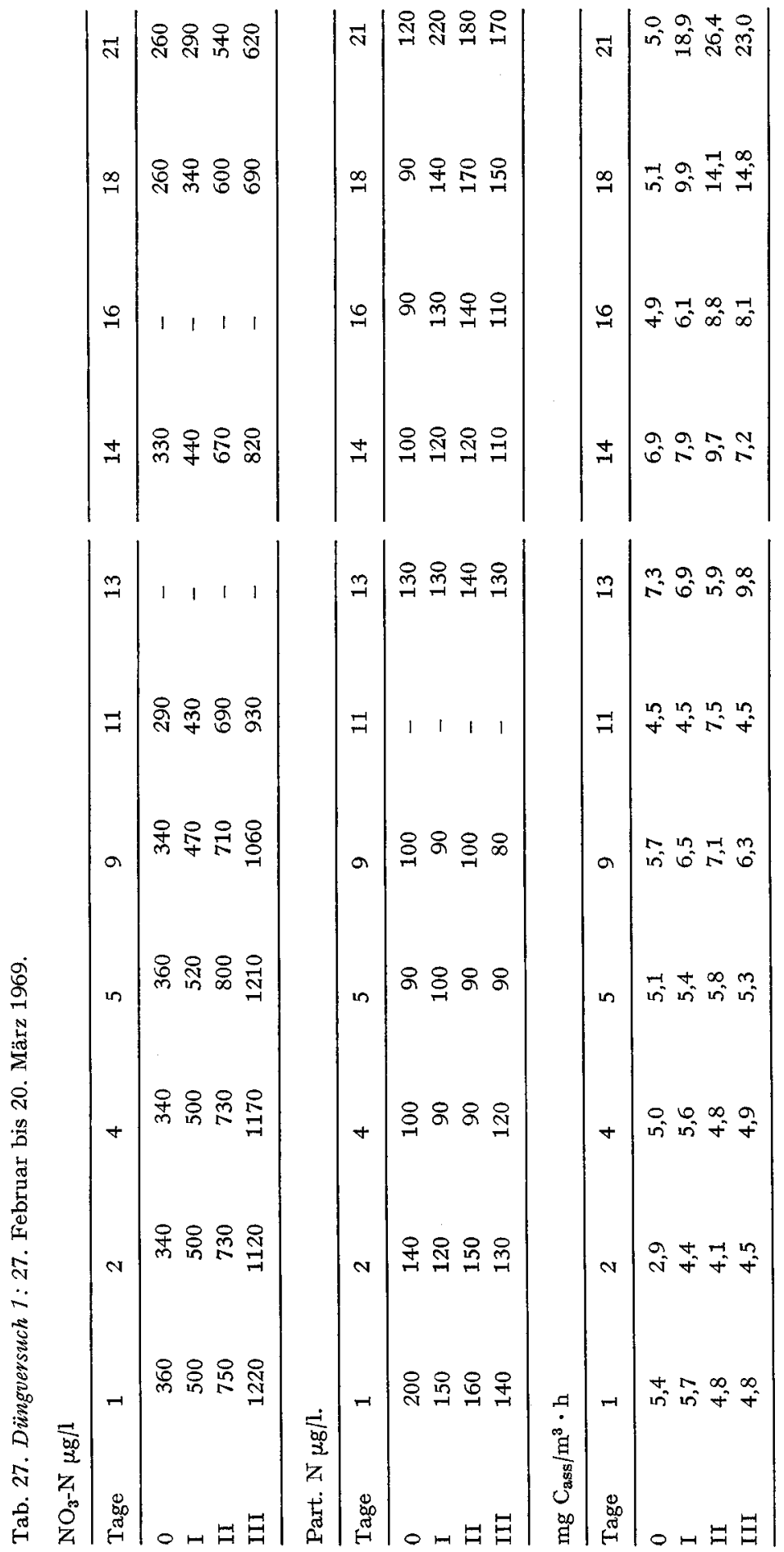




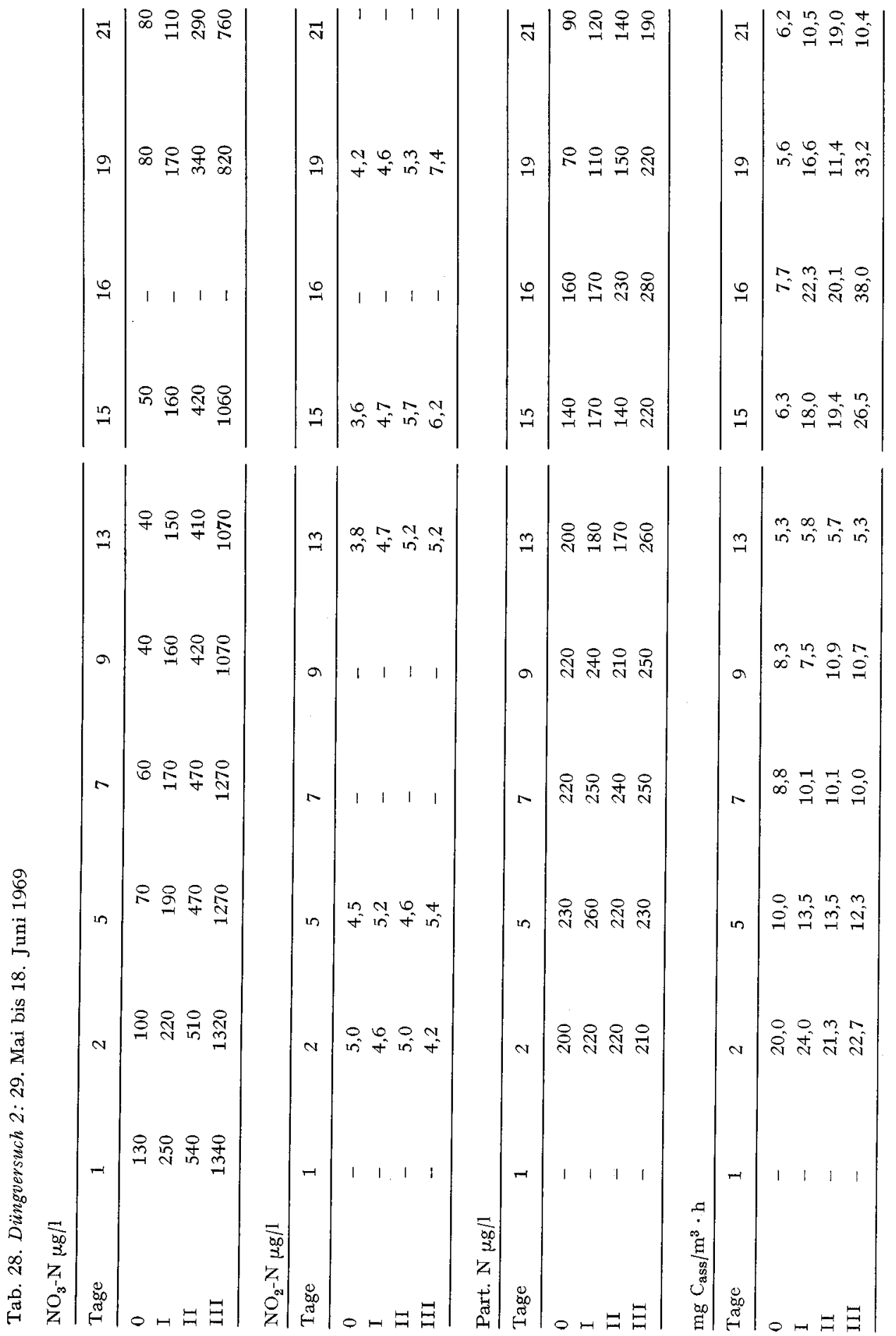


Düngversuch 1: 27. Februar bis 20. März 1969 (Tab. 27)

Nach einer Versuchsdauer von 13 Tagen lag die Nitratkonzentration in allen NTZ über $290 \mu \mathrm{g} \mathrm{N} / 1$. Eine wachstumsbegrenzende Wirkung des Stickstoffs konnte daher weitgehend ausgeschlossen werden. Das arithmetische Mittel der C-Assimilation während der Versuchsperiode lag in allen gedüngten Proben um 10\% höher als jenes in der Vergleichsprobe.

Die zusätzliche P-Düngung (etwa $25 \mu \mathrm{g} \mathrm{PO}_{4}-\mathrm{P} / \mathrm{l}$ ) nach dem 13. Tag in NTZ I, II und III bewirkte eine Steigerung der mittleren Photosyntheseraten von 100 bis $170 \%$, gleichzeitig nahm auch die Nitratzehrung und die Konzentrationen an partikulärem Stickstoff zu.

Der grösste Effekt der zusätzlichen P-Düngung wurde bei Versuchsabbruch am 21. Tag erreicht. Verglichen mit der NTZ O lagen in den NTZ I, II und III die Assimilationsraten 3,8-, 5,3- und 4,6mal höher.

Diingversuch 2: 29. Mai bis 18. Juni 1969 (Tab. 28)

Bis zum 13. Tag sank der Nitratgehalt in der NTZ O von 130 auf $40 \mu \mathrm{g} N / 1$. Die Steigerung der mittleren Photosyntheseaktivität in den gedüngten Proben betrug 16-17\%. Die zusätzliche P-Düngung nach dem 13. Tag bewirkte am 16. Tag verglichen mit der ungedüngten Probe maximal eine Versechsfachung der Photosyntheseraten. Vom 14. bis zum 21. Tag wurden die mittleren Photosyntheseraten in den NTZ I und II etwa verdreifacht, in der NTZ III vervierfacht. Eine Steigerung des partikulären Stickstoffs konnte erst mit der P-Düngung erzielt werden.

Dïngversuch 3: 22. August bis 9. September 1968 (Tab. 29)

Die Nitratdüngung erhöhte die mittleren Photosyntheseraten während der ersten 12 Tage um 6-30\%.

Nach dem 12. Versuchstag wurde NTZ I, NTZ II und NTZ III analog zu den beiden ersten Versuchen mit etwa $25 \mu \mathrm{g} \mathrm{PO}_{4}$-P/l gedüngt. Während der folgenden 6 Versuchstage bewirkte die zusätzliche P-Düngung eine Steigerung der mittleren Photosyntheseraten von $76 \%$ in NTZ I, eine solche von $215 \%$ in NTZ II und eine solche von $250 \%$ in NTZ III. Eine eindeutige Erhöhung des partikulären Stickstoffgehaltes wurde erst nach erfolgter P-Düngung in NTZ II und III erreicht.

Dïngversuch 4: 20. September bis 10. Oktober 1968 (Tab. 30)

Um eine Aussage über die Streuungen bei Versuchsbeginn zu erhalten, wurden die NTZ zuerst ohne Düngung aufgefüllt.

Die Nitratkonzentrationen des unveränderten Seewassers waren sehr niedrig. Im Vergleich zur NTZ 0 bewirkte die Nitratdüngung während der ersten 4 Tage eine Steigerung der mittleren Photosyntheseaktivität von $15-34 \%$.

Dïngversuch 5: 15. Oktober bis 31. Oktober 1969 (Tab. 31)

Auch in diesem Experiment wurden die NTZ I, II und III erst nach dem ersten Versuchstag mit Nitrat gedüngt. Die ursprünglichen Nitratkonzentrationen lagen zu diesem Zeitpunkt bei $30 \mu \mathrm{g} / \mathrm{l}$.

Während der Versuchsdauer von 7 Tagen bewirkte die Nitratdüngung verglichen mit der NTZ 0 eine Steigerung der mittleren Photosyntheseaktivität von 9-13\%. 


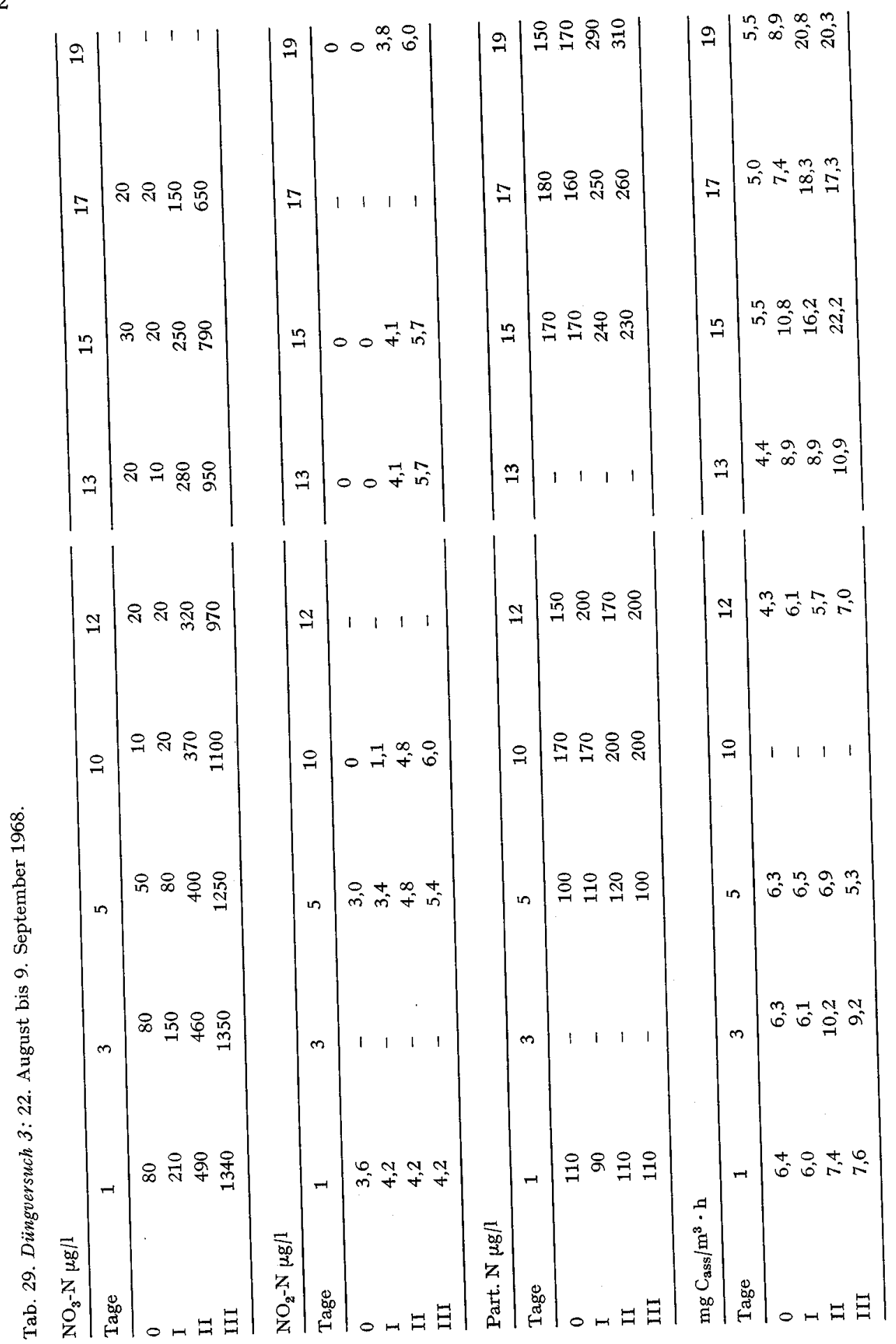


Tab. 30. Düngversuch 4: 20. September bis 10. Oktober 1968.

\begin{tabular}{lrrrrr}
$\mathrm{NO}_{3}-\mathrm{N} \mu \mathrm{g} / \mathrm{l}$ & \multicolumn{6}{c}{} & \multicolumn{1}{c}{} \\
\hline Tage & 0 & 1 & 3 & 10 & 6 \\
\hline 0 & 20 & 30 & 10 & 90 & 60 \\
I & 20 & 140 & 90 & 110 & 90 \\
II & 20 & 400 & 180 & 1200 & 1000 \\
III & 20 & 1340 & 1160 & &
\end{tabular}

\begin{tabular}{llllll}
$\mathrm{NO}_{\mathbf{2}}-\mathrm{N} \mu \mathrm{g} / \mathrm{l}$ & \multicolumn{5}{c}{} \\
\hline Tage & 0 & 1 & 3 & 4 & 6 \\
\hline 0 & 0 & 0 & 0 & - & 0 \\
I & 0 & 0 & 0 & - & 1,2 \\
II & 0 & 0 & 1 & - & 2,0 \\
III & 0 & 0 & 1 & - & 1,5 \\
\hline
\end{tabular}

\begin{tabular}{lrrrrr} 
Part. $\mu \mathrm{g} / 1$ & \multicolumn{5}{c}{} \\
\hline Tage & 0 & 1 & 3 & 4 & 6 \\
\hline 0 & 240 & 220 & 280 & 230 & - \\
I & 190 & 200 & 260 & 230 & 230 \\
II & 190 & 210 & 310 & 290 & 250 \\
III & 220 & 220 & 250 & 260 & 270 \\
\hline
\end{tabular}

\begin{tabular}{|c|c|c|c|c|c|}
\hline Tage & 0 & 1 & 3 & 4 & 6 \\
\hline 0 & 15,3 & 31,5 & 27,6 & 15,6 & - \\
\hline I & 14,3 & 31,5 & 38,8 & 15,5 & 32,6 \\
\hline II & 13,8 & 32,1 & 41,6 & 24,7 & 41,0 \\
\hline III & 13,8 & 34,0 & 41,5 & 17,1 & 31,2 \\
\hline
\end{tabular}

Nach dem 7. Tag wurde zusätzlich etwa $20 \mu \mathrm{g} \mathrm{PO}_{4}-\mathrm{P} / 1$ in NTZ I, NTZ II und NTZ III zugegeben. Dadurch wurden die mittleren Assimilationsraten in NTZ I und II etwa verdoppelt. In der NTZ III wurde dagegen nur eine Steigerung von $60 \%$ erreicht. Die Konzentration des partikulären Stickstoffs stieg in den mit Nitrat gedüngten Proben erst bei Zugabe von Phosphor gesichert an. Bei Versuchsabbruch wurde, verglichen mit der NTZ 0 , in der NTZ I ein Konzentrationssteigerung von $40 \%$, in den NTZ II und III eine solche von $80 \%$ erzielt.

\section{Dïngversuch 6: 22. August bis 31. August 1969 (Tab. 32)}

In diesem Experiment wurde die NTZ 0 mit unverändertem Seewasser aufgefüllt; die NTZ I wurde mit etwa $450 \mu \mathrm{g} \mathrm{NO} \mathrm{N}_{3} \mathrm{~N} / 1$, die NTZ II nur mit $20 \mu \mathrm{g} \mathrm{PO}_{4}-\mathrm{P} / 1$ und die NTZ III kombiniert mit Stickstoff und Phosphor gedüngt.

Die ursprünglichen Nitratkonzentrationen lagen bei $50 \mu \mathrm{g} N / 1$, Phosphat konnte keines nachgewiesen werden (weniger als $0,2 \mu \mathrm{g} \mathrm{PO}_{4}-\mathrm{P} / \mathrm{l}$ ). Die reine Nitratdüngung hatte keinen Einfluss auf die Primärproduktion, durch die P-Düngung wurde sie maximal um $120 \%$ gesteigert. Die kombinierte P-N-Düngung bewirkte praktisch keine weitere Erhöhung der Assimilationsraten.

Bei den Experimenten 4 und 5 ist noch auffallend, dass bei niederen Nitratkonzentrationen (weniger als $20 \mu \mathrm{g} / 1$ ) kein Nitrit nachgewiesen werden konnte. 


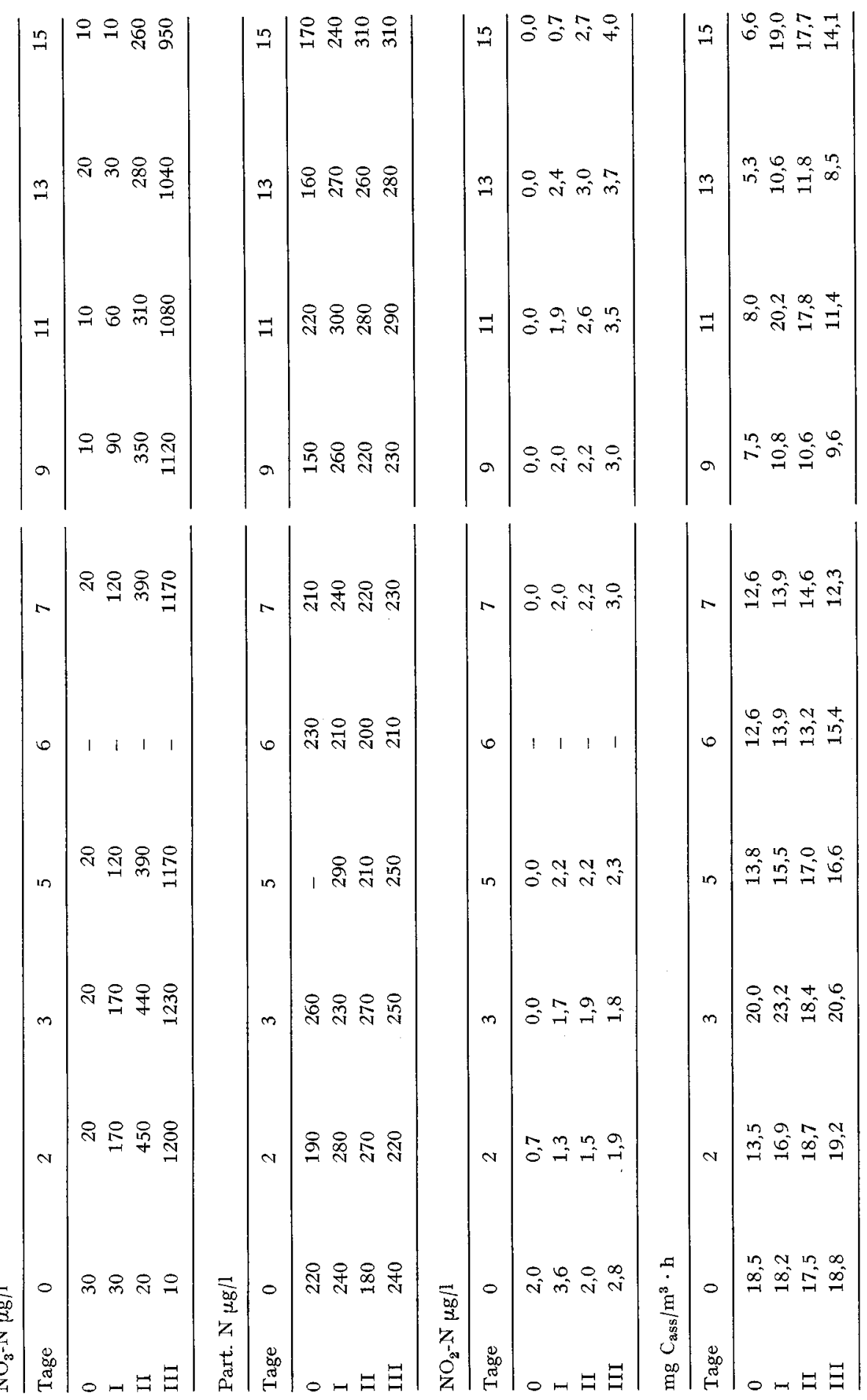


Tab. 32. Dïngversuch 6: 22. August bis 31. August 1969.

\begin{tabular}{|c|c|c|c|c|c|c|}
\hline Tage & 0 & 1 & 3 & 5 & 7 & 9 \\
\hline 0 & 40 & 40 & 30 & 40 & 50 & 50 \\
\hline I & 70 & 460 & 560 & 480 & 490 & 320 \\
\hline II & 70 & 60 & 60 & 10 & 30 & 20 \\
\hline III & 40 & 520 & 430 & 490 & 350 & 250 \\
\hline
\end{tabular}

\begin{tabular}{|c|c|c|c|c|c|c|}
\hline Tage & 0 & 1 & 3 & 5 & 7 & 0 \\
\hline 0 & 4,4 & - & 4,0 & 3,2 & 2,5 & 2.7 \\
\hline 1 & 4,4 & - & $\mathbf{5}, 1$ & 4,4 & 4,0 & 4,0 \\
\hline II & 4,4 & - & 3,8 & 0,4 & 0,2 & 0,1 \\
\hline III & 5,2 & - & 5,2 & 5,1 & 4,4 & 4,3 \\
\hline
\end{tabular}

Part. $N \mu \mathrm{g} / 1$

\begin{tabular}{lrrrrrr}
\hline Tage & 0 & 1 & 3 & 5 & $\mathbf{7}$ & 9 \\
\hline 0 & 170 & 180 & 160 & 200 & 280 & 220 \\
I & 160 & 160 & 190 & 180 & 250 & 180 \\
II & 160 & 210 & 240 & 250 & 330 & 300 \\
III & 180 & 150 & 190 & 250 & 320 & 260 \\
\hline
\end{tabular}

$\mathrm{mg} \mathrm{C}$ ass $/ \mathrm{m}^{3} \cdot \mathrm{h}$

\begin{tabular}{lllllll}
\hline Tage & 0 & 1 & 3 & 5 & 7 & 9 \\
\hline 0 & - & 8,6 & 30,5 & 11,8 & 25,7 & 26,4 \\
I & - & 9,4 & 25,9 & 15,0 & 25,2 & 25,0 \\
II & - & 8,6 & 34,5 & 25,8 & 41,3 & 43,8 \\
III & - & - & 38,5 & 19,6 & 41,9 & 49,8 \\
\hline
\end{tabular}

Bei den Seeuntersuchungen waren bei niederen Nitratkonzentrationen im Epilimnion ebenfalls die Nitritkonzentrationen gering. Bei hoher Photosyntheseaktivität und gleichzeitig hohen Nitratkonzentrationen deuten hohe Nitritkonzentrationen auf Nitratassimilation hin.

\section{Diskussion}

\subsection{Stickstoff als wachstumsbegrenzender Faktor}

In der Süsswasserliteratur sind wenige Angaben über eine wachstumsbegrenzende Wirkung von Nitrat erwähnt, während Stickstoff als limitierender Nährstoff im Meer vielfach nachgewiesen wurde [71, 72], obwohl dort das N:P-Verhältnis ideal vorliegt.

Auf Grund der Konzentrationsverhältnisse wurde von AмвÜнL [3] für den Baldeggersee eine temporär limitierende Wirkung des Nitrats postuliert. GoLDMAN [28] erhielt im Lake Venda (Alaska) bei $\mathrm{NO}_{3}$-Zugabe eine Steigerung der Photosyntheseaktivität in einem 13-Stunden-Experiment von $63 \%$, während eine P-Zugabe nicht stimulierend wirkte. In den Gewässern Berlins wiesen Bringmann et al. [12] mit Scenedesmus-Testkulturen hauptsächlich Nitrat als Begrenzungsfaktor nach.

Auch im dystrophen Kranichsee (DDR) wurde mit dem Haematococcus-Test Stickstoff zeitweise als wachstumsbegrenzend nachgewiesen [31], obwohl in diesem See das durchschnittliche N:P-Atomverhältnis bei 1:16 liegt. 
UHLMANN et al. [73] versuchen mit Hilfe des Wirkungsgesetzes der Wachstumsfaktoren nach Baule-Mitscherlich (s. VERDUiN [75]) die Eignung von Seen verschiedenen Trophiegrades als Nährstofflösung für Algen zu charakterisieren. Das Charakterisierungsmerkmal ist dabei die Abweichung der Nährstoffzusammensetzung vom idealen Biomassenverhältnis $\left(\mathrm{C}_{106} \mathrm{~N}_{16} \mathrm{P}_{1}\right)$.

Die Gleichung von Baule-Mitscherlich lautet nach VERDUIN [75]:

$$
Y=Y_{\max }\left(1-2^{-x}\right)\left(1-2^{-y}\right)\left(1-2^{-z}\right),
$$

wobei $Y$ der Ertrag (Produktion) und $Y_{\max }$ der Höchstertrag (wenn die Faktoren $x, y$ und $z$ optimal vorhanden sind) ist.

$x, y$ und $z$ sind Faktorintensitäten, die die Photosynthese beeinflussen. In unserem Fall ist $x, y$ und $z$ die Faktorintensität der Kohlenstoff-, Stickstoff- und Phosphorkonzentration.

In der Horwer Bucht haben wir während der Vollzirkulation ein Atomverhältnis von $\mathrm{C}_{\mathbf{2 7 0 0}} \mathrm{N}_{50} \mathrm{P}_{1}(24 \mathrm{mg}$ anorganischer Gesamt-C, $520 \mu \mathrm{g}$ Gesamt-N und $23 \mu \mathrm{g}$ Gesamt-P pro Liter).

Kohlenstoff ist also am reichlichsten vorhanden. Wir weisen also der Kohlenstoffkonzentration die Faktorintensität $x=7 \mathrm{zu}$, denn bei gegebenen Stickstoff- und Phosphorkonzentrationen wird mit dieser Faktorintensität $99 \%$ der möglichen Höchstproduktion erreicht:

$$
Y=Y_{\max C}\left(1-2^{-7}\right)=0,99 Y_{\max }{ }^{\cdot}
$$

Die nach UhLMANN und AlBRECHT berechneten Faktorintensitäten betragen im Vierwaldstättersee für Stickstoff $y=0,86$ und für Phosphor $z=0,274$.

In die Gleichung von VERDUIN eingesetzt, ergibt das:

$$
Y=Y_{\max }\left(1-2^{-7}\right)\left(1-2^{-0,86}\right)\left(1-2^{-0,274}\right)=0,08 Y_{\max } .
$$

Daraus ist ersichtlich, dass in der Horwer Bucht mit der aktuellen Nährstoffzusammensetzung nur $8 \%$ der theoretisch möglichen Höchstproduktion erreicht werden kann.

Durch eine Verdoppelung der N-Konzentration im Vierwaldstättersee würde die Faktorintensität für Stickstoff auf 1,72 erhöht. Setzt man diesen Wert in die Gleichung ein :

$$
Y=Y_{\max }\left(1-2^{-7}\right)\left(1-2^{-1,72}\right)\left(1-2^{-0,274}\right)=0,12 Y_{\max }
$$

so erhöht man den Ertrag um 50\%, eine Verdoppelung der P-Konzentration würde eine Ertragssteigerung von $80 \%$ zur Folge haben. Würden sowohl die Stickstoff- als auch die Phosphorkonzentrationen verdoppelt, dann würde die Ertragssteigerung $180 \%$ betragen.

Unter den berücksichtigten Komponenten ist Phosphor also der am meisten limitierende Faktor, aber auch mit einer Stickstoffdüngung sollte man eine Ertragssteigerung erhalten.

Bei den Düngexperimenten mit den Nährstofftestzellen betrug, trotz einer Steigerung der Nitratzugabe bis auf $1200 \mu \mathrm{g}$ N/1, die Erhöhung der Photosyntheseraten während des ganzen Jahres nur 6-34\%. Die starke Abhängigkeit der planktischen Primärproduktion von der P-Konzentration [24] wurde bestätigt, auch konnte erst bei der P-Düngung der Gehalt an partikulärem Stickstoff erhöht werden. Nach der 
erfolgten P-Düngung wirkten sich die künstlich erhöhten Nitratkonzentrationen aber nur zum Teil wachstumsfördernd aus.

In der Horwer Bucht konnte während der geringsten epilimnischen Nitratkonzentrationen (Tab. 15) durch Nitratzugabe (450 $\mu \mathrm{g} \mathrm{N} / 1$ ) in einem 6stündigen $\mathrm{C}^{14}$ Experiment keine Photosynthesesteigerung erreicht werden, durch die P-Zugabe (24 $\mu \mathrm{g} \mathrm{P} / \mathrm{l}$ ) in $2,5 \mathrm{~m}$ aber eine solche von $70 \%$.

Im Rotsee liegt während der Zirkulationszeiten ein Atomverhältnis von etwa $\mathrm{C}_{280} \mathrm{~N}_{18} \mathrm{P}_{1}$ (33 mg anorganischer Gesamt-C, $2400 \mu \mathrm{g}$ Gesamt-N und $300 \mu \mathrm{g}$ Gesamt-P) vor. Bezogen auf das ideale Biomassenverhältnis sind also Phosphor und Stickstoff etwa gleich limitierend.

Bei einem 6stündigen $\mathrm{C}^{14}$-Experiment konnte man mit einer Ammoniumdüngung maximal in $1 \mathrm{~m}$ eine Steigerung der Photosyntheserate von $56 \%$ erzielen, die PDüngung zeigte einen geringeren Effekt (Tab. 33). Im Rotsee können also Verhältnisse auftreten, bei denen Stickstoff wachstumslimitierend sein kann.

Um eine Aussage über die Produktion eines Gewässers machen zu können, darf diese aber nicht nur auf der Zirkulationskonzentration basieren, sondern vor allem auf der Nährstoffnachlieferung ins Epilimnion, sei es aus Zuflüssen, horizontalen und vertikalen Nährstoffzufuhren oder Nachlieferung durch das Ökosystem (kurzgeschlossener Stoffkreislauf, N-Fixierung).

Weiter ist der Zusammenhang zwischen Nährstoffkonzentration und Nährstoffaufnahmegeschwindigkeit einerseits und der Nährstoffkonzentration und der Wachstumsbegrenzung andererseits noch zu wenig bekannt.

EPPLEY et al. [17] haben an marinen Algenarten gezeigt, dass für die $\mathrm{NO}_{3}$ - und $\mathrm{NH}_{4}$-Aufnahmeraten in Abhängigkeit von der Konzentration die Michaelis-MentenGleichung anwendbar ist. Dabei variierte die Halb-Konzentrationskonstante (die Konzentration, bei der die Aufnahmerate die Hälfte der maximalen Aufnahmerate beträgt) $K_{\mathrm{s}}$ von Algenart zu Algenart. MAC IsAAK et al. [36] haben nachgewiesen, dass in oligotrophen Meeresbereichen die Algenpopulation an kleinere $K_{\mathrm{s}}$-Werte für die $\mathrm{NO}_{3}$ - und $\mathrm{NH}_{4}$-Aufnahme adaptiert ist als die Algenpopulation eutropher Bereiche.

Von den Algen werden in der trophogenen Schicht je P-Atom etwa $16 \mathrm{~N}$-Atome inkorporiert. Für eine bestimmte Algenart muss aber die Nitratkonzentration eine bestimmte Höhe erreichen, damit sie sich optimal entwickeln kann und konkurrenzfähig bleibt; in diesem Fall kann Nitrat artspezifisch limitierend sein.

\subsection{N-Fixierung}

N-Fixierung durch bestimmte Blaualgen konnten wir im Vierwaldstättersee nicht direkt nachweisen. Auffallend ist aber, dass im Herbst 1969 zum erstenmal Aphani-

Tab. 33. Photosyntheseraten im Rotsee (15. Oktober 1970), $\mathrm{NH}_{4} \mathrm{Cl}-\mathrm{Zugabe}\left(500 \mu \mathrm{g} \mathrm{NH} \mathrm{NH}_{4} \mathrm{~N} / \mathrm{l}\right.$ ), P-Zugabe $\left(20 \mu \mathrm{g} \mathrm{PO}_{4}\right.$ - $\left.\mathrm{P} / 1\right)$.

\begin{tabular}{lllrrrrr} 
Tiefe & $\mu \mathrm{g} / \mathrm{l}$ & & \multicolumn{2}{c}{$\mathrm{mg} \mathrm{C} / \mathrm{m}^{3} \cdot \mathrm{h}$} \\
& $\mathrm{PO}_{4}-\mathrm{P}$ & $\mathrm{NO}_{\mathbf{3}}-\mathrm{N}$ & $\mathrm{NH}_{\mathbf{4}}-\mathrm{N}$ & & $+\mathrm{N}$ & $+\mathrm{P}$ & $+\mathrm{N}+\mathrm{P}$ \\
\hline 0 & 5,6 & 10 & 26 & 98,3 & 92,3 & 98,3 & 74,8 \\
1 & 0 & 10 & 0 & 31,3 & 47,8 & 43,7 & $\mathbf{5 1 , 0}$ \\
2,5 & 1,7 & 10 & 0 & 11,0 & 13,4 & 10,6 & 11,3 \\
5 & 3,6 & 40 & 106 & 1,0 & 0,9 & 0,9 & - \\
\hline
\end{tabular}



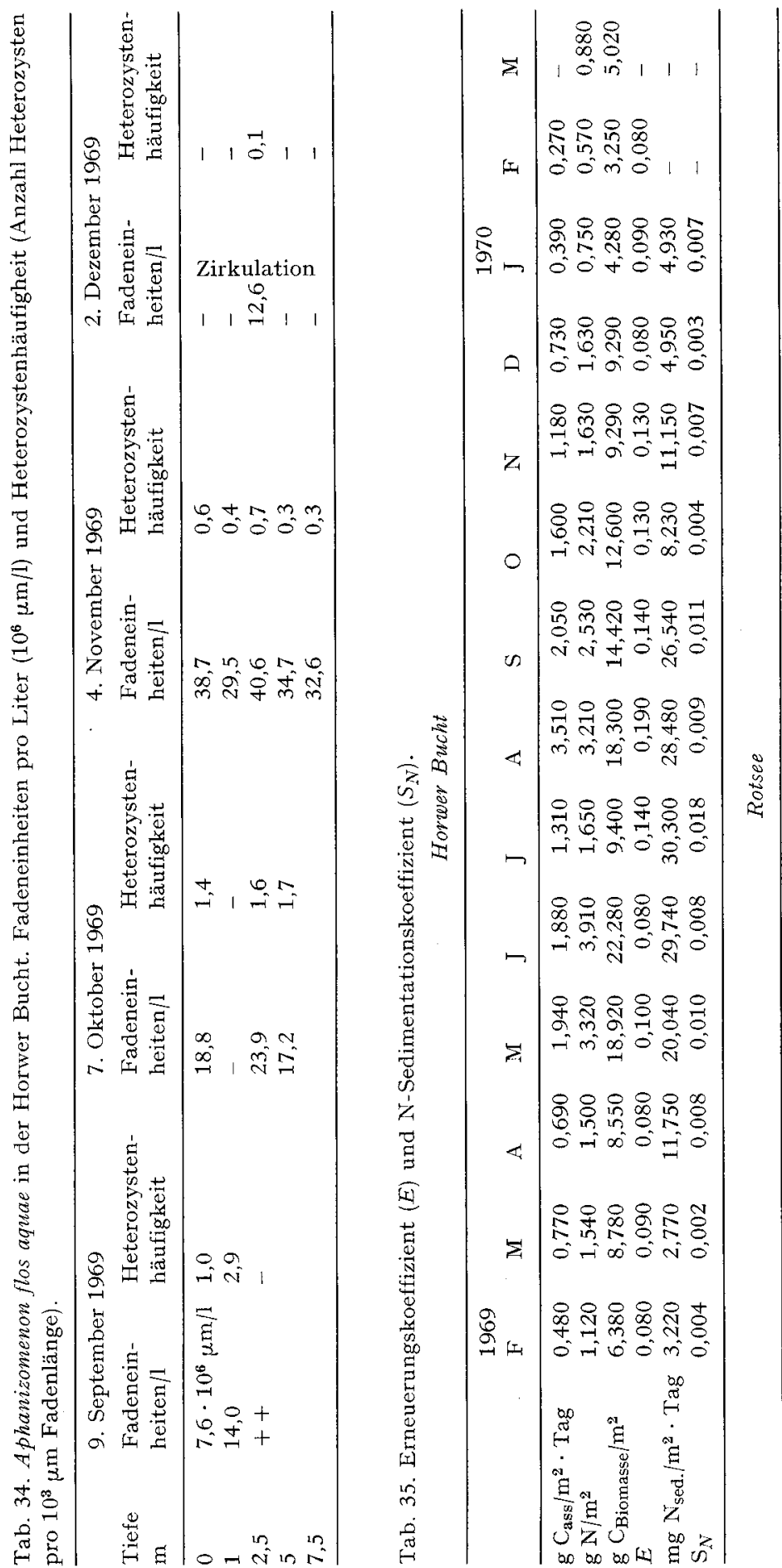

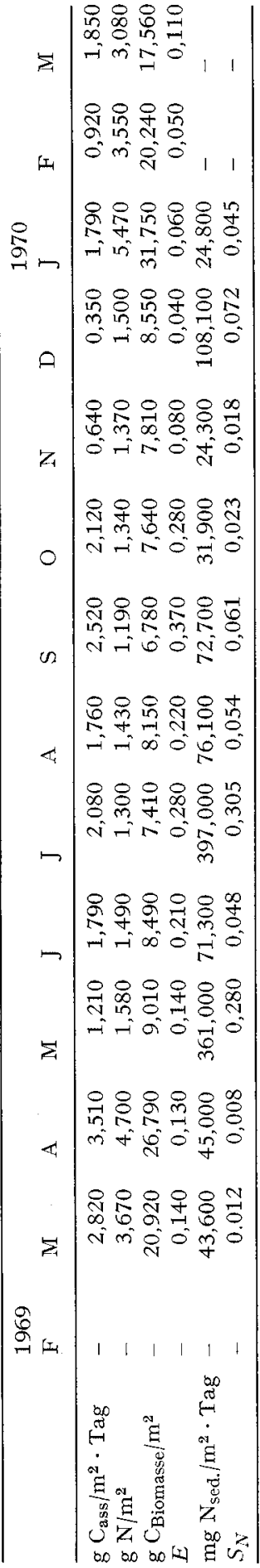


zomenon flos-aquae auftritt. Nach FAy et al. [20], STEwart [60] und OGAWA et al. [41] ist Aphanizomenon flos-aquae zur N-Fixierung befähigt. Diese Autoren vermuten, dass die Heterozysten am N-Fixierungsprozess beteiligt sind. OGAWA et al. [41] schliesst von der Anzahl der gebildeten Heterozysten in den Algenfäden auf $\mathrm{N}$ Fixierung, denn die Bildung von Heterozysten wird induziert, wenn man die Blaualgen in eine Kulturlösung überträgt, die nur atmosphärischen Stickstoff als NQuelle enthält. Tatsächlich war im Vierwaldstättersee die Heterozystenhäufigkeit bei Aphanizomenon während des Nitratminimums grösser als in den Monaten November/Dezember (Tab. 34).

Im Rotsee konnte man während des Jahres 1969, trotz ausgeprägten anorganischen N-Minima, nie grössere Anzahlen von Blaualgen feststellen, die zur N-Fixation befähigt sind (SCHEGG - mündliche Mitteilung).

Zusammenfassend kann man über die N-Fixierung in Seen sagen:

- Durch N-Fixierung kann das anorganische N-Angebot ergänzt werden, bei starker $\mathrm{N}$-Fixierung sind meist heterozystentragende Blaualgen anwesend.

- Die N-Fixierungen fallen zusammen mit $\mathrm{NO}_{3}$ - und $\mathrm{NH}_{4}$-Minima, hoher Wassertemperatur, starker Bestrahlung [53, 41].

- Die N-Fixierung kann auch weiter verlaufen, wenn energetisch leichter ausnutzbare N-Quellen erhältlich sind [16].

\subsection{Das N:P-Gewichtsverhältnis im partikulären Material}

In den Abb. 19, 20 und 21 ist der N-und P-Gehalt des partikulären Materials in der Horwer Bucht für verschiedene Tiefenstufen der trophogenen Schicht aufgetragen.

Nimmt man das $\mathrm{N}$ : P-Gewichtsverhältnis von 7,2:1 als ideal an [63], so zeigt sich, dass das Plankton in der Horwer Bucht in den Wintermonaten, bei guter P-Versorgung und niederer Produktion, ein kleineres Verhältnis aufweist als in den produktiven Sommermonaten. Man kann hier eine "Luxus-P-Fixierung" postulieren oder einen relativ hohen Anteil an nichtbiologischem partikulärem Phosphor.

Berechnet man für die Tiefen $0,2,5$ und $5 \mathrm{~m}$ das mittlere $\mathrm{N}: \mathrm{P}$-Verhältnis, so erhält man 8 , die Standardabweichung beträgt \pm 3 . Für die Tiefen $0,1,2,5$ und $5 \mathrm{~m}$ des Rotsees beträgt das Verhältnis 8,5 $\pm 3,5$.

Die generelle Annahme eines $\mathrm{N}: \mathrm{P}$-Verhältnisses von $7,2: 1$ ist problematisch. Dieses Verhältnis variiert:

- bei verschiedenen Algenarten (Zusammenstellung bei HEMENs et al. [30]),

- bei der gleichen Algenart bei verschiedenen physiologischen Bedingungen, wie zum Beispiel bei verschiedener Nährstoffversorgung [23, 26, 50, 59].

In der Horwer Bucht fielen eindeutig die Werte vom Juni 1969 (5 und 7,5 m) und August 1969 (10 und 12,5 m) hoch aus, das Verhältnis reichte dabei bis auf 22:1. Bei den Untersuchungen wurde jeweils ein hoher N-Anteil ermittelt, wenn im Plankton Oscillatoria rubescens überwiegte und eingeschichtet vorlag. Im Monat Juni (5 und $7,5 \mathrm{~m}$ ) und im Monat August $(10$ und $12,5 \mathrm{~m}$ ) betrugen die Oscillatoria-Biomassen 150 und $321 \cdot 10^{7} \mu \mathrm{m}^{3} / 1$ bzw. 543 und $273 \cdot 10^{7} \mu \mathrm{m}^{3} / 1$.

Entsprechend hohe Werte meldet Staub [59] für den Zürich- und Burgäschisee, auch PAvoni [44] ermittelte einen hohen N-Anteil pro Trockengewicht bei OscillatoriaNetzzügen im Vierwaldstättersee (über 10\%). Berechnet man den Eiweissgehalt des 

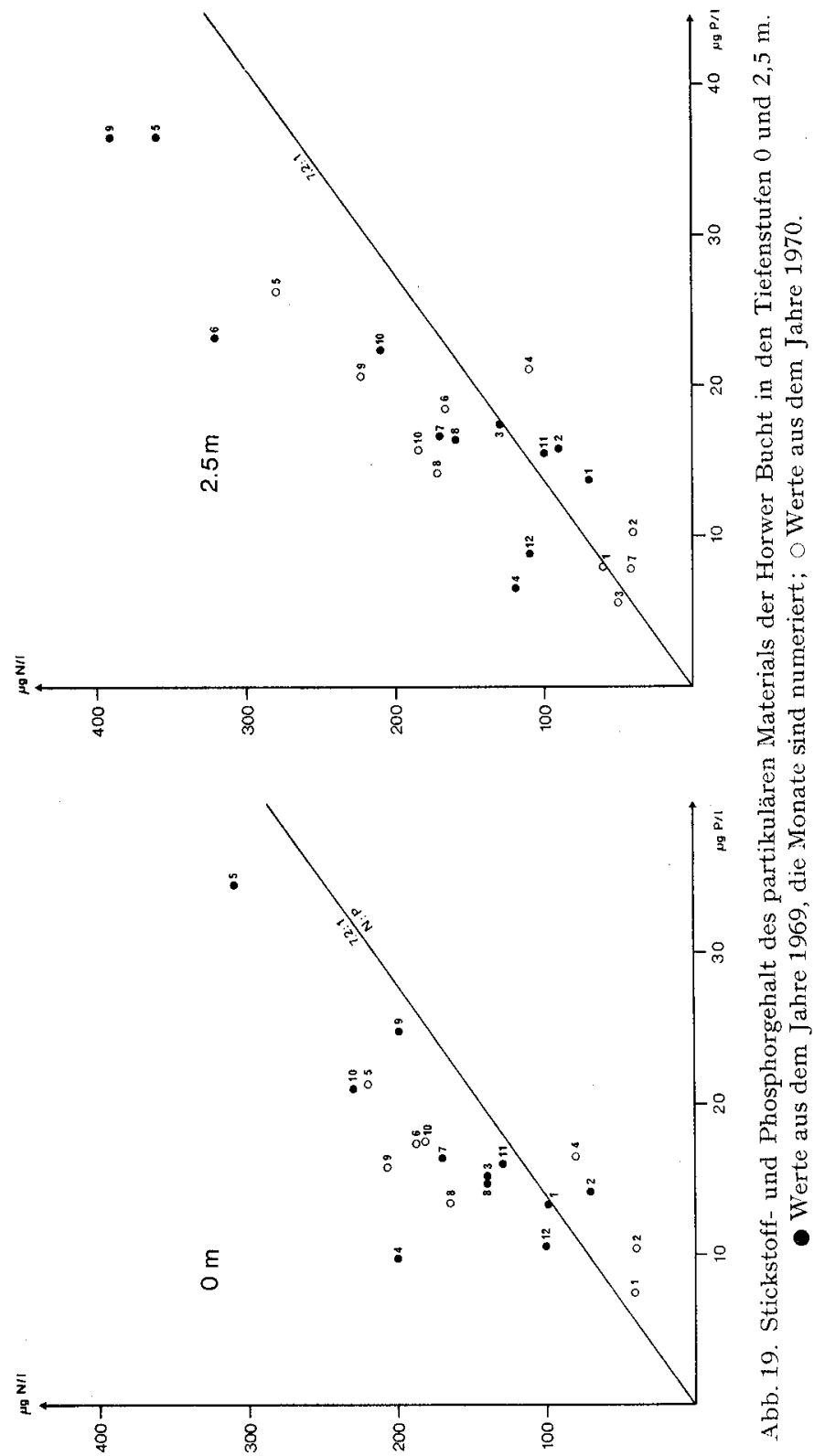


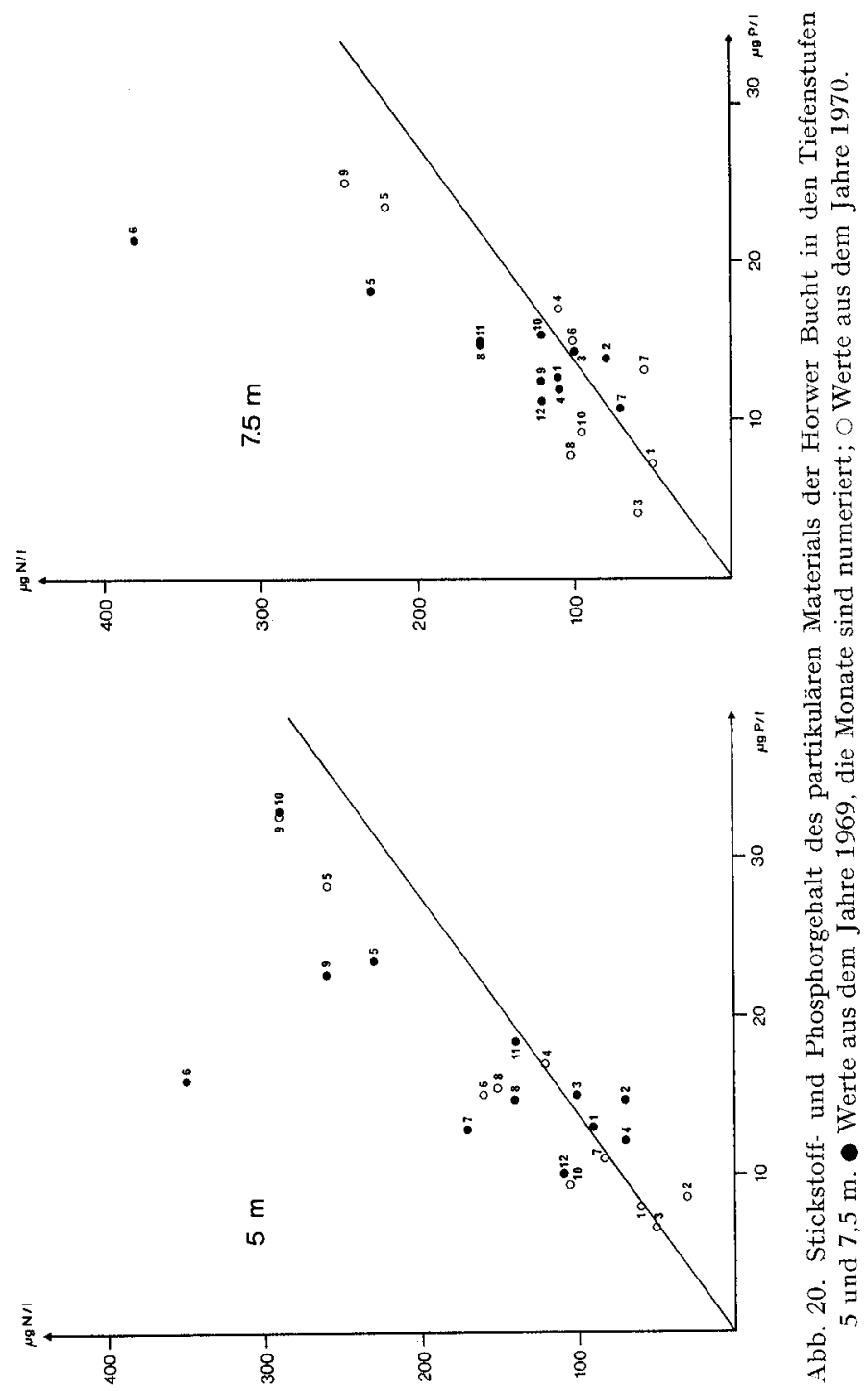




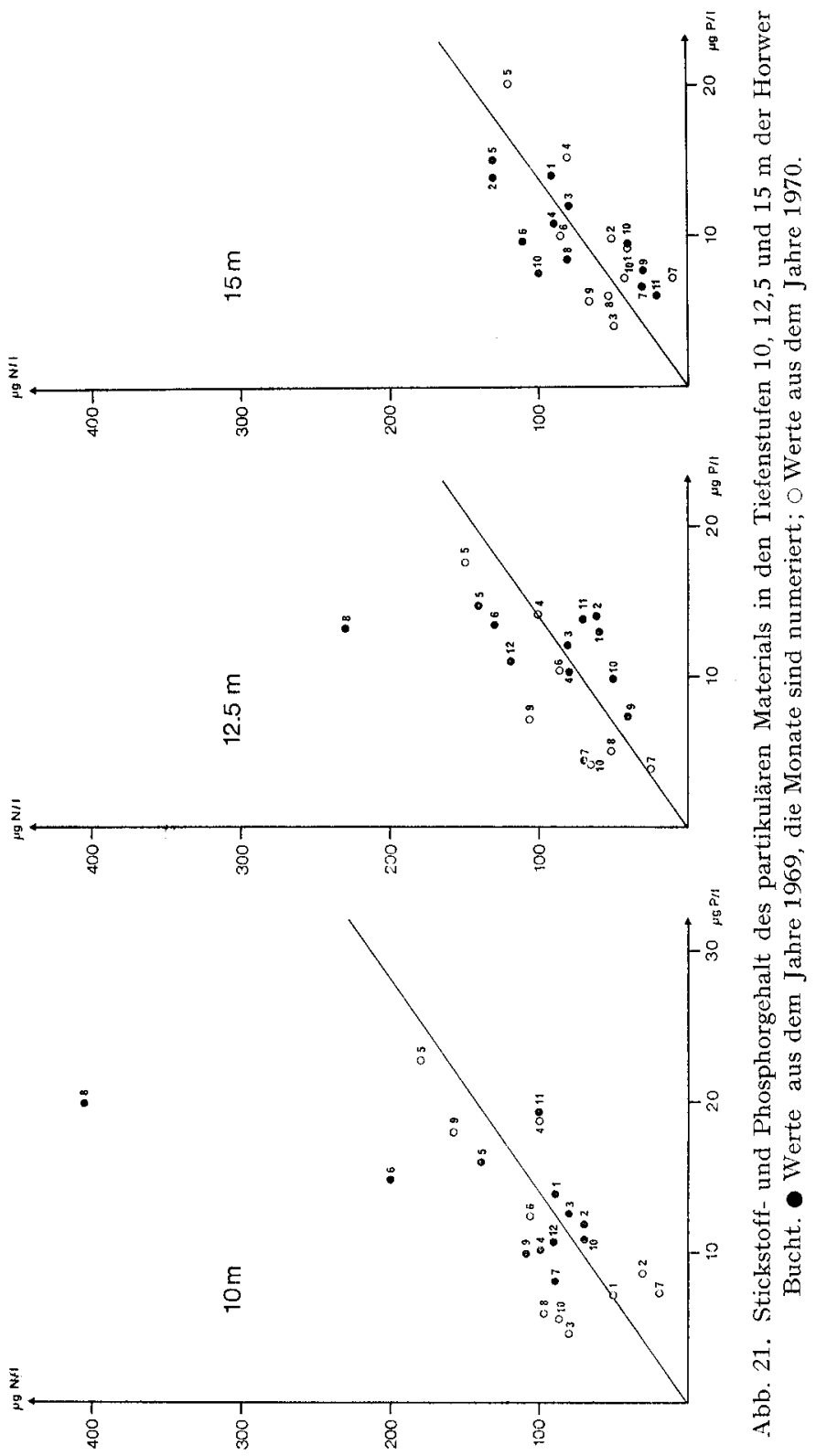


Planktons aus dem Kjeldahl-N-Gehalt mal 6,25, so würde man mehr als $60 \%$ Protein je Trockensubstanz erhalten, ein Wert der zu hoch liegt.

Nach ZimmermanN [79] entwickelt sich Oscillatoria rubescens im Vierwaldstättersee in jenen Tiefen optimal, in denen weniger als $5 \%$ des grünen Lichtes (VG9) gemessen wird. Der hohe N-Anteil wird wahrscheinlich durch Phycobiline (Phycoerythrin) bewirkt, die in den Zellen als Hilfspigmente die Lichtenergie des grünen Lichtes auf das Chlorophyll übertragen (chromatische Adaption).

In der Horwer Bucht ist das N : P-Gewichtsverhältnis des partikulären Materials nicht nur jahreszeitlich verschieden, sondern auch in den verschiedenen Tiefenstufen. Berechnet man für die Sommerstagnationsperioden 1969/70 (April bis Oktober) das mittlere N : P-Verhältnis, so erhält man für die euphotische Schicht $(0-10 \mathrm{~m})$ einen Wert von 10,3, für die Schichten 15 bis $35 \mathrm{~m}$ 7,1 und für die Tiefenstufen 45-60 m ein solches von 5,6. Im partikulären Material nimmt also mit zunehmender Tiefe clas N:P-Verhältnis ab. Dies lässt sich damit erklären, dass die N-Mineralisation auf dem Sedimentationsweg schneller verläuft als die P-Mineralisation. In den bodennahen Schichten ist der $\mathrm{PO}_{4}$-Gehalt während der Stagnationsperiode relativ hoch (5-32 $\left.\mu \mathrm{g} \mathrm{PO}_{4}-\mathrm{P} / 1\right)$, gleichzeitig wird durch die Photosyntheseaktivität des Planktons aus dem Epilimnion $\mathrm{CaCO}_{3}$ ausgefällt. Kalzit kann auf dem Sedimentationsweg mit dem Phosphat adsorptiv oder chemisch reagieren [63], das niedere $\mathrm{N}: \mathrm{P}$-Verhältnis in den Tiefen 45 und $60 \mathrm{~m}$ kann somit auch durch anorganisches, P-haltiges, partikuläres Material bewirkt werden.

\subsection{Der tägliche Biomassenzuwachs und Sedimentationsverlust}

Bezieht man die Tagesproduktion unter $1 \mathrm{~m}^{2}$ Seeoberfläche auf den Kohlenstoffgehalt der aktuell vorhandenen Biomasse in der trophogenen Schicht, so erhält man als Mass für das Wachstum der Algenpopulation den Erneuerungskoeffizienten [40]:

$$
\frac{\mathrm{mg} \mathrm{C} \mathrm{C}_{\text {ass }} / \mathrm{m}^{2} \cdot \mathrm{Tag}}{\mathrm{mg}}=E\left(t^{-1}\right) \text {. }
$$

Der Erneuerungskoeffizient ist auch ein Mass für die täglichen Umsatzzeiten des Stickstoffs.

Bei der gewählten Expositionsdauer für die $\mathrm{C}^{14_{-}}$Messungen von 4 Stunden $(10$ bis 14 Uhr) wird etwa 30-50\% der Tagesassimilationsleistung erreicht. Für die Berechnung der täglichen Primärproduktion wurde deshalb die Stundenleistung pro $1 \mathrm{~m}^{2}$ mit 10 multipliziert. Der Kohlenstoffanteil in der Biomasse wurde aus dem partikulären N-Gehalt und dem idealen N:C-Gewichtsverhältnis von 1:5,7 berechnet (Tab. 35).

In der Horwer Bucht beträgt der Erneuerungskoeffizient im Winter etwa 0,09, das heisst $9 \%$ der vorhandenen Biomasse wird täglich neu gebildet, im Sommer werden bis zu $19 \%$ täglich erneuert.

Es ist interessant, dass im Januar/Februar trotz höherem Erneuerungskoeffizienten in der Horwer Bucht die Biomasse geringer war als im Rotsee. Bedingt durch die Vollzirkulation ist in der Horwer Bucht eine hohe Verlustrate vorhanden, während im Rotsee unter der Eisdecke, die eine Turbulenz verhindert, eine hohe Populationsdichte aufgebaut werden kann. 
Entsprechend dem Erneuerungskoeffizienten lässt sich ein Sedimentationskoeffizient definieren:

$$
\frac{\mathrm{mg} \mathrm{N} \mathrm{N}_{\text {sed. }} / \mathrm{m}^{2} \cdot \mathrm{Tag}}{\mathrm{mg} \mathrm{N}_{\text {Biomasse }} / \mathrm{m}^{2}}=S_{N}\left(t^{-1}\right)
$$

Mit den Sedimentationsmessungen erhalten wir zwar nicht eine vollsändige Aussage über die Gesamtverluste an Biomasse, da die Verluste durch Autolyse, bakterielle Mineralisation und Frass nicht erfasst werden, auch findet währen des Auffangens des Seston-Sediments schon teilweise eine Mineralisation statt.

Aus der Tab. 35 ist ersichtlich, dass während der Sommerstagnation der Gehalt an partikulärem Stickstoff unter $1 \mathrm{~m}^{2}$ in der Horwer Bucht etwa doppelt so hoch ist wie im Rotsee. Die täglichen N-Sedimentationsraten sind aber im Rotsee immer höher. In der Horwer Bucht wird auf dem längeren Sedimentationsweg, der durch Zirkulation der Wassermassen noch verlängert wird, das sedimentierende Seston stärker der Mineralisation ausgesetzt. Der N-Gehalt pro Trockengewicht ist deshalb auch entsprechend gering $(0,3-1,3 \%)$.

Im Rotsee, dessen Temperaturen während der Sommerstagnation höher liegen und dessen Turbulenzen durch die windgeschützte Lage verringert werden, ist der Sedimentationsweg kürzer. Das in $5 \mathrm{~m}$ Tiefe aufgefangene Sediment ist deshalb jünger, dies zeigt sich auch im höheren N-Gehalt pro Trockengewicht (bis 4,3\%).

Unter der Annahme, dass der C-Gehalt etwa 10\% des Algenfrischgewichts betrage [40], lassen sich aus den Daten von FindenEGG [22] und GÄchter [24] für den Vierwaldstättersee Erneuerungskoeffizienten von 0,2 bis 1,7 berechnen. FIndENEGG [21] ermittelte für den Rotsee einen Erneuerungskoeffizienten von 1,6 (2. 6. 64). Da bei diesen Autoren die Biomassenberechnungen auf Planktonzählungen basieren, muss angenommen werden, dass mit der mikroskopischen Methode nach Utermöhl die Biomasse unterschätzt und daher ein zu hoher Erneuerungskoeffizient erhalten wird. Bei der Berechnung des Koeffizienten auf Grund von chemischen Analysendaten können die Werte zu niedrig ausfallen, wenn viel photosynthetisch inaktives Material (totes Phytoplankton, Bakterien, Zooplankton, Detritus) erfasst wird.

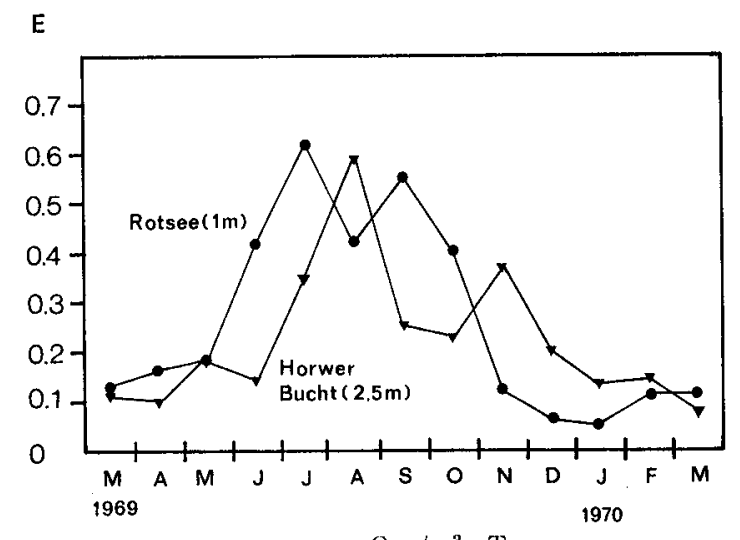

Abb, 22. Erneuerungskoeffizient pro $\mathrm{m}^{3}\left(=\frac{\mathrm{g} \mathrm{C}_{\mathrm{ass}} / \mathrm{m}^{3} \cdot \mathrm{Tag}}{\mathrm{g} \mathrm{C}_{\text {Biomasse }} / \mathrm{m}^{3}}\right)$ in der 2,5-m-Tiefenstufe der Horwer Bucht und in der 1-m-Tiefenstufe des Rotsees. 
PAvoNI 44] gibt für den Vierwaldstättersee ein Verhältnis von Algenfrischgewicht: partikulärem Stickstoff von 22,7 an. Um den C-Anteil in der Biomasse aus dem partikulären $\mathrm{N}-G$ ehalt $z u$ erhalten, müsste also mit 2,27 statt mit 5,7 multipliziert werden. Die Beträge für die Erneuerungskoeffizienten in Tab. 35 würden sich dann etwa verdoppeln.

In Abb. 22 sind die Erneuerungskoeffizienten je $1 \mathrm{~m}^{3}$ für die Tiefenstufe $1 \mathrm{~m}$ des Rotsees und 2,5 $\mathrm{m}$ der Horwer Bucht aufgetragen. Diese Tiefenstufen sind ja die Schichten maximaler Produktivität, auch konnte man hier die niedrigsten Phosphatund Nitrat-bzw. Ammoniumkonzentrationen nachweisen.

Es ist ersichtlich, dass hohe Erneuerungsraten im Sommer gemessen wurden. In der Horwer Bucht fielen im September und Oktober die Erneuerungskoeffizienten erstaunlich niedrig aus, mit grosser Wahrscheinlichkeit wirkten sich hier die geringen Nährstoffkonzentrationen, vor allem an Phosphor, wachstumsbegrenzend aus.

\subsection{Stickstoffbilanz}

Für die Abschätzung der in den See gelangenden Nährstoffe wird nur die Stagnationsperiode vom 14. April 1969 bis zum 13. Oktober 1969 (182 Tage) berücksichtigt. Für diese Zeit darf angenommen werden, dass sich die Nährstoffzufuhren im Epi- und Metalimnion einschichten und somit am Stoffumsatz teilnehmen.

\section{Horwer Bucht}

Einzugsgebiet: $16 \mathrm{~km}^{2}$

Einwohner im Einzugsgebiet: 10000

Seeoberfläche: $2 \mathrm{~km}^{2}$

Trophogene Schicht: $15 \mathrm{~m}$

Das Einzugsgebiet der Horwer Bucht ist etwa $\mathrm{zu} 2 / 5$ bewaldet und zu etwa $2 / 5$ mit Wiesland bedeckt. Nach den Untersuchungen der EAWAG (unveröffentlicht) beträgt die jährliche $\mathrm{N}$-Auswaschung pro $\mathrm{km}^{2}$ im Gebiet des Sarnersees, das topographisch und klimatologisch demjenigen der Horwer Bucht entspricht, $800 \mathrm{~kg}$ Gesamt-N für bewaldete Flächen, $1600 \mathrm{~kg} N$ für ungedüngtes und $2000 \mathrm{~kg} \mathrm{~N}$ für gediungtes Grasland. Für die Berechnung der natürlichen Zufuhren wurde eine mittlere Auswaschung von $1500 \mathrm{~kg} \mathrm{~N} / \mathrm{km}^{2}$ und Jahr angenommen. Die Pro-capite$\mathrm{N}$-Anfälle wurden mit $12 \mathrm{~g} \mathrm{~N}$ pro Einwohner und Tag eingesetzt [78]. Da die meisten Häuser Klärgruben besitzen, ist dieser Wert etwas zu hoch, wahrscheinlich findet durch Denitrifikationsprozesse schon teilweise eine N-Eliminierung statt, andererseits sind die industriellen Abwässer nicht berücksichtigt.

Die N-Zufuhren während der Stagnationsperiode in der Horwer Bucht:
a) Natürliche Zufuhr . . . . . . . . . . . . . . . . . . . . $6,0 \mathrm{~g} \mathrm{~N} / \mathrm{m}^{2}$
b) Zufuhr durch Abwässer . . . . . . . . . . . . . . . . . . . $10,9 \mathrm{~g} \mathrm{~N} / \mathrm{m}^{2}$
c) Zufuhr aus der Luft [18] . . . . . . . . . . . . . . . . . . . . $0,2 \mathrm{~g} \mathrm{~N} / \mathrm{m}^{2}$
d) Zehrung an gelösten N-Verbindungen: April minus Oktober . . 2,8 g N/m²
e) Zunahme an partikulärem Stickstoff: Oktober minus April . . 0,7 g N/m²
f) Verluste durch Sedimentation . . . . . . . . . . . . . . . $4,6 \mathrm{~g} \mathrm{~N} / \mathrm{m}^{2}$
g) Primärproduktion $\left(330,6 \mathrm{~g} \mathrm{C}_{\text {ass }} / \mathrm{m}^{2}\right.$ und 182 Tage $) . . . .58,0 \mathrm{~g} \mathrm{~N} / \mathrm{m}^{2}$ 
Rotsee Einzugsgebiet: $3,3 \mathrm{~km}^{2}$

Seeoberfläche: $0,47 \mathrm{~km}^{2}$

Trophogene Schicht: $5 \mathrm{~m}$

Das Einzugsgebiet des Rotsees beträgt 4,6 km², davon sind $1,3 \mathrm{~km}^{2}$ kanalisiert. Dieses Gebiet entwässert seit 1969 vollständig in die Reuss, nur die Regenüberläufe führen direkt in den Rotsee.

Solange die Regionalkläranlage noch nicht in Betrieb ist, leitet die Stadt Luzern ihre Abwässer direkt in die Reuss. Unterhalb dieser Abwassereinläufe wird seit 1922 durch einen Stollen Reusswasser in den Rotsee eingeleitet (etwa $0,3 \mathrm{~m}^{3} / \mathrm{sec}$ ).

Die Gesamt-N-Konzentration des Reusswassers direkt beim Ausfluss des Vierwaldstättersees beträgt etwa $0,6 \mathrm{mg} / \mathrm{N} / 1$ (Untersuchungen des kantonalen Labors Luzern 1967), bei der Stollenfassung muss aber mit etwa 1-2 mg Gesamt-N/1 gerechnet werden. Am 24. August 1970 ergab eine Analyse des See-Einlaufs 2,1 mg Gesamt-N/1 und $0,11 \mathrm{mg}$ Gesamt-P/1. Für die N-Auswaschung wurde als Basiswert $2200 \mathrm{~kg}$ Gesamt-N/km² und Jahr angenommen [4].

Die N-Zufuhren während der Stagnationsperiode in den Rotsee:

a) Natürliche Zufuhr . . . . . . . . . . . . . . . . . . . . $7,0 \mathrm{~g} \mathrm{~N} / \mathrm{m}^{2}$

b) Zufuhr durch den Reuss-Stollen . . . . . . . . . . 10,0-20,0 g N/m²

c) Zufuhr atmosphärisch. . . . . . . . . . . . . . . . . . . $0,2 \mathrm{~g} \mathrm{~N} / \mathrm{m}^{2}$

d) Zehrung an gelösten N-Verbindungen: April minus Oktober . . 9,7 g N/m²

e) Abnahme an partikulärem Stickstoff: Oktober minus April . . 3,4 g N/m²

f) Verlust durch Sedimentation . . . . . . . . . . . . $20,1 \mathrm{~g} \mathrm{~N} / \mathrm{m}^{2}$

g) Primärproduktion $\left(381,2 \mathrm{~g} \mathrm{C}_{\text {ass }} / \mathrm{m}^{2}\right.$ und 182 Tage $) . . . . . ~ . ~ 66,9 ~ g ~ N / \mathrm{m}^{2}$

Wir sehen, dass mit den angewandten Sedimentationsmessungen in der Horwer Bucht nur $8 \%$, im Rotsee $30 \%$, der Primärproduktion erfasst werden konnte. BACHOFEN [8] erfasste mit seinen Sedimentationsmessungen 5-7\% der im Epilimnion produzierten organischen Stoffe. OHLE [42] kommt mit Sedimentationsmessungen des organischen Kohlenstoffs auf ähnliche Ergebnisse. Auch im japanischen Lake Biwa [72] wurde mit $\mathrm{N}$-Sedimentationsmessungen nur $10 \%$ der Primärproduktion erfasst.

Dies sind erste Hinweise dafür, dass in der trophogenen Schicht durch Bakterien und das Zooplankton eine beträchtliche Mineralisation stattfindet. Durch diese Prozesse wird der Stickstoff regeneriert, und er steht den Primärproduzenten wieder zur Verfügung.

Der kurzgeschlossene Kreislauf wird weiter bewiesen durch die Tatsache, dass in beiden Seen die externen und internen N-Zufuhren nicht ausreichen, um die gemessene Primärproduktion aufrechtzuerhalten, sondern etwa die Hälfte muss durch Regenerationsprozesse nachgeliefert werden.

\section{Horwer Bucht}

Primärproduktion $(g+e)$. . . . . . . . . . . . . . . . . $58,7 \mathrm{~g} \mathrm{~N} / \mathrm{m}^{2}$

Externe Zufuhren und Zehrung $(a+b+c+d)$. . . . . . . . $19,9 \mathrm{~g} \mathrm{~N} / \mathrm{m}^{2}$

Durch kurzgeschlossenen Kreislauf geliefert . . . . . . . . . $38,8 \mathrm{~g} \mathrm{~N} / \mathrm{m}^{2}$

Rotsee

Primärproduktion $(g)$. . . . . . . . . . . . . . . . $66,9 \mathrm{~g} \mathrm{~N} / \mathrm{m}^{2}$

Externe Zufuhren und Zehrung $(a+b+c+d)$. . . . . 26,9 36,9 $\mathrm{g} \mathrm{N} / \mathrm{m}^{2}$

Durch kurzgeschlossenen Kreislauf geliefert . . . . . . . . 40,0-30,0 g N/m² 


\subsection{Ammonifikation, Nitrifikation und Denitrifikation}

Der Stickstoff in den absterbenden Algenzellen wird durch desaminierend tätige Bakterien zu Ammonium mineralisiert, wobei es keine Rolle spielt, ob aerobe oder anaerobe Verhältnisse herrschen [8]. Im Rotsee fand im Hypolimnion (5 $\mathrm{m}$ bis Grund) durch Ammonifikation eine $\mathrm{NH}_{4}$-Anreicherung von etwa $24 \mathrm{~g} \mathrm{~N} / \mathrm{m}^{2}$ statt (April bis Oktober); Rücklösungen aus dem Sediment müssen hier aber berücksichtigt werden. Von den anorganischen N-Verbindungen bildete im Rotsee deshalb Ammonium die Hauptkomponente. Nur während der Zirkulationsperioden traten im Hypolimnion durch Nitrifikationsprozesse bedingte höhere Nitrit- und Nitratkonzentrationen auf.

In der Horwer Bucht fand gleichzeitig mit der Ammonifikation auch Nitrifikation statt. Die hypolimnische Nitratanreicherung $\left(15-60 \mathrm{~m}\right.$ ) betrug $3,7 \mathrm{~g} \mathrm{~N} / \mathrm{m}^{2}$ (April bis Oktober).

Will man den «N-Rückhalt» eines Sees vollständig erfassen, so hat man die Denitrifikation zu berücksichtigen. Der Denitrifikationsschritt wird von Bakterien hauptsächlich unter Verwendung von organischen Wasserstoffdonatoren ausgeführt; als zusätzliche anorganische Wasserstoffdonatoren kommen $\mathrm{H}_{2} \mathrm{~S}$ und $\mathrm{H}_{2}$ in Frage. Denitrifikation tritt aber erst ein, wenn die Konzentration des gelösten Sauerstoffs nicht mehr ausreicht, um den Sauerstoffbedarf der Bakterienpopulation zu decken. JANNASCH [33] wies nach, dass bei Bildung von anaeroben Schwebestoffherden auch bei höherem Sauerstoffgehalt Denitrifikation möglich ist. Goering et al. [27] stellen mit Hilfe der $\mathbf{N}^{15}$-Methode Denitrifikation in einem subarktischen See fest. Sie zeigten, dass bei Sauerstoffschwund und reichlicher $\mathrm{NO}_{3}$-Konzentration das Nitrat in molekularen Stickstoff umgewandelt wurde. In der 1-m-Schicht wurden Denitrifikationsraten von $15 \mu \mathrm{g} / 1$. Tag und über dem Sediment eine solche von $90 \mu \mathrm{g} / 1$. Tag festgestellt.

VOLLENWEIDER [76] berechnete Denitrifikationsraten einiger schweizerischer Seen auf Grund folgender Annahmen, gleichbleibende mittlere Konzentration zur Zirkulationszeit vorausgesetzt:

$\mathrm{N}$-Seerückhalt $=\mathrm{N}$-Zufuhr $-\mathrm{N}$-Abfluss (1),

Denitrifikation $=\mathrm{N}$-Seerückhalt-N-Rückhalt im Seesediment (2).

Die Denitrifikationsraten variierten von 0,9 (Ägerisee) bis $20,7 \mathrm{~g} \mathrm{~N} / \mathrm{m}^{2}$ und Jahr (Greifensee). Während Phosphor in Seen zum grössten Teil in den Sedimenten zurückgehalten wird, wird Stickstoff hauptsächlich über Denitrifikationsprozesse ausgeschieden.

Da die N-Zufuhren zum Vierwaldstättersee und Rotsee nur grössenordnungsmässig angegeben sind und die genauen $\mathrm{N}$-Ausfuhren nicht erfasst wurden, konnten die jährlichen Denitrifikationsraten nicht ermittelt werden. Auf Grund der Nitratabnahme im Hypolimnion lassen sich im Rotsee in 7,5 m Tiefe (Mai/Juni) Denitrifikationsraten von etwa $5-10 \mathrm{mg} \mathrm{N} / \mathrm{m}^{3}$ und Tag berechnen.

EDWARDs et al. [19] bewiesen experimentell, dass Flußschlamm bei hohem Sauerstoffverbrauch auch bei überstehendem sauerstoffreichem Wasser Nitrat zu reduzieren vermag. $\mathrm{Ob}$ in den Schichten über dem Sediment des Vierwaldstättersees ebenfalls Denitrifikationen stattfinden, kann nicht beurteilt werden. BüHRER (mündliche Mitteilung) ermittelte im Seesediment der Horwer Bucht $10^{4}-10^{5}$ zur Denitrifikation befähigte Bakterienkeime in einem Gramm Nassgewicht. 


\section{Schlussfolgerungen}

Im Vierwaldstättersee wurden während der ganzen Sommerstagnationsperiode hohe Biomassen (part. N) und hohe Photosyntheseraten gemessen. Mit der Ausbildung der Thermokline werden die epilimnischen Schichten von den nährstoffreichen unteren hypolimnischen Schichten abgetrennt. Nach der starken Entfaltung des Planktons im Frühjahr müsste durch Sedimentationsverluste das Epilimnion an Nährstoffen verarmen. Da aber durch externe Zuflüsse ständig Nährstoffe nachgeliefert werden, kann sich eine beträchtliche «standing crop» aufrechterhalten.

Während der Stagnationszeit besteht also ein enger Zusammenhang zwischen der Zufuhr des am meisten limitierenden Nährstoffs und der Primärproduktion.

In den Jahren 1963-1968 betrugen im Vierwaldstättersee (Stelle Kreuztrichter) die jährlichen Zunahmen der mittleren Nitrat- und Gesamt-P-Konzentrationen $16 \mu \mathrm{g}$ $\mathrm{NO}_{3}-\mathrm{N} / 1$ und 1,6 $\mu \mathrm{g}$ Gesamt-P/1 [5]. Bezogen auf Phosphor wird also genügend Stickstoff zugeführt.

Mit ökologischen Experimenten im Vierwaldstättersee konnte in der vorliegenden Arbeit nachgewiesen werden, dass eine erhöhte Zufuhr von Stickstoff die planktische Primärproduktion praktisch nicht zu steigern vermag, wogegen der enge Zusammenhang zwischen Primärproduktion und Phosphorkonzentration $[24,81]$ bestätigt wurde. Während der kurzen herbstlichen anorganischen Stickstoffminima wird vermutlich durch den kurzgeschlossenen Stoffkreislauf bezüglich des vorhandenen Phosphors genügend Stickstoff nachgeliefert; auch können Fixationsprozesse einsetzen. Mit Hinsicht für den praktischen Gewässerschutz folgt daraus:

Werden im Einzugsgebiet des Vierwaldstättersees die Siedlungsabwässer nur in konventioneller Weise mechanisch-biologisch gereinigt, so wird die Primärproduktion weiter zunehmen. Als Folge können im Hypolimnion anaerobe Verhältnisse entstehen, welche die P-Rücklösung aus den Sedimenten sowie Denitrifikationsprozesse begünstigen. Da in biologisch gereinigtem Abwasser das N:P-Gewichtsverhältnis zugunsten des Phosphors verschoben ist (5:1), kann schliesslich, wenn nicht aus anderen Quellen grössere Mengen von Stickstoff zugeführt werden, auch dieser wachstumslimitierend werden.

Bezogen auf Phosphor sind die Nährstoffe C und N im Epilimnion während des ganzen Jahres im Überschuss vorhanden. Eine Sanierung wird die besten Erfolgschancen haben, wenn durch geeignete Massnahmen (Ringleitung, P-Eliminierung in einer dritten Reinigungsstufe, Einleitung des gereinigten Abwassers unter die Produktionsschicht) die P-Zufuhren ins Epilimnion erniedrigt werden können.

Durch die Inbetriebnahme des linksufrigen Abwassersammelkanals wird die spezifische N-Belastung der Horwer Bucht um etwa 65\%, die spezifische P-Belastung um $90 \%[24]$ verringert werden. Es wird interessant sein zu verfolgen, wie sich diese Sanierungsmassnahme auf die planktische Primärproduktion auswirken wird.

Im Rotsee wurden die grössten planktischen Biomassen in den Monaten Januar bis April ermittelt. Entsprechend hoch waren auch die Photosyntheseraten. Die Primärproduktion ist deshalb stark von der internen Nährstoffzufuhr durch die Herbst- und Frühjahrsteilzirkulation abhängig. Im Winter wird durch die Ausbildung einer Eisdecke eine stabile Schichtung aufgebaut. Wegen der höheren Viskosität des Wassers bei niederen Temperaturen verringern sich die Sedimentationsverluste; das 
Ausbleiben der Vollzirkulation verhindert, dass die Algenpopulation ständig verdünnt wird, so dass sich unter Eis, genügend Lichtintensität vorausgesetzt, eine grössere "standing crop" aufbauen kann als in der Horwer Bucht.

Nach dem Eisbruch kommt es jeweils zu Phytoplanktonmassenentfaltungen. Gleichzeitig erhöhen sich mit dem Aufbau der Sommerschichtung die Sedimentationsraten. Die oberen epilimnischen Schichten verarmen an Nährstoffen, und die Primärproduktion wird hauptsächlich von den allochthonen Nährstoffzufuhren aus dem Einzugsgebiet und dem Reuss-Stollen unterhalten.

Würde dem Rotsee sauberes, nicht abwasserbelastetes, Reusswasser zugeführt, dann würde die N-Belastung um etwa $20-50 \%$ verringert. Auf Grund verschiedener Parameter, wie der hohen Frühjahrsnährstoffkonzentrationen, der kleinen mittleren Tiefe und der geringen Wassererneuerung vor allem der hypolimnischen Wassermassen ist freilich zu schliessen, dass der Rotsee weiterhin ein eutrophes Gewässer bleiben wird.

Nach Vollenweider [76] ist für einen See mit einer mittleren Tiefe von $10 \mathrm{~m}$ eine Oberflächenbelastung von über $3 \mathrm{~g} \mathrm{~N} / \mathrm{m}^{2}$ und Jahr und $0,2 \mathrm{~g} \mathrm{P} / \mathrm{m}^{2}$ und Jahr bereits gefährlich. Diese kritische Belastbarkeitsgrenze wird aber auch bei vollständiger Sanierung aller Abwasserbelastungsquellen noch übertroffen werden. Immerhin darf man erwarten, dass im Sommer in den oberen Schichten die Primärproduktion kleiner ausfallen wird und sich somit auch grössere Sichttiefen einstellen werden.

Als weitere zusätzliche Sanierungsmöglichkeiten müssten noch andere Massnahmen überlegt werden, die vor allem darauf abzielen, die Wassererneuerungszeit zn erhöhen, wie zum Beispiel hydraulische Veränderungen der Zuflüsse und des Abflusses, oder Anordnungen, die es ermöglichen, die tiefen Wasserschichten direkt dem Seeabfluss zuzuführen.

\section{Zusammenfassung}

In den Jahren 1969/70 wurden der mesotrophe Vierwaldstättersee (Stelle Horwer Bucht) und der hoch eutrophe Rotsee in physikalischer (Temperatur, subaquatische Lichtverhältnisse), chemischer (Stickstoff- und Phosphorkomponenten, Sauerstoff, Schwefelwasserstoff, Säurebindungsvermögen) und biologischer Hinsicht (Primärproduktion, Seston-Sedimentation, Planktonanalyse) untersucht.

Besondere Beachtung wurde der zeitlichen und räumlichen Verteilung der anorganischen $\left(\mathrm{NO}_{3}, \mathrm{NH}_{4}, \mathrm{NO}_{2}\right)$ und organischen Stickstoffkomponenten (part. $\mathrm{N}$ und gelöster organischer $\mathrm{N}$ ) geschenkt.

Für die Bestimmung des part. $N$ wurde eine genaue und störungsfreie Analysenmethode erarbeitet. Die Wasserproben werden durch Glasfaserfilter (GF/C Whatman) mit einer Deckschicht aus Magnesiumhydroxidkarbonat (p.A. Merck) filtriert und der Filterrückstand inklusive Filter aufgeschlossen, wodurch Störungen durch das im Wasser gelöste Nitrat beim Kjeldahl-Aufschluss wegfallen. Bei der Filtration von $200 \mathrm{ml}$ Probewasser mit einem Gehalt von $50 \mu \mathrm{g}$ part. N/1 beträgt die Standardabweichung $s= \pm 10 \mu \mathrm{g} N / 1$. Die Bestimmung des part. $\mathrm{N}$ ist also auch in oligotrophen Gewässern möglich.

In allen Tiefen der Horwer Bucht ist Nitrat während des ganzen Jahres die Hauptkomponente des anorganischen Stickstoffs. Im Rotsee hingegen, bedingt durch die anaeroben Verhältnisse im Hypolimnion, fällt der Hauptteil auf Ammonium. 
Gegen den Herbst hin war in beiden Seen in den Schichten maximaler Photosyntheseaktivität eine deutliche Zehrung von anorganischen N-Verbindungen festzustellen. Die hypolimnische Nitratanreicherung betrug in der Horwer Bucht $(15-60 \mathrm{~m})$ am Ende der Sommerstagnation 3,7 $\mathrm{g} \mathrm{NO}_{3}-\mathrm{N} / \mathrm{m}^{2}$; im Rotsee betrug die hypolimnische $\mathrm{NH}_{4}$-Anreicherung $(5-14 \mathrm{~m}) 24 \mathrm{~g} \mathrm{NH}_{4}-\mathrm{N} / \mathrm{m}^{2}$ (Tab. 12, 13 und 14, Abb. 10, 11, 12, 13 und 14).

Die epilimnischen Konzentrationen an part. $\mathrm{N}$ schwankten in der Horwer Bucht zwischen 30 und $420 \mu \mathrm{g} / 1(0-15 \mathrm{~m})$, im Rotsee zwischen 130 und $3440 \mu \mathrm{g} \mathrm{N} / 1$ $(0-5 \mathrm{~m})$. Im Gegensatz zur Horwer Bucht wurden im Hypolimnion hohe Konzentrationen an part. $\mathrm{N}$ gemessen. Die höchste epilimnische "standing crop» (part. $\mathrm{N} / \mathrm{m}^{2}$ ) wurde im Rotsee jeweils in den Monaten Januar/Februar unter Eis und nach Eisbruch in den Monaten März/April ermittelt, in der Horwer Bucht in den Monaten Mai/Juni und August/September (Tab. 17 und 20, Abb. 15 und 16).

Die epilimnischen Konzentrationen an gelöstem organischem Kjeldahl-N lagen in der Horwer Bucht bei 20-210 $\mathrm{gg} \mathrm{N} / 1$, der Gehalt unter $1 \mathrm{~m}^{2}$ Seeoberfläche (0-15) bei $1,00-2,36 \mathrm{~g} \mathrm{~N} / \mathrm{m}^{2}$. Im Rotsee betrugen die Konzentrationen an gelöstem organischem Kjeldahl-N 150-880 $\mu \mathrm{g}$ N/1. Der Gehalt an gelöstem N unter $1 \mathrm{~m}^{2}$ Seeoberfläche (0-5) variierte von $1,27-2,87 \mathrm{~g} \mathrm{~N} / \mathrm{m}^{2}$ (Tab. 18,19 und 20).

Während der Stagnationsperiode (April bis Oktober) wurden in der Horwer Bucht N-Sedimentationsraten von 8-34 $\mathrm{mg} \mathrm{N} / \mathrm{m}^{2}$ und Tag, im Rotsee von 32-397 $\mathrm{mg} \mathrm{N} / \mathrm{m}^{2}$ und Tag gemessen, das heisst in der Horwer Bucht sedimentieren täglich 1-2\% und im Rotsee 2-37\% des vorhandenen part. $\mathrm{N}$ aus (Tab. 35, Abb. 17 und 1.8).

Die höchsten Assimilationsraten betrugen in der Horwer Bucht $63 \mathrm{mg} \mathrm{C}_{\text {ass }} / \mathrm{m}^{3}$ und Stunde, im Rotsee $287 \mathrm{mg} \mathrm{C}$ ass $/ \mathrm{m}^{3}$ und Stunde. Mit Hilfe der täglichen Assimilationsleistung ( $\mathrm{g} \mathrm{C}_{\text {ass }} / \mathrm{m}^{2} \cdot \mathrm{Tag}$ ) und des vorhandenen partikulären Stickstoffs in der trophogenen Schicht wurden tägliche Erneuerungskoeffizienten von 0,08-0,19 für die Horwer Bucht und 0,05-0,37 für den Rotsee ermittelt (Tab. 23, 24 und 35).

In der Horwer Bucht schwankte das N:P-Gewichtsverhältnis im partikulären Material sowohl jahreszeitlich als auch im Tiefenprofil. Während der Stagnationsperiode lag in den Tiefenstufen 0-10 $\mathrm{m}$ das mittlere Verhältnis bei 10,5, in den Tiefenstufen 15-35 $\mathrm{m}$ bei 7,1 und in 45-60 $\mathrm{m}$ bei 5,6. Ein hohes Gewichtsverhältnis (bis zu 22:1) wurde jeweils in jenen Tiefenstufen festgestellt, in denen Oscillatoria rubescens eingeschichtet war (Abb. 19, 20 und 21).

In der trophogenen Schicht des Rotsees betrug das N:P-Gewichtsverhältnis während des Jahres $8,5 \pm 3,5$.

Im Vierwaldstättersee wurde mit durchsichtigen Plastikzylindern (sogenannte Nährstofftestzellen) von 14001 Volumen, die in 2,5 $\mathrm{m}$ Tiefe versenkt wurden, der Einfluss der Nitratdüngung (Zugabe von $\mathrm{NaNO}_{3}$ p.A. Merck) geprüft. Es wurde eine Steigerung der mittleren Photosyntheseaktivität erreicht (6-34\%); verglichen mit der starken Produktionssteigerung bei Phosphorzugabe ist der Effekt der Nitratdungung gering. Eine Steigerung des partikulären Stickstoffs in den Nährstofftestzellen konnte nur nach der Phosphatdüngung erreicht werden (Tab. 27 bis 32).

Da die internen Zufuhren (epilimnische N-Zehrung ) und die externen Zufuhren (N-Belastung) nicht ausreichen, um die gemessene Primärproduktion aufrechtzuerhalten, und da mit den Sedimentationsmessungen ebenfalls nur ein geringer Anteil der Primärproduktion erfasst werden konnte, wird ein kurzgeschlossener 
Kreislauf (intrabiocoenotisch) postuliert, der der N-Sedimentation entgegenwirkt und im Epilimnion Stickstoff regeneriert.

Die Untersuchungen im Vierwaldstättersee zeigen, dass von den Nährstoffen C, $\mathrm{N}, \mathrm{P}$ Phosphor am meisten limitierend wirkt. Während der kurzen herbstlichen Minima an anorganischem Stickstoff können auch N-Fixationen durch Blaualgen stattfinden (Tab. 34).

Um die Eutrophierung des Vierwaldstättersees zu verlangsamen, wird auf Grund der vorliegenden Untersuchung empfohlen, durch geeignete Massnahmen zuerst einmal die P-Zufuhren ins Epilimnion zu erniedrigen.

Werden einmal alle Siedlungsabwässer vom Rotsee ferngehalten, dann wird er auf Grund verschiedener Parameter, wie hohe Nährstoffkonzentration im Frühjahr, geringe mittlere Tiefe, kleine Erneuerungszeit, ein eutrophes Gewässer bleiben. Je nach der Qualität, die man an das Wasser des Rotsees stellt, müssen noch andere Massnahmen in Betracht gezogen werden, die eine schnellere Erneuerung vor allem der hypolimnischen Wassermassen ermöglichen.

\section{SUMMARY}

In 1969/70 the physical (temperature, under water light field), chemical (nitrogen and phosphorus components, oxygen, sulphide, alkalinity) and biological (measurement of the primary production with the ${ }^{14} \mathrm{C}$-technique, sedimentation from the trophic layers, plankton analyses) properties of the mesotrophic Lake of Lucerne (Horw Bay) and the highly eutrophic Rotsee were
investigated.

Special studies were carried out on the seasonal distribution of $\mathrm{NO}_{3}, \mathrm{NO}_{2}, \mathrm{NH}_{4}$, and particulate and soluble organic nitrogen in the different depths of the two lakes.

A micro-Kjeldahl method for the determination of particulate organic nitrogen in lake water is described. The water samples are filtered on glass fibre filters ( $\mathrm{GF} / \mathrm{C}$ Whatman, $55 \mathrm{~mm}$ ) covered with a layer of magnesium carbonate (Magnesiumhydroxidcarbonate p. A. Merck). With the method proposed, the influence of nitrates on the determination of organic nitrogen is eliminated. The precision of the method filtering $200 \mathrm{ml}$ lake water at the $50 \mu \mathrm{g} \mathrm{N} / 1$ level is $s= \pm 10 \mu \mathrm{g} \mathrm{N} / 1$. The method enables the particulate nitrogen content of oligotrophic lake water samples to be deter-
mined.

In the Horw Bay the main inorganic $\mathrm{N}$ component during the whole year is $\mathrm{NO}_{3}$; in the Rotsee ammonia is predominant owing to anaerobic conditions in the hypolimnion. Towards autumn the two lakes showed a depletion of inorganic $\mathrm{N}$ compounds in the layers with high productivity. At the end of the stagnation period the increase of $\mathrm{NO}_{3}$ was $3.7 \mathrm{~g} \mathrm{NO}_{3}-\mathrm{N} / \mathrm{m}^{2}$ in the hypolimnion $(15-60 \mathrm{~m})$ of the Horw Bay; in the Rotsee the hypolimnic increase of ammonia was $24 \mathrm{~g} \mathrm{NH}_{4}$ $\mathrm{N} / \mathrm{m}^{2}(5-14 \mathrm{~m})$ (Tables 12, 13, 14; illustrations 10,11, 12, 13 and 14).

The concentrations of particulate $\mathrm{N}$ in the epilimnion $(0-15 \mathrm{~m})$ of the Horw Bay varied from 30 to $420 \mu \mathrm{g} \mathrm{N} / \mathrm{l}$, in the Rotsee from 130 to $3400 \mu \mathrm{g} \mathrm{N} / 1$, but contrary to the Horw Bay the hypolimnic content of particulate $\mathrm{N}$ was always high. In the Rotsee a great standing crop (particulate $\mathrm{N} / \mathrm{m}^{2}$ ) was measured under ice in January/February and after it had thawed in March/April. In the Horw Bay the standing crop was great in May/July and August/September (Tables 17 and
20, illustrations 15 and 16).

Dissolved organic Kjeldahl-N concentrations varied in the epilimnion of the Horw Bay from 20 to $210 \mu \mathrm{g} \mathrm{N} / \mathrm{l}$, the content per unit area for the entire trophogenic zone being $1.00-2.36 \mathrm{~g} \mathrm{~N} / \mathrm{m}^{2}$. In the Rotsee concentrations of $150-880 \mu \mathrm{g}$ of soluble organic $\mathrm{N} / \mathrm{l}$ were measured; the content per unit area was $1.27-2.87 \mathrm{~g} \mathrm{~N} / \mathrm{m}^{2}$ (Tables 18,19 and 20).

The highest photosynthetic rate obtained in the Horw Bay was $63 \mathrm{mg} \mathrm{C} \mathrm{C}_{\text {ass }} / \mathrm{m}^{3}$. hour and in the Rotsee $287 \mathrm{mg} \mathrm{C}$ ass $/ \mathrm{m}^{3} \cdot$ hour. The specific growth rate (production biomass quotient) was calculated on the basis of the daily primary production rate and the particulate nitrogen per unit area for the entire trophogenic zone. The specific growth rate varied in the Horw Bay from 0.08 to 0.19 and in the Rotsee from 0.05 to 0.37 (Tables 23,24 and 35 ). 
In the Horw Bay the $\mathrm{N}: \mathrm{P}$ weight ratio in the particulate material differs not only during the course of the year but also in the different depths. During the stagnation period the average ratio was 10.5 in $0-10 \mathrm{~m}, 7.1$ in $15-35 \mathrm{~m}$ and 5.6 in $45-60 \mathrm{~m}$. Very high $\mathrm{N}: \mathrm{P}$ ratios $(22: 1)$ were measured in those depths where Oscillatoria rubescens was interstratified. The average ratio during the year vas $8.5 \pm 3.5(0-5 \mathrm{~m})$ in the Rotsee (illustrations 19,20 and 21$)$.

The fertilizing influence of nitrates $\left(\mathrm{NaNO}_{3}\right.$ p.A. Merck) on the phytoplankton production was tested with plastic containers $(1,4001$ volume) which were exposed in situ in $2.5 \mathrm{~m}$ in the Lake of Lucerne. The average increase in photosynthetic rates was insignificant $(6-34 \%)$ compared with the high increase effected by the addition of phosphates. The concentrations of particulate nitrogen in the plastic containers could only be raised by means of phosphate fertilization (Tables 27 to 32 ).

During the stagnation period (April to October) in the Horw Bay the $\mathrm{N}$-Sedimentation rates were 8-34 $\mathrm{mg} \mathrm{N} / \mathrm{m}^{2}$. day and in the Rotsee $32-397 \mathrm{mg} \mathrm{N} / \mathrm{m}^{2}$. day. Measurements have shown that in the Horw Bay approximately $1-2 \%$ and in the Rotsee $2-37 \%$ of the particulate $\mathrm{N}$ settles each day, disappearing from the trophogenic layers (Table 35, illustrations 17 and 18).

Because internal supplies (epilimnic $N$ consumption) and external imports ( $N$ loading) are not sufficient to maintain the primary production during the stagnation period measured and because sedimentation measurements can determine only a small fraction of the primary production, an intrabiocoenotic cycle is postulated which regenerates nitrogen within the trophic layer.

The investigations in the Lake of Lucerne revealed that, regarding the nutrients $C, N, P$, phosphorus is the most limiting factor. When inorganic nitrogen is at its lowest level $\mathrm{N}$-fixation by blue-green algae must also be taken in consideration (Table 34).

In conclusion, corrective measures should be taken as a first step to limit the phosphorus supplies in the trophogenic layers.

Even if all domestic sewage were kept away from the Rotsee, this lake would still be eutrophic as can be seen in the light of several parameters (high nutrient concentrations in spring, small rate of water renewal especially in the hypolimnic layers). Depending on the water quality desired, other measures have to be examined, which above all enable a better rate of water renewal.

\section{LITERATURVERZEICHNIS}

[1] Alsterberg, G., Die Winklersche Bestimmungsmethode für in Wasser gelösten, elementaren Sanerstoff sowie ihve Anwendung bei Anwesenheit oxydierbarev Substanzen, Biochem. Z., S. 170 (1926).

[2] АмвӥнL, H., Die praktische Anwendung dev elehtrochemischen Sauerstoffbestimmung im Wasser, Schweiz. Z. Hydrol, 22, 23-39 (1960).

[3] Амвய̈HL, H., Die Nährstoffzufuhr zum Hallwilersee, Schweiz. Z. Hydrol. 22, 563-597 (1960).

[4] Амв Abwass. GWF 107/14, 336-363 (1966).

[5] АмвӥнL, H., Die neueste Entwricklung des Vierwaldstättersees (Lake of Lucerne), Verh. int. Verein. theor, angew. Limnol. 17, 219-230 (1969).

[6] АмвӥнL, H., und SchмıD, M., Bestimmung geringster Mengen von Phosphation im Wasser von Binnenseen, Schweiz. Z. Hydrol. 27, 172-183 (1965).

[7] Amstrong, F. A., und TibBitts, S., Photochemical Combustion of Organic Matter in Sea Water, for Nitrogen, Phosphorus and Carbon Determination, J. mar. biol. Ass. U. K. 48, 143-152 (1968).

[8] Bachofen, R., Stoffhaushait und Sedimentation im Baldegger-und Hallwilersee, Diss., JurisVerlag Zürich, S. 1-118 (1960)

[9] Barsdate, R. J., und Dugdale, R. C., Rapid Conversion of Organic $N$ to $N_{2}$ for Mass Spectrometry: An Automated Dumas Procedure, Analyt. Biochem. 13, $1-5$ (1965).

[10] Billaud, V.A., Nitrogen Fixation and the Utilization of Other Inorganic Nitrogen Sources in a Subarctic Lake, J. Fish. Res. Bd. Can. 25, 2101-2110 (1968).

11] Bloesch, J., Diss., EAWAG Zürich, in Vorbereitung.

[12] BringmanN, G., und KÜHN, R., Nitrat und Phosphat als Begrenzungsfaktor des Algenwachstumtests, Gesundheit-Ingenieur 86, 210-214 (1965).

[13] CaIn, B. J., Nitrogen Utilization in 38 Fresh-Water Chlamydomonad Algae, Can. J. Bot. 43, $1367-1378$ (1965). 
[14] Domogalla, B. P., Juday, C., und Peterson, W. H., The Forms of Nitrogen Found in Certain Lake Waters, J. Biol. Chem. 63, 269-285 (1925).

[15] Dugdale, R.C., und Gokring, J.J., Uptake of New and Regenerated Forms of Nitrogen in Primary Productivity, Limnol. Oceanogr. 12, 196-206 (1967).

[16] Dugdale, V.A., und Dugdale, R.C., Nitrogen Metabolism in Lakes. III. Tracer Studies of the Assimilation of Inorganic $N$-Sources, Limnol. Oceanogr. 10, 53-57 (1965).

[17] EPPLEY, R.W., Rogers, J.H., und Mc CARTHY, J.J., Half-Saturation Constants for Uptake of Nitrate and Ammonium by Marine Phytoplankton, Limnol. Oceanogr. 14, 912-920 (1969).

[18] ERIKkson, E., A ir Precipitation as Sources of Nutrients, in : Handbuch der Pflanzenernährung und Düngung, Bd. II (Springer-Verlag, Wien und New York 1966).

[19] Edwards, R.W., und Rolley, H. T. J., Oxygen Consumption of River Water, J. Ecol. 53 , $1-19(1965)$.

[20] Fay, P., Stewart, W.D.P., Walsby, A.E., und FogG, G. E., Is the Heterocyst the Site of Nitrogen Fixation in Blue-Green Algae, Nature, 220, 23, 810-812 (1968).

21] Findenegg, I., Factors Controlling Primary Productivity. Especially with Regard to Water Replenishment, Stratification and Mixing, Memorie Ist. ital. Idrobiol., Supp1. 18, 105-119 (1965).

[22] FindenegG, I., Phytoplankton und Primärproduktion einiger ostschweizerischer Seen und des Bodensees, Schweiz. Z. Hydrol. 28, 148-172 (1966).

[23] FuHs, G.W., Rates of Phosphorus-Controlled Growth in the Diatoms Cyclotella Nana and Thalassiosira Fluviatilis, J. Phycol. 5, 312-321 (1969)

24] GÄCHTER, R., Phosphorhaushalt und planktische Primärproduktion im Vierwaldstättersee (Horwer Bucht), Schweiz. Z. Hydrol. 30, 2-66 (1968).

[25] Garside, C., und RiLeY, J.P., A Thin-Layer Chromatographic Method for the Determination of Plant Pigments in Sea Water and Cultures, Analytica chim. Acta 46, 179-191 (1969).

[26] Gerloff, G.C., und Skoog, F., Cell Contents of Nitrogen and Phosphorus as a Measure of Their Availability for Growth of Microcystis Aeruginosa, Ecology 35, 348-353 (1954).

[27] Goering, J. J., und Dugdale, V.A., Estimates of Rates of the Denitrification in a Subarctic Lake, Limnol. Oceanogr. 17, 1.13-117 (1966).

28] Goldman, C. R., Primary Productivity and Micronutrients Limiting Factors in Some North Amevican and New Zealand Lakes, Vehr. int. Verein. theor. angw. Limnol. 15, 365-374 (1964).

[29] Harvey, H.W., The Chemestry and Fertilitiy of Seawater (Cambridge University Press, 1955).

[30] Hemens, J., und Mason, M.S., Sewage Nutrient Removal by a Shallow Algal Stream, Water Res. (Pergamon Press) 2, 277-287 (1968).

[31] HeDLICH, R., Die wachstumsbegrenzenden Nährstoffe in Talsperren auf dem Gebiet der DDR, Fortschr. Wasserchem, H. 8, (Akademie-Verlag Berlin), S. 99-106.

[32] Holm-Hansen, O., Determination of Particulate Organic Nitrogen, Limnol. Oceanogr. 73 , 175-178 (1968).

[33] Jannasch, H.L., Versuche über Denitrifikation und die Verfügbarkeit des Sanerstoffes in Wasser und Schlamm, Arch. Hydrobiol. 56, 355-359 (1960).

[34] Kliffmüller, R., Beiträge zum Stoffhaushalt des Bodensees (Obersee) II, Arch. Hydrobiol., Suppl. 35, 309-371 (1969).

[35] KROGH, A., und LANGE, E., Quantitative Untersuchungen über Plankton, Kolloide und gelöste organische und anorganische Substanzen in dem Furesee, Int. Revue ges. Hydrobiol. Hydrogr. $26,20-53(1931)$.

[36] Mac IsAax, J. J., und Dugdale, R.C., The Kinetics of Nitrate and Ammonia Uptakeby Natural Population of Marine Phytoplankton, Deep Sea Res. 16, 45-58 (1969).

[37] Menzel, D.W., und Ryther, J.H., The Composition of Particulate Organic Matter in the Western North Atlantic, Limnol. Oceanogr. 9, 179-186 (1964).

[38] Minder, L., Der Rotsee, Schweiz. Z. Hydrol. 11, 245-253 (1949).

39] Müller, R., und Wrdemann, O., Die Bestimmung des Nitrat-Ions im Wasser, Vom Wass. (Jahrbuch für Wasserchem. und Wasserreinigungstechnik, Verlag Chemie) 12, 247-271. (1955).

[40] Nauwerck, A., Die Beziehung zwischen Zooplankton und Phytoplankton im See Erken,

- Symb. bot. upsal. 17, 1-163 (1963).

[41] OGAwA, R.E., und CARR, J.R., The Influence of Nitrogen on Heterocyst Production in BlueGreen Algae, Limnol. Oceanogr. 14, 342-351 (1969). 
[42] OHLE, W., Der Stoffhaushalt der Seen als Grundlage einer allgemeinen Stoffwechseldynamik der Gewüsser, Kieler Meeresforsch. 18, 107-120 (1962).

[43] OHLE, W., Interstitiallösungen der Sedimente, Nährstoffgehalt des Wassers und Produktion des Phytoplanktons in Seen, Helgoländer wiss. Meeresunters. 10, 411-429 (1964).

44] Pavoni, M., Beziehung zwischen Biomasse und Stickstoffgehalt des Phytoplanktons und die daraus ableitbare Anwendung der Bestimmungsmethoden fïr die Praxis, Schweiz. Z. Hydrol. 37 , 110-127 (1969).

[45] Perret, P., Diss. über den Sempachersee, Universität Basel, in Vorbereitung

[46] Postma, H., The Cycle of Nitrogen in the Wadden Sea and Adjacent Areas, Neth. J. Sea Res. 3, 186-221 (1966).

[47] Prochazkova, L., Einfluss der Nitrate und Nitrite auf die Bestimmung des organ. Stickstoffs und Ammoniumions im Wassev, Arch. Hydrobiol. 56, 179-185 (1960).

1487 RedField, A.C., KeTchum, B.H., und Richards, F.A., The Influence of Organisms on the Composition of Seawater, in: M. N. Hill, The Sea, Bd 2, S. 26-77 (1963).

[49] Rohde, W., Standard Correlations between Pelagic Photosynthesis and Light, Memorie Ist. ital. Idrobiol., Suppl. 18, 365-381 (1965).

[50] Richardson, B., Orcutt, D. M., Schwertner, H. A., Martinez, C. I., und Wilchline, H. E., Effects of Nitrogen Limitation on the Growth and Composition of Unicellular Algae in Continuous Culture, Appl. Microbiol. 78, 245-250 (1969).

[52] Sauberer, F., Empfehlungen für die Durchführung von Strahlungsmessungen an und in Gewässern, Mitt. int. Verein. theor. angew. Limnol. 11 (1962).

[53] Sayyer, C.N., und Ferullo, A.F., Nitrogen Fixation in Natural Waters under Controlled Laboratory Conditions, Techn. Rep. Taft Sanit. Eng. Control. W. 61-3, S. 100-103 (1961).

[54] SchegG, E, Die limnische Produktion unter besonderer Berïcksichtigung des Bakterienanteils, Diplomarbeit an der EAWAG Zürich (1967), unveröffentlicht.

[55] SchegG, E., Diss. EAWAG Zürich, in Vorbereitung.

[56] Sснміd, M., und AмвüHL, H., Die Bestimmung geringster Mengen von Gesamiphosphor im Wasser von Binnenseen, Schweiz. Z. Hydrol. 27, 183-192 (1965).

[57] Scrmid, M., Die Bestimmung kleinev Mengen von organischem Stickstoff im Wasser von Binnenseen, Schweiz. Z. Hydrol. 30, 244-266 (1968).

[58] Stadelmann, P., Vergleich der Messung der limnischen Produktion nach der Sauerstoff-und C-14-Methode am Beispiel einiger Seen mit verschiedenem Trophiegrad, Diplomarbeit an der EAWAG Zürich (1966), unveröffentlicht.

[59] Staub, R., Ernährungsphysiologische-autökologische Untersuchungen an dev planktischen Blaualge Oscillatoria Rubescens D.C., Schweiz. Z. Hydrol. 23, 82-198 (1961).

[60] Stewart, W. D.P., Nitrogen Input into Aquatic Ecosystems, in: D. J. Jackson, Algae, Man and the Envivonment, Syracus University Press (1968), S. 53-72.

[61] Strickland, J.D.H., und Parsons, T. R., A Manual of Seawater Anlysis, Bull. Fish. Res. Bd Can., Nr. 125, 2. Aufl. (1965).

62] Strickland, J.D.H., und Parsons, T.R., A Pratical Handbook of Seawater, Bull. Fish. Res. Bd Can., Nr. 167 (1968).

[63] Sтumm, W., Diskussionsbeitrag zum Vortrag von G. A. Rohlich, Adv. Wat. Pollut. Res. (London) 2, 216-230 (1964).

[64] Stumm, W., und Leckie, J.O., Phosphate Exchange with Sediments; Its Role in the Productivity of Surface Waters, Presented at the 5th International Water Pollution Research Conference 1970 (proceedings to be published by Pergamon Press, 1971).

65] SyRETT, P. J., The Assimilation of Ammonia and Nitrate by Nitrogen Stavved Cells of Chlovella Vulgaris, II und III, Physiologia P1. 9, 19 S. und 28 S. (1956).

66] Thомаs, E.A., Empirische und experimentelle Untersuchungen zur Kenntnis der Minimumsstoffe in 46 Seen der Schweiz und angrenzender Gebiete, Schweiz. Ver. Gas- und Wasserfachm. 9/10, 1-11 (1953).

[67] Tromas, E.A., Stoffhaushalt und Sedimentation im oligotrophen Agerisee und im eutrophen Pfäffiker-und Greifensee, Memorie Ist. ital. Idrobiol., Suppl. 8, 357-465 (1955).

[68] Thomas, E. A., Sedimentation und Stoffhaushalt im Türlersee, Schweiz. Ver. Gas- und Wasserfachm. 12, 1-11 (1956). 
[69] Thomas, E.A., Der Eutrophierungsvorgang bei Seen Zentraleuropas, Schweiz. Wasser- und Energiewirtschaft 60, 115-125 (1968).

[70] Thomas, W.H., On the Nitrogen Deficiency in the Tropical Pacific Oceanic Phytoplankton: Photosynthetic Parameter in Poor and Rich Water, Limnol. Oceanogr. 15, 380-385 (1970).

[71] Thomas, W.H., Effect of Ammonium and Nitrate Concentration on Chlorophyll Increase in Natural Tropical Pacific Phytoplankton Populations, Limnol. Oceanogr. 15, 386-394 (1970).

[72] Toyoda, Y., Horie, S., und SaIJo, Y., Studies on the Sedimentation in Lake Biwa from the Viewpoint of Lake Metabolism, Mitt. int. Verein. theor. angew. Limnol. 14, 243-255 (1968).

[73] Uhlman, D., und AlbRecht, E., Biochemische Faktoren der Eutrophierung von TrinkwasserTalsperren, Limnologica (Berlin) 6, 225-245 (1968).

[74] UteRMöHL, H., Zur Vevvollkommnung dev quantitativen Phytoplanktonmethodik, Mitt. int. Verein. theor. angew. Limnol. 9, 1-38 (1958).

[75] Verduin, J., Principles of Primary Productivity: Photosynthesis under Completely Natural Conditions, in: D. J. JACKson, Algae and Man, (New York 1964), S. 221-238.

[76] VOLLENWEIDER, R.A., Scientific Fundamentals of the Eutrophication of Lakes and Flowing Waters, with Particular Reference to Nitrogen and Phosphorus as Factors in Eutrophication, OECD report, Paris, DAS/CSI/ 68.28 (1968).

[77] Vollenweider, R.A., A Manual on Methods for Measuring Primary Production in Aquatic Environments, Blackwell Scientific Publications (Oxford und Edinburgh), IBP Handbook
Nr. 12 (1969).

[78] Wuhrmann, K., Probleme der dritten Reinigungsstufe von Abwässern, Föderation Europäischer Gewässerschutz (FEG), Informationsblatt Nr. 14, S. 67-78 (1967).

[79] ZimmermanN, U., Ökologische und physiologische Untersuchungen an der planktischen Blaualge Oscillatoria rubescens D.C. unter besondever Berücksichtigung von Licht und Temperatur, Schweiz. Z. Hydrol. 37, 1-58 (1969).

[80] ZüLLIG, H., Sedimente als Ausdruck des Zustandes eines Gewässers, Schweiz. Z. Hydrol. 18, 5-186 (1956).

[81] Gächter, R., SzaBó, E., und Mareš, A., Die lokale Beeinflussung eines stehenden Gewässers durch eine punktförmige Abwasserbelastung; ein divekter Nachweis der wachstumsbegrenzenden Wirkung des Phosphors im Vierwaldstättersee, Schweiz. Z. Hydrol. 33, 66-72 (1971).

\section{VERDANKUNG}

Herrn Prof. Dr. O. Jaag, Direktor der EAWAG, möchte ich danken, dass ich im guteingerichteten Hydrobiologischen Laboratorium der ETH in Kastanienbaum einen Arbeitsplatz benutzen
durfte.

Herrn Dr. H. Ambühl, Leiter der Limnologischen Abteilung der EAWAG und des Hydrobiologischen Laboratoriums Kastanienbaum, möchte ich für die grosszügige Unterstützung und die vielen Hilfereichungen bei den Düngversuchen wie auch für die kritische Durchsicht des Manuskripts danken.

Gleichzeitig mit meinen Seeuntersuchungen wurden die gleichen Seestellen im Sinne einer Teamarbeit durch Dr. R. Gächter und drei Doktoranden der EAWAG bearbeitet. Teilaspekte dieser gemeinsamen Untersuchung werden in folgenden besondern Arbeiten erscheinen:

E. Schegg: Prim.ärproduktion und bakterielle Destruktion

J. Bloesch: Phosphorkreislauf und Sedimentation

H. Bührer: Physiologische Bakteriengruppen im Seesediment danken.

Ich möchte diesen Kollegen für die Überlassung verschiedener Analysenwerte herzlichst

$\mathrm{Zu}$ besonderem Dank verpflichtet bin ich Herrn Dr. R. Gächter, der durch wissenschaftliche Anregungen, unermüdliche Diskussionen und mit vielen Hinweisen meine Arbeit unterstützte.

Die Arbeit wurde mit der finanziellen Hilfe der "Stiftung der Wirtschaft zur Förderung des Gewässerschutzes» ausgeführt.

Adresse des Autors:

Dr. P. Stadelmann

Eidg. Anstalt für Wasserversorgung, Abwasserreinigung und Gewässerschutz an der ETH

CH-8600 Dübendovf 